\title{
AVALIAÇÃO DO CULTIVO DE CANA-DE-AÇÚCAR EM SISTEMAS AGROFLORESTAIS EM PIRACICABA, SP
}

\section{Luís Fernando Guedes Pinto}

\begin{abstract}
Tese apresentada à Escola Superior de Agricultura "Luiz de Queiroz", Universidade de São Paulo, para obtenção do título de Doutor em Agronomia, Área de Concentração:
\end{abstract} Fitotecnia.

\author{
P I R A C I C A B A \\ Estado de São Paulo - Brasil \\ Dezembro - 2002
}




\title{
AVALIAÇÃO DO CULTIVO DE CANA-DE-AÇÚCAR EM SISTEMAS AGROFLORESTAIS EM PIRACICABA, SP
}

\section{Luís Fernando Guedes Pinto \\ Engenheiro Agrônomo}

\section{Orientador: Prof. Dr. MARCOS SILVEIRA BERNARDES}

\begin{abstract}
Tese apresentada à Escola Superior de Agricultura "Luiz de Queiroz", Universidade de São Paulo, para obtenção do título de Doutor em Agronomia, Área de Concentração: Fitotecnia.
\end{abstract}

P I R A C I C A B A

Estado de São Paulo - Brasil

Dezembro - 2002 
Dados Internacionais de Catalogação na Publicação (CIP)

DIVISÃO DE BIBLIOTECA E DOCUMENTAÇÃO - ESALQ/USP

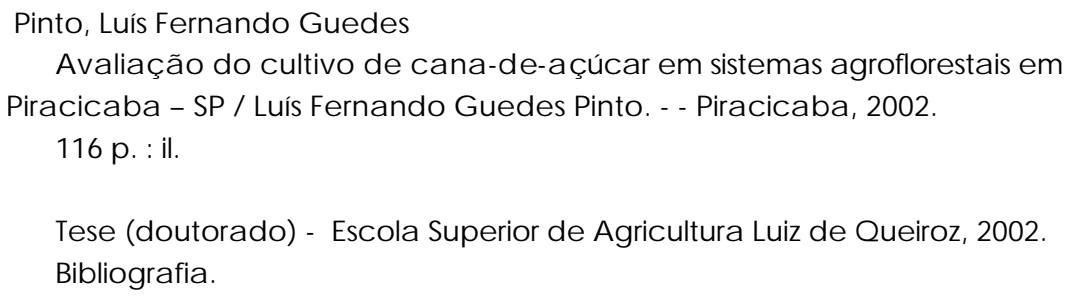

1. Ca na-de-açúcar 2. Pira cic a ba 3. Sistema a groflorestal I. Título

CDD 633.61

\section{"Permitida a cópia total ou parcial deste documento, desde que citada a fonte - $\mathrm{O}$ autor"}




\section{Agradecimentos}

Prof. Dr. Marcos Bernardes, pela oportunidade de treinamento, consistente e objetiva orientação e visão crítica dos SAFs e do universo científico.

Profs. Drs. Gerd Sparovek, Antonio Roberto Pereira, José Luiz Stape e Gil Miguel de Sousa Câmara pelas valiosas contribuições ao trabalho.

Meine Van Noordwijk, Betha Lusiana, Rachmat Mulia, Johan Iwald e Yayuk pela orientação e Josephine Prasetyo, Paul Burguers e família, Gregoire Vincent e família, Kristianinti, Esyh, Wilma Garrity e toda equipe do ICRAF Sudeste da Ásia pela recepção na Indonésia.

FAPESP, pela bolsa de estudos concedida, que viabilizou as atividades no Brasil e na Indonésia.

AFOCAPI (Associação dos Fornecedores de Cana-de-açúcar de Pìracicaba), representada pelo Eng. Agr. Marcos Farhat, Lázaro e Eduardo, por todo apoio ao trabalho.

Produtor Alair Furlan, Fazenda São José, representada por Francisco Spatti e Usina São João pela concessão das áreas para os experimentos de campo.

Colegas Ciro Abbud Righi, Edson Roberto Teramoto, Leila Sobral Sampaio, Norma Mingone Segovia e Aureny Lunz por ajudas diversas.

Ao Prof. Dr. Paulo Roberto de Camargo e Castro, técnicos do Depto de Produção Vegetal Adilson Aparecido Dias, Ananias Ferreira de Souza, Cláudio do Espírito Santo 
Ferraz, Luis Cláudio Pereira de Souza, Helena e do Depto de Ciências Biológicas, Alexandre, pela colaboração nos trabalhos de campo.

Prof. Andrew Gillespie e seus orientados de 1999 do Departamento de Florestas e Recursos Naturais da Universidade de Purdue, EUA, pela receptividade e oportunidade de treinamento e aprendizado.

Projeto Piracena, pelo fornecimento das imagens digitais de Piracicaba.

Simone, Eduardo e toda minha família, pelo amor, inspiração e apoio irrestrito às minhas idéias e iniciativas.

Todos os demais que contribuíram para realização deste trabalho! 


\section{SUMÁRIO}

Página

AVALIAÇÃO DO CULTIVO DE CANA-DE-AÇÚCAR EM SISTEMAS
AGROFLORESTAIS EM PIRACICABA, SP

AGROFLORESTAIS EM PIRACICABA, SP

vii

RESUMO

vii

SUMMARY

Viii

1 INTRODUÇÃ

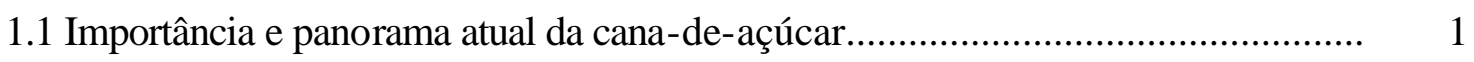

2 REVISÃO DE LITERATURA.................................................................. 3

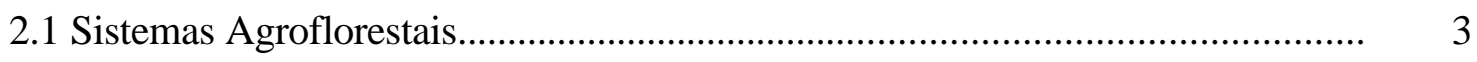

2.2 Interações biofísicas em SAFs...................................................................... 3

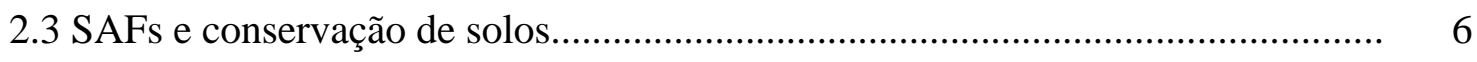

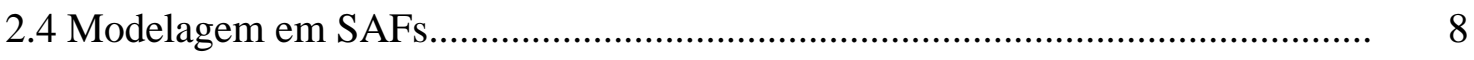

3 IDENTIFICAÇÃO E SELEÇÃO DE TERRAS E ÁRVORES PARA CULTIVO DE CANA-DE-AÇÚCAR EM SISTEMAS AG ROFLORESTAIS $\begin{array}{llll}\text { NA } & \text { REGIÃO } & \text { DE } & \text { PIRACICABA, } \\ \text { SP } & & \end{array}$

SP

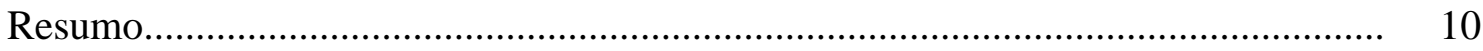

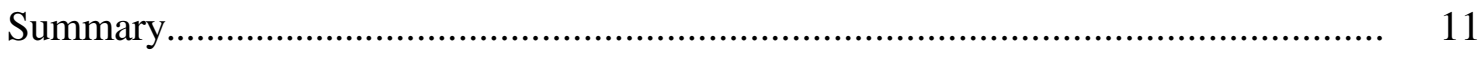

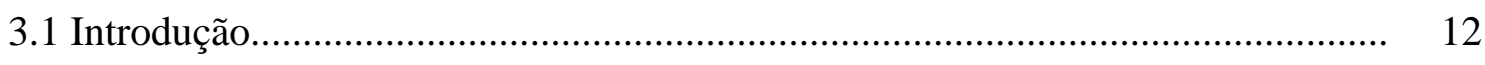

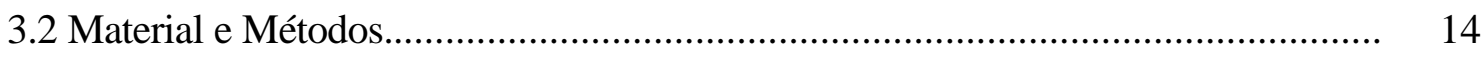

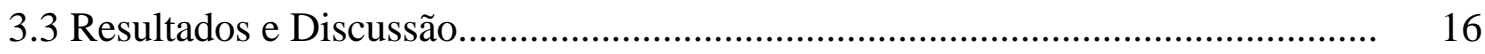

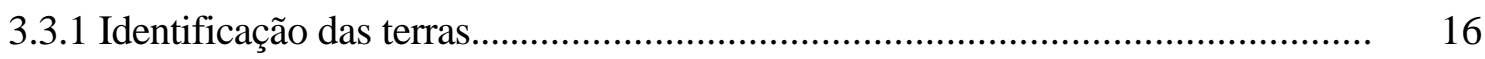

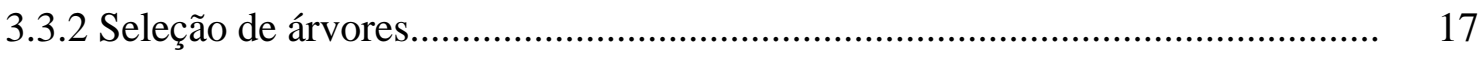

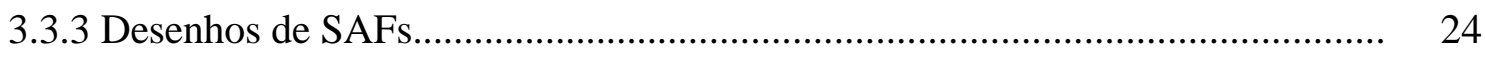


4 SIMULAÇÃO DO CRESCIMENTO E PRODUÇÃO DE SISTEMAS AGROFLORESTAIS COM CANA-DE-AÇÚCAR EM PIRACICABA, 27 SP

Resumo. 27

Summary. 28

4.1 Introdução. 29

4.2 Material e Métodos 31

4.3 Resultados e Discussão. 40

4.3.1 Crescimento e produção das plantas sem interação entre árvores e cultura....... $\quad 40$

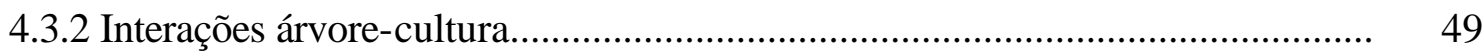

4.3.3 Balanço hídrico e solos........................................................................... 58

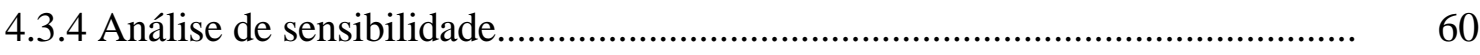

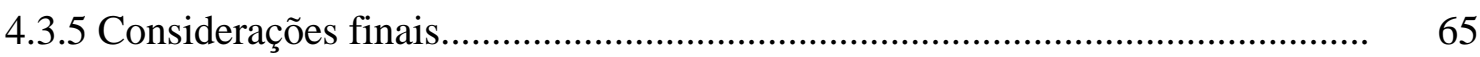

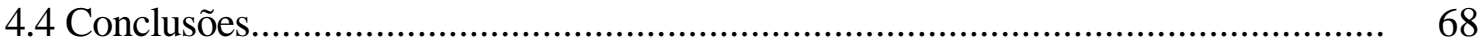

5 CRESCIMENTO E PRODUÇÃO DE PLANTAS EM INTERFACES CANA-DE-AÇÚCAR X SERINGUEIRA E CANA-DE-AÇÚCAR $X$ EUCALIPTO.

Resumo. 69

Summary..... 70

5.1 Introdução. 71

5.2 Material e Métodos 73

5.2.1 Estudo 1 - interface cana-de-açúcar x seringueira.......................................... 73

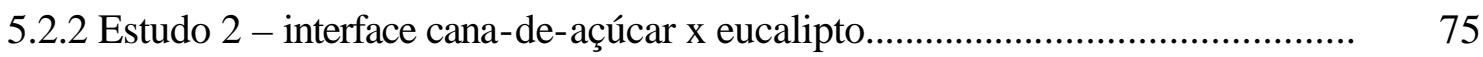

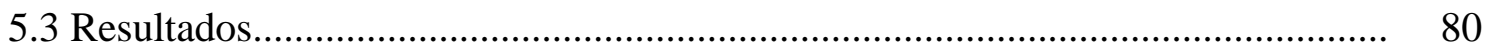

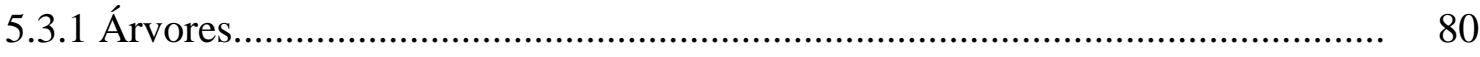

5.3.2 Cana-de-Açúcar............................................................................... 81

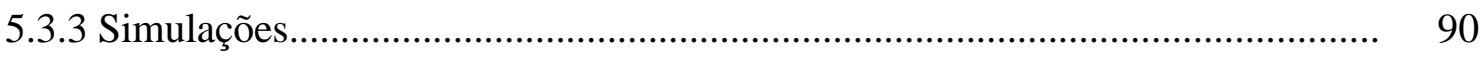

5.3.4 Simulação do ciclo do SAF cana-de-açúcar x eucalipto.................................... 92 


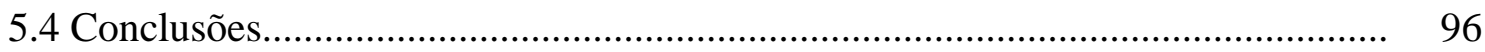

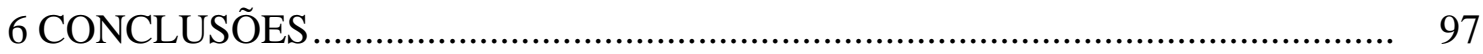

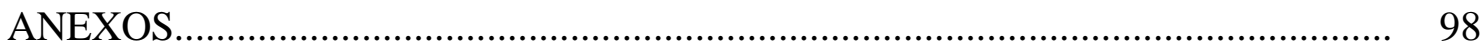

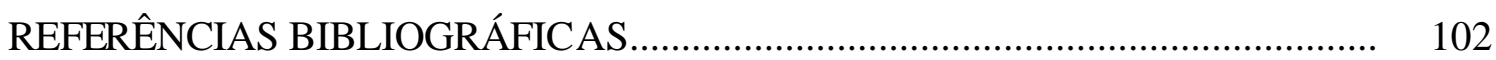




\title{
AVALIAÇÃO DO CULTIVO DE CANA-DE-AÇÚCAR EM SISTEMAS AGROFLORESTAIS EM PIRACICABA, SP
}

\author{
Autor: LUÍS FERNANDO GUEDES PINTO \\ Orientador: Prof. Dr. MARCOS SILVEIRA BERNARDES
}

\section{RESUMO}

Na região de Piracicaba, grande parte dos pequenos produtores cultivam cana-deaçúcar em áreas de alta declividade, mas a mecanização da colheita tem inviabilizado seu cultivo nesta condição. Sistemas agroflorestais (SAFs) podem compatibilizar a produção da cultura neste cenário, com a conservação de recursos naturais, porém, há falta de pesquisa sobre seu cultivo nestes sistemas. Portanto, o uso de modelos de simulação e avaliações de campo da interface árvore-cultura podem desempenhar importante papel para investigar seus potenciais e restrições. Assim, identificamos e selecionamos terras e árvores para cultivo dos SAFs e avaliamos o crescimento e produção de plantas dos SAFs cana-de-açúcar x seringueira e cana-de-açúcar x eucalipto. Realizamos dois experimentos de campo e utilizamos o modelo WaNuLCAS e um modelo que simula a disponibilidade de radiação para culturas intercalares, relacionando-o com a produção de matéria seca da cultura. SAFs em aléias em contorno são alternativa viável para cultivo de cana-de-açúcar no município de Piracicaba, havendo diversas espécies arbóreas exóticas e nativas que podem compor estes SAFs, destacando-se seringueira e eucalipto. Luz e água são limitantes ao crescimento da cultura e há aumento da competição de acordo com o crescimento das árvores. A importância relativa entre competição abaixo e acima do solo depende da distância das árvores. Contudo, o SAF cana-de-açúcar x eucalipto tem produção semelhante ao monocultivo de cada espécie. Os modelos permitiram avaliar os SAFs e orientar experimentos, mas suas indicações devem ser verificadas em experimentos de campo. A recomendação dos SAFs deve ser feita após análise econômica dos mesmos.

Palavras-chave: eucalipto, interações, luz, modelo, seringueira 


\title{
ASSESSMENT OF SUGARCANE CULTIVATION IN AGROFORESTRY SYSTEMS IN PIRACICABA, SP, BRAZIL
}

\author{
Author: LUÍS FERNANDO GUEDES PINTO \\ Adviser: Prof. Dr. MARCOS SILVEIRA BERNADES
}

\section{SUMMARY}

In Piracicaba, many smallholders grow sugarcane in areas of high solpe, but the mechanization of the harvest process has made inviable its cultivation under this situation. Agroforestry systems (AFs) are an alternative that may join the cultivation of the crop under this scenario with conservation of natural resources. However, there is lack of research of its cultivation in AFs. Therefore, the use of simulation models and evaluation of on-farm tree-crop interfaces may play an important role to investigate its potentials and restrictions. Thus, we identified and selected lands and trees to the cultivation of the AFs and assessed plant growth and yield of sugarcane $\mathrm{x}$ rubber and sugarcane $\mathrm{x}$ eucalyptus AFs. We did two field experiments and used the WaNuLCAS model and another one that simulates the available irradiance for intercrops, related with their dry matter production. Contourhedgerows are a feasible alternative for sugarcane cultivation in Piracicaba, where many tree species may be part of it, especially rubber and eucalypts. Light and water are limiting factors for crop growth and competition increases with tree growth. The relative importance of each variable depends on the distance from the trees. However, the sugarcane $\mathrm{x}$ eucalyptus AF has similar production of the monocropping of each specie. The models allowed to assess the AFs and to drive field trials, but their results should be verified in experiments. The recomendation of the AFs should be done after their economic analysis.

Key-words:: eucalyptus, interactions, light, model, rubber 


\section{INTRODUÇÃO}

\subsection{Importância e panorama atual da cana-de-açúcar}

A cana-de-açúcar é uma das principais culturas agrícolas do país, e a mais importante do Estado de São Paulo, ocupando 2,7 milhões de ha, empregando 368,8 mil equivalenteshomens-ano (45,4\% da força de trabalho na agropecuária paulista) e sendo responsável por 27,2\% ( $\mathrm{R}$ \$2,2 bilhões/ano) do valor da produção agropecuária do Estado (Gonçalves \& Souza, 1998a). Devido à aspectos políticos, legislativos e tecnológicos, a prática da queimada prévia à colheita está sendo gradativamente eliminada, implicando em significativas transformações no sistema de produção canavieiro. A principal mudança tem sido a mecanização da colheita, que tem repercutido nas demais modificações do sistema. A viabilidade para implantação do novo sistema depende da declividade das terras - até $12 \%$ (Sparovek et al. 1997), e da disponibilidade de capital para investimento do produtor; sendo economicamente viáveis as áreas contínuas acima de 500 ha (Gonçalves \& Souza, 1998a). Segundo estes autores, as mudanças implicarão num desemprego de 86,5 a 230 mil trabalhadores e criarão impactos diretos sobre os pequenos produtores do Estado, já que 93\% dos mais de 11.000 produtores têm áreas de produção inferiores a 125 ha (Gonçalves \& Souza, 1998b). Assim, em função da importância desta cultura, as transformações em curso terão impactos diretos sobre a qualidade de vida e sobre os recursos naturais do Estado de São Paulo.

Segundo Sparovek \& Lepsch (1995), a cana-de-açúcar ocupava, em 1991, 49,3 \% da área total do município de Piracicaba, num total de 86.819 ha. Da área total cultivada no município, 37\% localizava-se em terras inaptas para colheita mecanizada (Sparovek et al., 1997). Esta situação provavelmente não se alterou significativamente até o momento e as áreas com restrição à colheita mecanizada em Piracicaba envolverão terras com solos em alta declividade e alta suscetibilidade à erosão e degradação, condição predominante em áreas de pequenos produtores. Em função deste cenário de potencial incremento de degradação ambiental e deterioração social, é importante avaliar sistemas de produção alternativos para 
cana-de-açúcar, em áreas inaptas à colheita mecanizada, considerando aspectos ecológicos, agronômicos e sócio-econômicos.

A discussão de alternativas para o sistema de produção canavieiro para a região de Piracicaba surgiu a partir do encontro de pesquisadores e técnicos na II Semana de cana-deaçúcar de Piracicaba, realizada na ESALQ, em 1997. Sua elaboração conceitual evoluiu e envolveu pesquisadores da ESALQ e Instituto Agronômico de Campinas e técnicos da Prefeitura de Piracicaba e da Associação de produtores de cana-de-açúcar da região. Esta equipe elaborou um projeto que envolve um componente de pesquisa e outro de desenvolvimento regional (Bernardes \& Sparovek, 1998; Bernardes et al., 1998), que aponta sistemas agroflorestais como uma alternativa para a produção de cana-de-açúcar em áreas com restrição à colheita mecanizada. 


\section{REVISÃO DE LITERATURA}

\subsection{Sistemas Agroflorestais}

Nair (1989) define Sistemas Agroflorestais (SAFs) como sistemas de uso da terra e tecnologias onde espécies lenhosas perenes são usadas na mesma unidade de manejo que culturas agrícolas ou animais em algum arranjo espacial e sequência temporal. Em SAFs há interações ecológicas e econômicas entre os diferentes componentes, implicando num sistema mais complexo do que as monoculturas, sendo algumas das suas potencialidades a produção de múltiplos benefícios e a otimização do aproveitamento de recursos.

Para Sanchez (1995), o desenvolvimento da agrofloresta como ciência deve basear-se em quatro aspectos: i) interação entre seus componente por luz, água e nutrientes (pode ser negativa-competitiva ou positiva-complementar); ii) complexidade (ecológica e socioeconômica); iii) lucratividade (produção e mercado) e iv) sustentabilidade (conservação dos recursos naturais como biodiversidade, solos, recursos hídricos e carbono).

\subsection{Interações biofísicas em SAFs}

Anderson \& Sinclair (1993) revisaram as interações ecológicas em SAFs e ressaltaram que estas dependem basicamente de fatores espaciais e temporais dos sistemas e da análise dos recursos limitantes ao crescimento vegetal. Apontaram também a importância da separação entre a competição acima e abaixo do solo pelos recursos e ressaltaram a possibilidade de reduzir a competição através da diferenciação de nichos no sistema ou a elaboração de sistemas em que o componente arbóreo e a cultura explorem de maneira diferenciada os recursos disponíveis. 
A razão e extensão em que os recursos biofísicos são capturados e utilizados pelos componentes de SAFs são determinados pela natureza e intensidade das interações entre seus componentes. O efeito destas interações é geralmente determinado pela influência do componente arbóreo nos demais ou no sistema como um todo e é expresso em função de respostas quantificáveis (Rao et al., 1997). Segundo os autores, o estudo das interações em agrofloresta requer a análise de diversos processos complexos, mas pode ser simplificado se estas forem classificadas de acordo com os fatores que são mais afetados como: fertilidade do solo (inclui interações químicas, físicas e biológicas); competição (envolve interações por água e nutrientes do solo, radiação e fatores microclimáticos); doenças e pragas; conservação do solo e alelopatia. Muitas das interações e seus efeitos são interdependentes, não podem ser analisados isoladamente e têm importâncias relativas em cada tipo de SAF e realidade local.

De acordo com Ong (1996), é preciso um estudo científico estruturado para análise quantitativa das interações cultura-árvore de maneira a: i) fornecer um método para determinar quais benefícios podem ser esperados em cada situação; ii) avaliar a importância relativa de cada interação; iii) quantificar vantagens de SAFs não somente em produção, mas quanto a outros benefícios ambientais.

Considera-se que SAFs podem maximizar o proveitamento dos recursos acima e abaixo do solo, tanto no espaço como no tempo, pois assume-se que as plantas perenes (herbáceas ou arbóreas) possuem sistema radicular mais profundos e dossel mais alto que as plantas anuais. Logo, de acordo com Ong et al. (1991), de maneira potencial, o melhor aproveitamento de recursos pode ocorrer por:

- cultivo de culturas e árvores com demanda de recursos (luz, água e nutrientes) em épocas distintas da demandada pela espécie arbórea;

- aumento da fotossíntese em dossel misto, com melhor aproveitamento da luz, oriundo da combinação de plantas $\mathrm{C}_{3}$ e $\mathrm{C}_{4}$ com diferentes níveis de tolerância à sombra;

- alterações microclimáticas positivas, devido à diminuição da amplitude da temperatura do ar e do solo, umidade do ar e do solo e diminuição do vento; 
- fixação e transferência de nitrogênio da atmosfera para o solo, através de árvores simbiontes com bactérias fixadoras;

- melhoria das características físicas do solo;

- reciclagem de nutrientes;

- melhor aproveitamento da água armazenada no solo.

Demais referências sobre interações em SAFs são: Szott et al. (1991), Monteith et al. (1991), e Ong \& Huxley (1996).

A complementaridade por recursos pode ser considerada uma das principais características a ser buscada num SAF. Desta forma, Cannell et al. (1996) sintetizaram de maneira genérica os aspectos de complementaridade e competição das interações árvorecultura em relação a aquisição de recursos, onde pode-se referenciar as principais hipóteses biofísicas destes sistemas. Assim, os autores sugerem que a hipótese central para pesquisa em agrofloresta seja:

"Benefícios do plantio de árvores com culturas somente ocorrerão quando o componente arbóreo do sistema for capaz de obter recursos (água, nutriente e luz) que as culturas não obteriam preliminarmente", isto é, quando houver complementaridade de obtenção de recursos entre árvores e culturas.

Tal hipótese foi sintetizada através do seguinte modelo:

$$
\mathrm{I}=\mathrm{F}-\mathrm{C}
$$

onde

I - aumento na produção da cultura

F - aumento da produção da cultura devido à efeitos favoráveis das árvores sobre o recurso (efeito de complementaridade).

C - diminuição da produção da cultura devido à efeitos relativos à competição das árvores sobre o recurso (efeito de competição). 


\subsection{SAFs e conservação de solos}

Entre os sistemas agroflorestais existentes, é necessário identificar aquele(s) que possa(m) ser aplicado(s) para a atual situação dos pequenos produtores que cultivam canade-açúcar em solos declivosos de Piracicaba.

Segundo Lal (1991), a taxa de degradação de solos tropicais é menor em SAFs do que em culturas anuais. $\mathrm{O}$ autor coloca que a matéria orgânica do solo, $\mathrm{pH}$, estrutura, taxa de infiltração, CTC, e saturação por bases são mantidas em níveis mais favoráveis em SAFs devido à redução do escoamento superficial e da erosão, fixação de nitrogênio por leguminosas, diminuição da amplitude térmica do solo e melhoria de sua porosidade. Complementarmente, Buresh (1995) indica o aumento do teor de matéria orgânica e da eficiência da ciclagem de nutrientes. Young (1988) afirmou que um dos principais serviços da agrofloresta é a conservação do solo, mudando de uma abordagem de engenharia para uma biológica de conservação, com a ênfase da cobertura do solo, ao invés de barreiras físicas para controlar erosão.

Segundo Young (1997a), sistemas de multi-estratos e cultivo em renques ou aléias (contour hedgerow - $\mathrm{CH}$ ) são os principais tipos de SAFs para controlar erosão e escoamento superficial. Entre estes, o último $(\mathrm{CH})$ é o melhor indicado para cultivo de culturas anuais em solos declivosos. McDonald et al. (1997) definiu CH como o cultivo de renques de árvores (ou uma cultura perene) em forma de uma barreira ao longo dos contornos do terreno em declive, com as áreas entre os renques usados para produção agrícola.

Para Young (1997a), as principais funções dos renques de árvores são:

1) controlar a perda de solo através do efeito da cobertura do solo;

2) reduzir o escoamento superficial, aumentar infiltração e reduzir a perda de solo devido ao efeito da barreira;

3) manter a matéria orgânica do solo através dos resíduos da copa e das raízes;

4) conduzir à progressiva formação de terraços entre os renques, através do acúmulo de solo na parte superior dos renques e sua estabilização pelos caules e raízes das árvrores. 
Esta última função de modificação da declividade do terreno é de grande importância para o cultivo de culturas anuais entre os renques, pois este processo tem impactos especialmente sobre o gradiente de fertilidade do solo entre os renques. Adicionalmente, este processo está ligado à principal hipótese desta pesquisa, pois a alteração do declive pode viabilizar o cultivo mecanizado entre os renques de árvores. Do ponto de vista teórico há duas hipóteses para a explicação da formação de terraços e redistribuição do solo entre os renques. De acordo com Young (1997a), o processo ocorre devido à erosão diferenciada entre os renques, com a perda de solo no topo do renque e seu acúmulo na base do renque subsequente. Entretanto, Garrity (1996) propõe que a movimentação do solo entre os renques ocorre devido ao efeito da realização de cultivos sucessivos, movimentando o solo sempre do topo de um renque para a base do renque inferior.

Confirmando o potencial da utilização com sucesso de $\mathrm{CH}$ na região de Piracicaba, Fujisaka (1997) descreveu as situações onde este sistema poderia ser empregado, assim como características desejáveis do mesmo:

- em climas úmidos e sub-úmidos, podendo combinar controle da erosão com cultivo agrícola em declives amenos a moderados;

- onde os solos são relativamente produtivos e erosão é um problema;

- situações onde a população local está alcançando o estado onde o uso extensivo da terra não é mais possível.

Young (1997a) enfatizou algumas vantagens deste sistema quando comparado com o sistema de abordagem de engenharia de terraços:

- uso suplementar de árvores estabilizando estruturas de terra e fornecendo produção desta porção de terra ocupada por árvores;

- custos de estabelecimento e manutenção do sistema de renques devem ser menores e com menor demanda de trabalho que o sistema de terraços, embora demande maior trabalho na instalação; 
- há evidências que a produção da cultura não altera significativamente do seu monocultivo, embora possa haver distribuição irregular da produção entre os renques; podendo ser maior na parte inferior que na superior.

No mesmo trabalho, o autor sintetizou o resultado de nove experimentos de $\mathrm{CH}$ com objetivo de controlar erosão, em diferentes ambientes tropicais, especialmente da Ásia e África. De maneira geral, nestes experimentos os renques de linhas únicas ou duplas de árvores ou arbustos são podadas e espaçados entre quatro e oito metros. Em todos os experimentos com terras em declividades menores que $20 \%$, a erosão foi menor que o nível tolerável (10 toneladas/ha/ano), sendo entre seis a 30 vezes menor que os controles de monocultivo. Para declividades maiores (até 45\%), o sistema pode também ser utilizado, porém o espaçamento entre os renques deve ser menor, diminuindo substancialmente a área disponível á cultura e demandando maior intensidade de trabalho para o manejo dos renques.

\subsection{Modelagem em SAFs}

A utilização de instrumentação computacional tem se tornado uma poderosa ferramenta para a realização de planejamentos e análises ambientais racionais e adequadas. Segundo Crestana (1994), é possível observar, modelar, avaliar e simular remotamente o comportamento local de variáveis edafoclimáticas. Assim, através de modelagens, simulações e manipulações de imagens, parte-se dos laboratórios para o campo com maior segurança dos resultados esperados e obtêm-se economia de tempo e recursos.

Modelagem e simulações não geram dados, porém podem testar e gerar hipóteses, orientar a experimentação no campo e prever o comportamento de determinado sistema em condições desconhecidas (Pereira, 1984).

Desta forma, Muetzelfeldt \& Sinclair (1993) afirmam que a modelagem faz parte dos aspectos estratégicos da pesquisa em agrofloresta e concluem que esta técnica pode fornecer uma forma de integrar conhecimentos de diferentes disciplinas em uma estrutura de trabalho comum, podendo definir metas claras para pesquisa e ser usada também para explorar e avaliar rapidamente opções de manejo agroflorestal. Neste contexto, outras importantes 
referências de modelagem matemática em agrofloresta são Ong \& Huxley (1996), Young (1997b) e Sinclair \& Lawson (1997) que sintetizam, apresentam e analisam diversos modelos para aplicação em SAFs, incluindo crescimento, produção, arranjamento espacial, diversos tipos de interações entre culturas, árvores e ambiente abaixo e acima do solo.

Desta forma, o objetivo geral deste trabalho é avaliar a viabilidade do uso de sistemas agroflorestais para cultivo de cana-de-açúcar na região de Piracicaba. 


\title{
3 IDENTIFICAÇÃo E SELEÇÃo DE TERRAS E ÁRVORES PARA CULTIVO DE CANA-DE-AÇÚCAR EM SISTEMAS AGROFLORESTAIS NA REGIÃO DE PIRACICABA, SP.
}

\author{
Autor: LUÍS FERNANDO GUEDES PINTO \\ Orientador: Prof. Dr. MARCOS SILVEIRA BERNARDES
}

\section{RESUMO}

Na região de Piracicaba grande parte dos pequenos produtores cultivam cana-deaçúcar em áreas de grande declividade, mas a mecanização da colheita tem inviabilizado seu cultivo nesta condição. Assim, identificamos e selecionamos terras e árvores visando compatibilizar a produção da cultura e a conservação de recursos naturais em sistemas agroflorestais. Identificamos os solos presentes no intervalo de 12-20\% de declividade, selecionamos árvores com potencial para serem cultivadas com cana-de-açúcar e avaliamos os desenhos dos sistemas a serem adotados. Argissolo Vermelho-Amarelo e Neossolo Litólico são os solos mais representativos e as espécies arbóreas exóticas coco-anão-verde, eucalipto, pupunheira, seringueira e outras 11 espécies nativas têm potencial para serem cultivadas com cana-de-açúcar em sistemas agroflorestais de aléias em contorno.

Palavras-chave: aléias, árvores nativas, árvores exóticas, erosão 


\title{
IDENTIFICATION AND SELECTION OF LANDS AND TREES TO CULTIVATION OF SUGARCANE IN AGROFORESTRY SYSTEMS IN PIRACICABA, BRAZIL
}

\author{
Author: LUÍS FERNANDO GUEDES PINTO \\ Adviser: Prof. Dr. MARCOS SILVEIRA BERNARDES
}

\section{SUMMARY}

In Piracicaba many smallholders grow sugarcane in areas of high solpe, but the mechanization of the harvest process has made inviable its cultivation under this situation. Thus, we assessed the viability of agroforestry systems to join crop production and conservation of natural resources in the region. We identified the soils present at the slope class of $12-20 \%$, selected tree species with potential to be cultivated with sugarcane and evaluated the design of the systems to be adopted. The most representative soils are Typic kandiuldult and Lithic hapludoll. The exotic tree species coconut, eucalypts, pejibaye and rubber and 11 other native ones have potential to be grown in contourhedgerows with sugarcane.

Key-words: contourhedgerows, erosion, exotic trees, native trees 


\subsection{Introdução}

A região de Piracicaba é tradicional produtora de cana-de-açúcar, totalizando 6,9 milhões de toneladas da cultura, o que representa $18 \%$ da produção do Estado de São Paulo (Orplana, 1996). Segundo Sparovek \& Lepsch (1995), em 1991, esta cultura ocupava 49,3 $\%$ da área do município de Piracicaba, num total de 86.819 ha. Em função de aspectos legislativos e tecnológicos, a prática da queimada prévia à colheita está sendo gradativamente eliminada, implicando em transformações no sistema de produção canavieiro, sendo a mecanização da colheita a mais significativa. A viabilidade para implantação do novo sistema depende da declividade das terras, possível até 12\%, (Sparovek et al., 1997) e é economicamente viável para áreas contínuas maiores que 500 ha (Gonçalves \& Souza, 1998).

A região possui 4951 fornecedores de cana-de-açúcar, o que representa $43 \%$ do Estado, sendo que 84\% destes cultivam áreas menores que 50 ha (Orplana, 1996). Da área total cultivada no município de Piracicaba, 37\% localizava-se em terras inaptas para colheita mecanizada (Sparovek et al., 1997). Em função do cenário de potencial degradação ambiental, pela intensificação do uso do solo sem a adoção de tecnologias adequadas, e deterioração social, pela rentabilidade econômica dos sistemas e dispensa de mão-de-obra, é importante avaliar sistemas de produção alternativos para cana-de-açúcar na região. Entre as alternativas para a permanência do cultivo da cana-de-açúcar destacamos os Sistemas Agroflorestais (SAFs) devido às seguintes justificativas:

a) Em regiões tropicais de clima húmido e sub-úmido, devido à presença de copas e sistemas radiculares diferenciados entre os componentes da cultura e arbóreo, é possível haver maior e melhor aproveitamento dos recursos luz, água e nutrientes, resultando numa maior produção biológica primária que os monocultivos (Ong et al., 1991). Uma das principais formas de avaliação da produção relativa de sistemas agroflorestais é o Índice de Equivalência de Área (IEA). IEA é a razão entre a área de um monocultivo e outra com consorciação de culturas, que resulte numa mesma produção, sobre o mesmo nível de manejo. Uma consorciação mais produtiva que o monocultivo resulta em um IEA maior que 1 (Ong, 1996). 
b) SAFs contribuem para a conservação de solos, pois a presença das árvores pode controlar a erosão significativamente, inclusive em condições de declive acentuado (Young, 1988). Para Young (1997a), as principais funções de renques de árvores (aléias) em SAFs em solos declivosos são o controle da perda de solo através do efeito da cobertura do solo, redução do escoamento superficial e aumento da infiltração

c) SAFs são sistemas de uso da terra muito adequados para pequenas propriedades e agricultura familiar, pois, além dos produtos agrícolas comercializáveis, podem fornecer produtos de subsistência como frutos, alimentos, madeira, forragem e lenha (Nair, 1989).

d) SAFs podem também contribuir para a recuperação da biodiversidade (Pimentel et al., 1992; Vandermeer et al., 1998). Contudo, deve-se considerar a integração e função de várias escalas entre o agroecossistema e a paisagem, pois isoladamente, podem cumprir papel limitado (Poiani et al., 2000).

Assim, este trabalho teve os seguintes objetivos:

1) identificar e selecionar as terras da região onde sistemas agroflorestais possam compatibilizar a produção de cana-de-açúcar com a conservação de solos, 2) identificar e selecionar espécies lenhosas perenes com potencial para serem utilizadas em sistemas agroflorestais com cana-de-açúcar nas terras selecionadas da região e 3) identificar desenhos de sistemas agroflorestais que possibilitem o cultivo de cana-de-açúcar em terras declivosas da região de Piracicaba; considerando desenho como determinada combinação de distribuição espacial e temporal de espécies e de práticas e manejo de um SAF. 


\subsection{Material e Métodos}

O município de Piracicaba localiza-se a S $22^{\circ} 42^{\prime} 30^{\prime \prime}$, W $47^{\circ} 38^{\prime} 01^{\prime \prime}$; altitude de $554 \mathrm{~m}$ e possui clima Cwa, segundo a classificação de Koeppen. De acordo com Sentelhas et al. (1998), o clima é sub-tropical úmido, com verão chuvoso e seca de inverno. A temperatura média anual é de $21,4{ }^{\circ} \mathrm{C}$, com temperaturas médias mensais de $24,8^{\circ} \mathrm{C}$ no verão e $17,1^{\circ} \mathrm{C}$ no inverno. A precipitação média anual é de $1278 \mathrm{~mm}$, sendo distribuídos $1000 \mathrm{~mm}$ de outubro a março e $278 \mathrm{~mm}$ entre abril e setembro.

O município possui área de 137.134 ha (Piracena, 2000), sendo a unidade de estudo, devido à disponibilidade de dados sócio-econômicos e pedológicos existentes, além de ser uma unidade básica para o planejamento de ações públicas. Como o município é extenso e representativo de uma região com características climáticas, edáficas e sócio-econômicas semelhantes, especialmente para a produção de cana-de-açúcar, os resultados podem ser extrapolados para a macro-região definida pela Associação dos Fornecedores de cana-deaçúcar de Piracicaba, que abrange 18 municípios como Capivari, Santa Bárbara D’Oeste, São Pedro e Limeira.

Para a identificação das terras representativas do município com potencial para cultivo de cana-de-açúcar em SAFs, amostramos a porção da bacia do Rio Piracicaba presente no município. Esta abrange 104.915 ha, representando $76 \%$ da área do município. A identificação foi feita com base no banco de dados digital e georreferenciado do Projeto Piracena, executado pelo CENA/USP. Utilizamos os mapas de solos, originário do IAC, na escala de 1:100.000 e topografia, originário do IBGE, na escala de 1:50.000.

O critério para identificação das terras foi a declividade, principal determinante dos potenciais de mecanização e susceptibilidade à erosão. O limite inferior definido foi de $12 \%$, onde é possível a mecanização da colheita da cultura no sistema tradicional, e o superior $20 \%$, onde ainda há eficiência de conservação de solo pelos SAFs (Young, 1997a). Cabe salientar que os SAFs com cana-de-açúcar podem também ser adotados em declividades inferiores à $12 \%$, entretanto, o foco deste trabalho é identificar situações críticas, onde o monocultivo da 
cultura não é recomendado e a adoção do SAF pode viabilizar seu cultivo com baixo risco de erosão.

Os mapas digitais de pedologia e topografia foram manipulados no Sistema de Informações Geográficas Idrisi (Eastman, 1992). Fizemos a interseção entre o mapa de classes de declividade e o de solos, que gerou um mapa final com os solos presentes na classe de declividade selecionada. Os solos foram agrupados e classificados de acordo com a legenda do primeiro solo de cada associação presente na legenda original do IAC (Oliveira \& Prado, 1989). Posteriormente, a legenda foi atualizada de acordo com o atual Sistema Brasileiro de Classificação de Solos (EMBRAPA, 1999), seguindo o mapa atualizado de Oliveira et al. (1999). Finalmente, os solos foram contabilizados por Classe da nova classificação.

As espécies lenhosas perenes (árvores) foram selecionadas com base em dados de literatura. Adotamos os critérios: i) adaptação às condições edafoclimáticas locais; ii) potencial para contribuir para conservação do solo; iii) potencial de geração de renda; iv) potencial de aceitação e uso pelos agricultores da região, v) possibilidade de processamento e comercialização locais e vi) contribuição à biodiversidade local.

A identificação dos melhores desenhos de SAFs para cultivo de cana-de-açúcar foi feita com base em revisão de literatura. Identificamos os potenciais e restrições de desenhos, experiências de SAFs em condições semelhantes à deste trabalho e consideramos as técnicas empregadas no cultivo de cana-de-açúcar na região com colheita mecanizada. 


\subsection{Resultados e Discussão}

\subsubsection{Identificação das terras}

A manipulação dos mapas básicos mostrou que pelo menos $8,43 \%$ da área total do município (11.556,32 ha) está no intervalo entre 12 e 20\% de declividade. As classes de solos presentes neste intervalo, sua área total e relativa no município foram: i) Argissolos VermelhoAmarelos (PVA; 5406,88 ha e 3,94\%), ii) Neossolos Litólicos (RL; 2931,36 ha e 2,14\%), iii) Neossolos Quartzarênicos (RQ; 1182 ha e 0,86\%), iv) Latossolo Vermelho-Escuro (LE; 481,48 ha e 0,35\%), v) Latossolo Roxo (LR; 295,52 ha e 0,22\%), vi) Latossolo VermelhoAmarelo (LV; 236,84 e 0,17\%) e vii) Outros (1.022,24 ha e 0,75\%). A distribuição espacial dos solos (Figura 1) mostra que na área amostrada há presença desta classe de declive em praticamente todo o município, o que possivelmente representa distintas realidades sócioeconômicas e níveis tecnológicos de produção. Percebe-se também a sua distribuição em pequena áreas não contíguas, o que evidencia que os SAFs deverão ser implantados em pequena escala e com diferentes orientações em relação à orientação da radiação solar.

Para fins de manejo, os principais solos identificados (Argissolos Vermelho-Amarelos e Neossolos Litólicos), apresentam fertilidade variável, atributo que pode ser corrigido para a produção agroflorestal. Contudo, destacam-se pela suscetibilidade à erosão, por serem solos rasos ou abruptos e estarem presentes em declividades moderadas (Oliveira, 1999); reforçando a importância de sistemas de produção com eficiente conservação do solo. Assim como para nutrientes, estes solos não devem apresentar limitações para disponibilidade de água para cultivo de cana-de-açúcar na região de Piracicaba, mesmo se consorciados com

árvores. Se necessário, pode-se empregar irrigação para eventuais espécies arbóreas com alta demanda hídrica. Portanto, a competição por luz deve ser considerada como principal fator para desenho dos SAFs. 


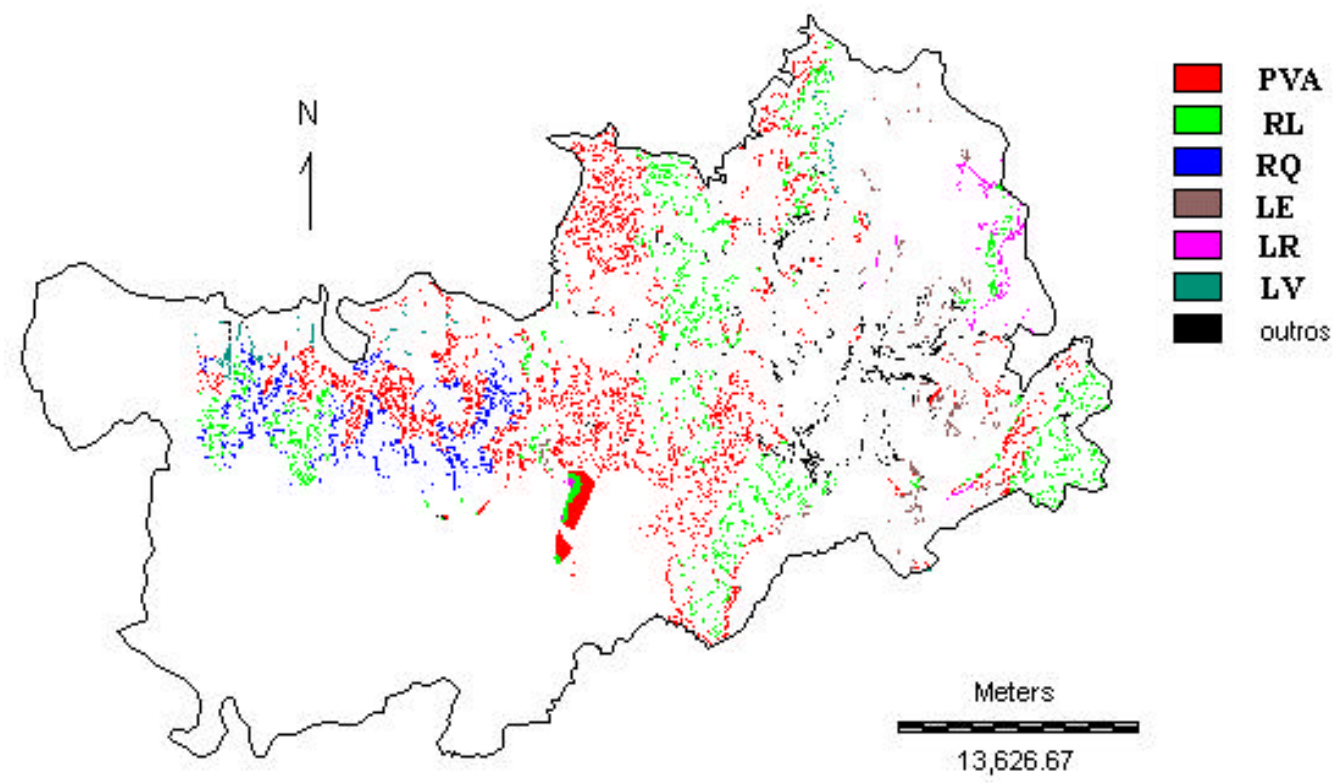

Figura 1 -. Distribuição espacial dos solos presentes no intervalo de declividade de 12-20\% na bacia do Rio Piracicaba, presentes no município de Piracicaba. (PVA - Argissolos Vermelho-Amarelos, RL - Neossolos Litólicos, RQ - Neossolos Quartzarênicos, LE - Latossolos Vermelho-Escuros, LR - Latossolos Roxos e LV - Latossolos Vermelho-Amarelos).

\subsubsection{Seleção de árvores}

Os dados da CATI (1997) indicam que dos 103.790,68 ha cultivados no município de Piracicaba, 50.981,80 são ocupados por cana-de-açúcar e 45.974 ha por pastagens. Quanto ao plantio de árvores, há 1494,9 ha ocupados por eucaliptos, 1920 ha por frutíferas (banana, abacate, citrus e manga, entre outras) e 18,70 ha por outras espécies, principalmente café. Há também o cultivo isolado de palmito e urucum, totalizando 888 propriedades com outras atividades além da cana-de-açúcar. Verifica-se que embora o uso da terra seja concentrado em duas culturas, há relativa diversificação de pequenas áreas de produtores com outras culturas, onde destacam-se árvores. Logo, há potencial de aceitação dos produtores da região pelo cultivo de árvores que possam gerar produtos comercializáveis e renda. Desta forma, avaliamos os demais critérios para as espécies exóticas domesticadas coco-anãoverde, eucalipto, pupunheira e seringueira, sugeridos em estudo previamente elaborado para a 
região por Bernardes \& Sparovek (1998). A Tabela 1 apresenta estas espécies e algumas características relevantes para seu cultivo.

Lima (1993) revisou o uso de eucalipto em sistemas agroflorestais em várias regiões do Brasil e concluiu pela sua viabilidade para o Estado de São Paulo, podendo haver benefícios tanto para o eucalipto quanto para as culturas intercaladas. $\mathrm{O}$ autor também afirma que as espécies de eucalipto contribuem para a conservação de solos, indicando que o escoamento superficial e erosão diminuem sensivelmente em plantações presentes em terrenos anteriormente degradados.

Coco-anão pode ser cultivado no Sudeste do Brasil, considerando-se baixas temperaturas e umidade relativa como principais fatores limitantes. Estes podem ser contornados com escolha de variedades, tratos culturais, irrigação e altitudes que evitem baixas temperaturas e geadas (Passos, 1998a). Quanto à conservação do solo destaca-se o denso sistema radicular fasciculado, que tem como principal função a forte fixação da planta e que ocupa o solo em raio de até $2 \mathrm{~m}$ do caule, em profundidades entre 0,2 e 0,8 m (Passos, 1998b).

Bernardes \& Fancelli (1990) avaliaram o cultivo de seringueira intercalar à citrus e afirmaram que praticamente todo o Planalto Paulista (exceto as regiões de elevada altitude) é preferencial para a heveicultura. Os autores também indicam, que além de possuir dossel fechado, a seringueira apresenta um denso e extenso sistema radicular na superfície do solo; fatores que contribuem para a conservação do mesmo.

A pupunheira deve ser cultivada em ambientes quentes e úmidos, preferencialmente em áreas com temperatura média anual de $22^{\circ} \mathrm{C}$ e precipitação anual acima de $1600 \mathrm{~mm}$ (Bovi, 1993). Sua principal característica que contribui para a conservação do solo é o rápido perfilhamento, que resulta na formação de touceiras fortemente fixadas ao solo.

A avaliação econômica revelou que um projeto de produção de cana-de-açúcar com 6 cortes acumulou resultado negativo de U\$ 2,16 ha ${ }^{-1}$ ano $^{-1}$ nas previsões da safra de 2000 (FNP, 1999). Todavia, este foi um ano atípico do setor e, portanto, também coletamos os 
dados da previsão das safras de 1998 e 1999 (U\$178 ha ${ }^{-1}$ ano $^{-1}$, FNP (1997) e U\$ 370 ha $^{-1}$ ano $^{-1}$, FNP (1998)), ambos em projeto de 6 cortes.

Todas as espécies avaliadas apresentaram desempenho econômico similar ou superior ao da cana-de-açúcar. Coco-anão apresentou resultado positivo de U\$ $2.503 \mathrm{ha}^{-1} \mathrm{ano}^{-1}$, em projeto de trinta anos; pupunha obteve U\$ 715 ha $^{-1}$ ano $^{-1}$ em 15 anos de cultivo e seringueira proporcionou U\$ $4.287 \mathrm{ha}^{-1}$ ano $^{-1}$ em projeto de 32 anos de plantio, todos nas previsões da safra de 2000 (FNP, 1999). Rodriguez \& Rodrigues (1999) avaliaram o desempenho de eucalipto para projetos de 7 anos de produção de madeira para a indústria, que acumulou resultado de U\$ 301 ha $^{-1}$ ano $^{-1}$; sendo que para outros usos como madeira para serraria, postes e óleos de folhas o valor pode ser muito maior. Logo, há evidências de que os SAFs possam ser mais lucrativos que o monocultivo da cana-de-açúcar, como em estudo semelhante realizado por Benjamin et al. (2000) com milho e árvores madeireiras no meio oeste dos EUA.

Contudo, nenhuma das espécies contribuem à biodiversidade local, já que são exóticas das Florestas Mesófilas Semidecíduas presentes na região. Portanto, também avaliamos árvores nativas do Estado de São Paulo. Por serem nativas, estas foram automaticamente consideradas adaptadas às condições edafoclimáticas da região.

A avaliação foi feita confrontando-se a revisão de Ferretti et al. (1995) com as de Carvalho (1994). O primeiro trabalho listou espécies consideradas nativas do Estado de São Paulo e Carvalho (1994) revisou o potencial de cultivo e uso da madeira de 100 espécies arbóreas brasileiras, classificando seu potencial para diversos usos em: i) madeireiras promissoras - as que possuem valor econômico comprovado, com produção de madeira valiosa, desempenho silvicultural aceitável, aptidão para programas de regeneração artificial e recomendadas para plantios puros ou mistos no sul e norte do país; ii) potenciais - as que possuem os mesmos atributos das promissoras, porém apresentam menos informações de plantios experimentais. Logo, todas as espécies destas duas categorias que coincidiram com Ferretti et al. (1995) foram consideradas com potencial para emprego nos SAFs com canade-açúcar de Piracicaba. 
As espécies promissoras foram araribá, canafístula, ipê-felpudo, louro-pardo, jequitibá-branco, jequitibá-rosa e mandiocão e as potenciais pau-marfim, jatobá e aroeiraverdadeira. Também selecionamos a espécie de palmito jussara. A Tabela 2 apresenta as espécies e algumas de suas características silviculturais.

O paradigma entre adoção de espécies exóticas domesticadas ou nativas (geralmente não domesticadas) deve considerar aspectos de manejo e mercado, nos quais este trabalho está inserido. Num primeiro momento, seu principal objetivo é apresentar alternativas de uso da terra aos pequenos produtores de cana-de-açúcar da região, priorizando a conservação do solo e a manutenção ou elevação da renda. Dentre os critérios adotados para a seleção de árvores, entendemos que as nativas contribuem significativamente para a biodiversidade e podem contribuir igualmente às exóticas para a conservação do solo. Contudo, as exóticas domesticadas possuem alta previsibilidade, manejo silvicultural e mercados conhecidos. Por outro lado, a biologia, manejo e mercado da maioria das nativas ainda são relativamente pouco conhecidos, confirmando Huxley (1996), que afirma que os componentes de um SAF passaram por diferentes níveis de seleção genética, implicando numa distinta combinação entre previsibilidade, plasticidade e resistência à distúrbios ou variações climáticas. Além disso, o retorno econômico de plantações de madeira nativas é em geral mais demorado que o das exóticas e os importantes benefícios diretos e indiretos da biodiversidade ainda não são repassados economicamente aos agricultores (Daily et al., 1998).

Assim, visando o sucesso da adoção de árvores e a implantação de SAFs pelos produtores de cana-de-açúcar da região de Piracicaba, indicamos o plantio inicial com espécies domesticadas. As nativas não domesticadas devem ser introduzidas gradualmente de acordo com suas exigências ecológicas, principalmente luz. As tolerantes à sombra devem ser plantadas no sub-bosque das aléias, aproveitando-se das modificações microclimáticas que favoreçam seu desenvolvimento. Tal enriquecimemto das aléias pode ocorrer através da substituição de plantas de exóticas mortas. As não tolerantes à sombra podem ser cultivadas na borda das aléias, visando seu alargamento gradual. O plantio planejado de exóticas e nativas pode também ser adotado em uma estratégia de substituição progressiva do 
monocultivo da cana-de-açúcar por uma vegetação florestal produtiva. Finalmente, tanto as exóticas quanto as nativas proporcionam produtos (madeira, frutos, látex, folhas, palmito) que podem ser processados em usinas de pequena escala, assim como comercializadas pelos próprios produtores e suas cooperativas. 
Tabela 1. Espécies arbóreas exóticas domesticadas selecionadas para cultivo em sistemas agroflorestais com cana-de-açúcar na região de Piracicaba

\begin{tabular}{|c|c|c|c|c|c|c|}
\hline Nome popular & Nome científico & Produto & $\begin{array}{l}\text { Exigência em } \\
\text { fertilidade do solo }\end{array}$ & Resistência a seca & $\begin{array}{l}\text { Necessidade } \\
\text { de } \\
\text { mecanização }\end{array}$ & $\begin{array}{l}\text { Demanda por } \\
\text { mão-de-obra }\end{array}$ \\
\hline Coco-anão-verde & Cocos nucifera & fruto & média & média & baixa & média \\
\hline Eucalipto & Eucalyptus grandis & madeira & baixa & média & média & baixa \\
\hline \multirow[t]{2}{*}{ Eucalipto } & & folhas, madeira & média & média & média & média \\
\hline & Eucalyptus citriodor & & & & & \\
\hline Pupunha & Bactris gasipaos & palmito & média & média & baixa & alta \\
\hline Seringueira & Hevea brasilliensis & látex, madeira & baixa & alta & baixa & média \\
\hline
\end{tabular}

Fonte: Bernardes \& Sparovek (1998) 
Tabela 2. Espécies arbóreas nativas selecionadas para cultivo em sistemas agroflorestais com cana-de-açúcar na região de Piracicaba

\begin{tabular}{|c|c|c|c|c|}
\hline Nome popular & Nome científico & Produto & Crescimento & Tolerância à sombra \\
\hline aroeira verdadeira & Myracrodruon urundeuva & madeira & Médio & $\begin{array}{l}\text { tolerante no estágio } \\
\text { juvenil }\end{array}$ \\
\hline Araribá & Centrolobium tomentosum & madeira & Médio & $\begin{array}{l}\text { tolerante no estágio } \\
\text { juvenil }\end{array}$ \\
\hline Canafístula & Peltophorum dubium & madeira & Médio & $\begin{array}{l}\text { tolerante no estágio } \\
\text { juvenil }\end{array}$ \\
\hline ipê-felpudo & Zeyheria tuberculosa & madeira & Médio & $\begin{array}{l}\text { tolerante no estágio } \\
\text { juvenil }\end{array}$ \\
\hline louro-pardo & Cordia trichotoma & madeira & Médio & $\begin{array}{l}\text { tolerante no estágio } \\
\text { juvenil }\end{array}$ \\
\hline Jatobá & $\begin{array}{l}\text { Hymenaea courbaril var } \\
\text { stilbocarpa }\end{array}$ & madeira & Lento & tolerante \\
\hline jequitibá-branco & Cariniana estrellensis & madeira & Médio & $\begin{array}{l}\text { tolerante no estágio } \\
\text { juvenil }\end{array}$ \\
\hline jequitibá-rosa & Cariniana legalis & madeira & Médio & $\begin{array}{l}\text { tolerante no estágio } \\
\text { juvenil }\end{array}$ \\
\hline Jussara & Euterpe edulis & Palmito & Médio & $\begin{array}{l}\text { tolerante no estágio } \\
\text { juvenil }\end{array}$ \\
\hline Mandiocão & Didymopanax morototoni & madeira & Rápido & intolerante \\
\hline pau-marfim & Balfourodendron riedelianum & madeira & Médio & $\begin{array}{l}\text { tolerante no estágio } \\
\text { juvenil }\end{array}$ \\
\hline
\end{tabular}

Fonte: Carvalho (1994) 


\subsubsection{Desenhos de SAFs}

Segundo Young (1988), sistemas de multiestratos e cultivo em aléias em contorno (contourhedgerow) são os principais tipos de SAF para controlar erosão e escoamento superficial em regiões declivosas. Entre estes, o último é o mais indicado para cultivo de culturas anuais e semi-perenes. McDonald et al. (1997) definiram aléias em contorno como o cultivo de aléias em forma de uma barreira ao longo dos contornos do terreno em declive, com as faixas entre as aléias usadas para produção das culturas.

A alteração do declive discutida por Young (1997a) e Garrity (1996) pode viabilizar o cultivo mecanizado entre as aléias em áreas de declive moderado. Para o cultivo da canade-açúcar, a adoção de aléias em contorno proporciona também benefícios na sistematização dos talhões e consequente melhor aproveitamento da terra e eficiência de operações agrícolas. A existência das aléias e o papel conservacionista das árvores permitem realizar a sulcação com paralelismo e pouca sinuosidade na faixa entre as aléias, eliminar linhas mortas e terraços no talhão, aumentar o comprimento dos talhões, construir carreadores em nível acompanhando paralelamente à sulcação. Tais características favorecem positivamente a mecanização da colheita e possibilitam o acompanhamento da evolução da tecnologia de produção hoje praticada na região. O sistema também é adequado aos critérios de formato de talhões e eficiência operacional de máquinas agrícolas. Segundo Mialhe et al. (1983), talhões retangulares devem possuir largura da ordem de no mínimo 1/5 de seu comprimento para apresentar eficiência de percurso próxima da máxima. Além deste critério, a distância entre as aléias será um valor múltiplo do espaçamento entre as linhas de cana-de-açúcar exigidos para a colheita mecanizada.

Confirmando o potencial da utilização com sucesso de aléias em contorno na região de Piracicaba, Fujisaka, (1997) revisou diversas experiências internacionais onde este sistema foi adotado e sintetizou as situações onde faz sentido seu emprego: a) em climas úmidos e subúmidos, podendo combinar controle da erosão com cultivo agrícola em declives amenos a moderados; b) onde os solos são relativamente produtivos e erosão é um limitante à produção 
sustentável; c) situações onde o tamanho da população local é incompatível com o uso extensivo da terra.

Estudos preliminares também comprovam o caráter conservacionista de SAFs para cultivo de cana-de-açúcar. Bernardes et al (1998) realizaram simulações aplicando a Equação Universal de Perda de Solo (USLE) para cultivo de cana-de-açúcar com renques de culturas perenes, comparada com a cultura em monocultivo com terraceamento convencional para um Podzólico Vermelho-Amarelo abrupto de Piracicaba. A perda de solo foi de 19,7 ton ha' ${ }^{1}$.ano. ${ }^{-1}$ para o cultivo com cultura perene contra 24,4 ton $\mathrm{ha}^{-1}$.ano ${ }^{-1}$ do sistema convencional. Seguindo-se os parâmetros discutidos como competição por luz, formato dos talhões e espaçamento entre as linhas de cana-de-açúcar, deve-se posteriormente avaliar o espaçamento ideal entre os renques de árvores, assim como o número de linhas de árvores por renque e seu espaçamento, entre árvores e entre linhas de árvores. Assim, o SAF deve cumprir seu papel de conservação de solo e manter seu rendimento em valores que proporcionem IEA igual ou maior que 1 em relação aos seus respectivos monocultivos. 


\subsection{Conclusões}

1) Os SAFs com cana-de-açúcar podem ser implantados de maneira geral no município de Piracicaba, especialmente nos solos com alta suscetibilidade à erosão, destacando-se o Argissolo Vermelho-Amarelo e o Neossolo Litólico, presentes no intervalo de declividade entre 12 e $20 \%$.

2) As espécies arbóreas coco-anão-verde, eucalipto, pupunheira, seringueira, araribá, aroeira-verdadeira, canafístula, ipê-felpudo, jatobá, jequitibá-branco, jequitibá-rosa, jussara, louro-pardo, mandiocão e pau-marfim têm potencial para serem utilizadas em SAFs em renques na região de Piracicaba.

3) Em sistemas agroflorestais, a cana-de-açúcar deve ser cultivada em aléias em contorno nas terras declivosas de Piracicaba; considerando o sistema de colheita mecanizado e a conservação de solos. 


\title{
4 SimulaçÃo do CRESCIMENTO E PROduÇÃo DE SiSTEMAS AGROFLORESTAIS COM CANA-DE-AÇÚCAR EM PIRACICABA, SP.
}

\author{
Autor: LUÍS FERNANDO GUEDES PINTO \\ Orientador: Prof. Dr. MARCOS SILVEIRA BERNARDES
}

\section{RESUMO}

A cana-de-açúcar (Saccharum officinarum) ocupa grandes áreas em regiões tropicais, porém há falta de pesquisa sobre seu cultivo em sistemas agroflorestais. Portanto, o uso de modelos de simulação pode desempenhar importante papel para investigar seus potenciais e restrições. Assim, este trabalho visou avaliar o cultivo de cana-de-açúcar em sistemas agroflorestais em aléias de eucalipto (Eucalyptus grandis) e seringueira (Hevea brasiliensis) com o uso do modelo WaNuLCAS. Procurou também avaliar a adequação do modelo como ferramenta para indicar sistemas agroflorestais como alternativa de uso da terra. Cada sistema foi simulado por 20 anos em dois solos de Piracicaba, SP, onde avaliou-se os efeitos da radiação solar e água no crescimento e produção das plantas. As simulações mostraram que os sistemas são viáveis, mas radiação solar e água são fatores limitantes. A competição por estes recursos aumenta com o crescimento das árvores e depende das características das árvores e o manejo dos sistemas. O WaNuLCAS foi uma ferramenta útil para avaliação dos sistemas, indicar fatores limitantes, tendências qualitativas e fornecer subsídios para experimentação de campo. Os resultados devem ser confirmados por dados de campo.

Palavras-chave: água, eucalipto, modelo, seringueira, sombra, wanulcas 


\title{
SIMULATION OF PLANT GROWTH AND YIELD IN AGROFORESTRY SYSTEMS WITH SUGARCANE IN PIRACICABA, BRAZIL.
}

\author{
Author: LUÍS FERNANDO GUEDES PINTO \\ Adviser: Prof. Dr. MARCOS SILVEIRA BERNARDES
}

\section{SUMMARY}

Sugarcane (Saccharum officinarum) occupies large areas of tropical regions, but there is lack of research of its cultivation in agroforestry systems (AFs). Thus the use of simulation models may play an important role to investigate its potentials and restrictions. This work aimed to assess alley cropping systems with sugarcane and rubber (Hevea brasiliensis) and eucalyptus (Eucalyptus grandis) by the use of the WaNuLCAS model and also to evaluate the suitability of the model as a tool to assess AFs as a land use alternative. Each system was simulated for 20 years in two soils of Piracicaba, Brazil and the effect of light and water on plant growth was evaluated. Simulations showed that AFs with rubber and eucalyptus are viable but light and water are limiting factors. Competition for these resources increases with tree growth and depends on tree characteristics and management of the systems. WaNuLCAS was an useful tool to assess the systems, to indicate limiting factors, qualitative tendencies and to provide subisidies for field experimentation. Its results should be confirmed by field data.

Key words: eucalyptus, model, rubber, shade, wanulcas, water 


\subsection{Introdução}

A cana-de-açúcar é cultivada em diversas regiões tropicais do planeta, num total de 19,4 milhões de ha entre países da Ásia (8,6 milhões de ha), América do Sul (6,0 milhões de ha), América Central e do Norte (2,9 milhões de ha), África (1,4 milhões de ha) e Oceania (0,5 milhões de ha). Brasil (4,9 de milhões de ha) e Índia (3,7 milhões de ha) são os maiores produtores mundiais (FAO, 1999). O monocultivo é o sistema predominante, mas o nível de manejo varia entre padrões de alta tecnologia e intenso uso de insumos à pequena adoção de tecnologia e baixo uso de insumos e entre produção em pequenas até grandes propriedades.

Devido à questões ambientais e sócio-econômicas, atualmente é necessário identificar e pesquisar sistemas de produção alternativos para regiões onde a cultura é tradicionalmente cultivada, como Piracicaba, SP. Os novos sistemas devem considerar o padrão tecnológico de produção e visar a conservação dos recursos naturais (Pinto et al., 2001). Entre as avaliações de sistemas alternativos de produção de cana-de-açúcar, há trabalhos sobre seu

consorciamento com batata, milho, girassol e feijão na Ásia e África (Govinden, 1990; Kwong et al., 1996; Sharma et al.,1997) e com feijão e outras culturas no Brasil (De-Souza \& DeAndrade, 1985 e Rolim, 1989). Zarin et al. (1998) avaliou a cultura para sistemas agroflorestais de derruba e queima na Amazônia.

Todavia, não há estudos sistemáticos sobre a viabilidade de seu cultivo em sistemas agroflorestais (SAFs) para as regiões de cultivo intensivo da cultura. No capítulo anterior, discutimos a viabilidade do emprego de SAFs para cultivo de cana-de-açúcar em Piracicaba (SP) e indicamos seringueira e eucalipto, entre outras, como espécies com potencial para utilização nestes sistemas. Todavia, ressaltamos a necessidade de avaliações quantitativas do seu potencial de produção anteriores à recomendação destes aos produtores.

Como há carência de experimentos e dados sobre o desempenho da cultura em sistemas agroflorestais, o uso de modelos matemáticos torna-se uma ferramenta estratégica para especular sobre os seus potenciais e restrições. Segundo Lott et al. (2000), como a pesquisa experimental e a posterior transferência de tecnologia em agrofloresta são retardadas 
pelo longo tempo necessário para que um sistema se torne maduro, o desenvolvimento de modelos de simulação, fornecendo avaliações quantitativas do desempenho de sistemas agroflorestais, pode oferecer uma alternativa eficiente e de baixo custo para seleção preliminar de sistemas potenciais. Além disso, modelagem e simulações podem testar e gerar hipóteses, orientar a experimentação de campo, prever o comportamento de dado sistema em condições desconhecidas (Pereira, 1984) e podem fornecer subsídios para definição de políticas (Sinclair \& Lawson, 1997). Todavia, as iniciativas de modelos genéricos de modelagem em sistemas agroflorestais, liderados pelos modelos HyPAR (Mobbs et al., 1998) e WaNuLCAS (Van Noordwijk \& Lusiana, 1999) são recentes e seus autores têm reforçado a importância de testá-los em diferentes regiões e de criar um amplo banco de dados de clima, solos e parâmetros de culturas e árvores calibrados localmente para uma maior facilidade de uso destes modelos.

Neste contexto, este trabalho teve como objetivos: i) usar simulações com o modelo WaNuLCAS para averiguar o potencial de sistemas agroflorestais cana-de-açúcar com seringueira e com eucalipto na região de Piracicaba, SP, Brazil, ii) avaliar a adequação do WaNuLCAS para análises de SAFs como opção de uso da terra.

\subsection{Material e Métodos}

Realizamos as simulações com a versão 2.06 do modelo WaNuLCAS (Water, Nutrient and Light Capture in Agroforestry Systems). Este simula interações, crescimento e produção de culturas e árvores em SAFs, desenvolvido pelo ICRAF. Considera as interações entre cultura e árvore acima e abaixo do solo pela captura dos recursos luz, água e nutrientes com intervalo de cálculo diário. A absorção de recursos ocorre simultaneamente entre o

componente arbóreo e da cultura, dependendo da demanda de cada componente e da proporção que cada um ocupa na atmosfera e no solo. A proporção da captura de radiação é determinada pelo IAF de cada componente e o conteúdo de água no solo e a densidade 
radicular da cultura e das árvores são as variáveis que determinam a proporção da captura de água e nutrientes.

O modelo divide o espaço horizontal ocupado pelas árvores e culturas em quatro zonas onde as interações entre árvores e culturas ocorrem em diferentes intensidades (Figura 1). Incorpora opções de manejo como espaçamento, poda, adição de fertilizantes, colheita de frutos e madeira, sangria, queima e presença de plantas invasoras e pragas (Van Noordwijk \& Lusiana, 2000). Foi desenvolvido para trabalhar no programa de modelagem dinâmica Stella (Hannon \& Rut,1997) e possui, entre outros, os seguintes componentes:

1) Clima - i) dados diários de chuva, que podem ser fornecidos por dados históricos reais ou gerados a partir de probabilidades diárias; ii) temperatura média do solo, que afeta somente processos edáficos, iii) evapotranspiração potencial, a partir de dados diários ou da média anual.

2) Solo - dividido em quatro camadas com profundidades a serem definidas pelo usuário, considerando-se propriedades físicas e químicas. As características hidráulicas do solo são derivadas a partir da aplicação de equações de Van Genuchten (Pedotransfer Functions), que consideram textura, densidade e matéria orgânica do solo.

3) Absorção de luz - considera o índice de área foliar de ambos componentes e suas relativas alturas em cada zona espacial. São considerados três (3) estratos aéreos, sendo o superior somente com dossel das árvores, um intermediário com dossel misto (folhas e galhos das árvores e folhas da cultura) e um inferior com dossel da cultura. O modelo somente considera radiação de origem zenital.

4) Balanço de água - inclui precipitação, infiltração, escoamento superficial, evaporação superficial, absorção por árvores e cultura e percolação.

5) Balanço de nitrogênio - inclui entradas por fertilizantes de até quatro aplicações anuais, fixação atmosférica e mineralização de matéria orgânica do solo e resíduos frescos. A absorção pelas árvores e cultura é separada em colheita, exportada da área, e resíduos reciclados. A lixiviação de nitrogênio mineral na forma de nitrato é calculada em função do 
balanço de água, a concentração de nitrogênio e a constante de adsorção de nitrato para cada camada.

6) Absorção de água e nitrogênio - é governada, tanto para a árvore como para a cultura, pela demanda, baseada na densidade radicular e constantes de difusão efetiva. O crescimento de raiz é representado para a cultura por um aumento da densidade radicular em cada camada até o florescimento e declínio gradual após este momento, sendo um valor máximo de densidade radicular definido por camada e zona espacial. Para as árvores, assumese que a densidade radicular em todas as camadas e zonas espaciais seja constante, com possível equilíbrio entre crescimento e declínio.

7) Competição por água e nutrientes - é baseada no compartilhamento do potencial de absorção para árvores e cultura, baseado na combinação da densidade radicular; em função do comprimento de raiz relativo multiplicado pela demanda relativa de cada componente.

8) Matéria orgânica do solo - a decomposição segue os conceitos e terminologia do modelo Century (Parton et al., 1994).

9) Crescimento da parte aérea - tanto de culturas como de árvores é calculada em base diária, multiplicando-se o crescimento potencial, que é dependente do clima, pelo menor valor dos três fatores relativos de estresse: sombreamento, limitação de água e de nitrogênio. 
10) Erosão - o modelo incorpora, entre outras opções, uma adaptação da Equação universal de Perda de Solo (Wischmeier \& Smith, 1978).

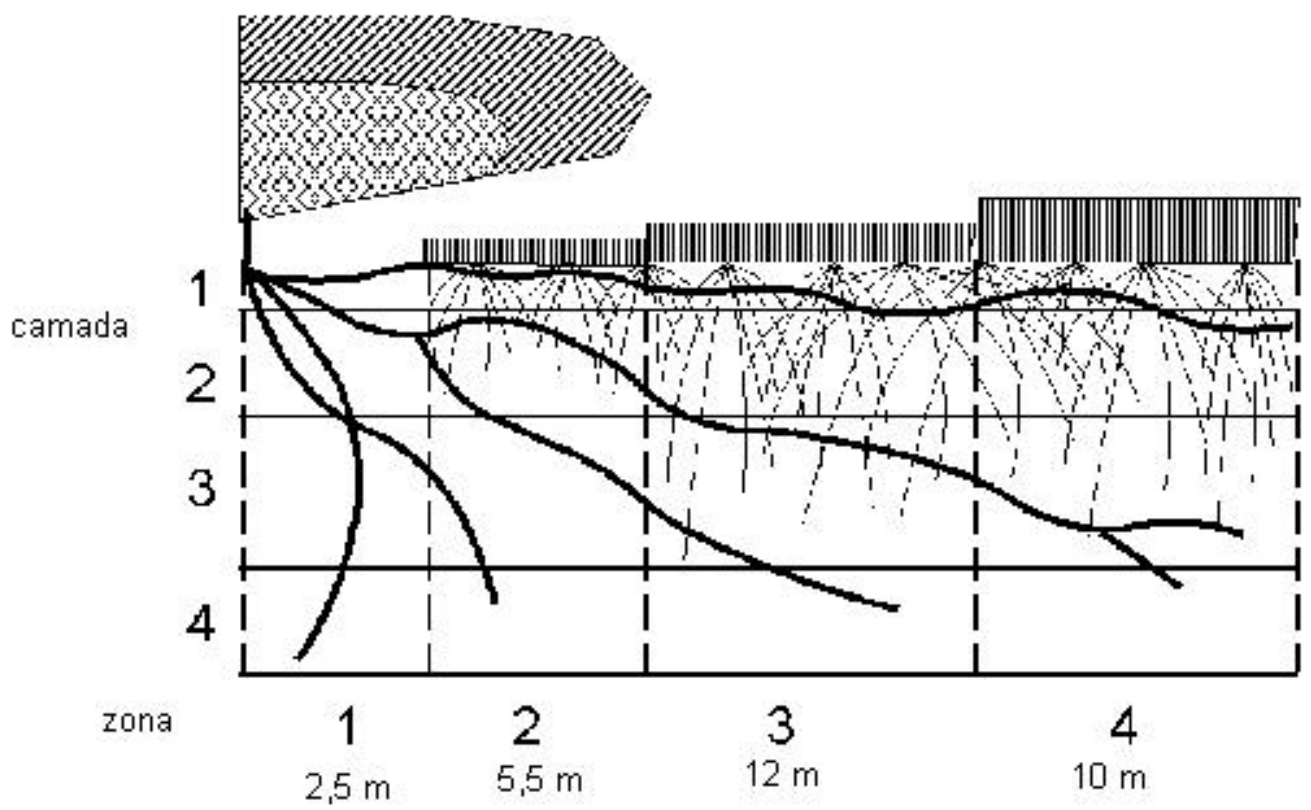

Figura 1 - Esquema geral da distribuição de zonas espaciais e camadas de solo do modelo WaNuLCAS e dos sistemas simulados. Adaptado de Van Noordwijk \& Lusiana (2000)

Os principais passos para cálculo do crescimento da cultura são descritos abaixo.

1) cálculo do IAF ( $\mathrm{m}^{2}$ folha $\mathrm{m}^{-2}$ solo) em função da biomassa aérea, proporção da massa de folha sobre a massa de biomassa aérea (PF) e área foliar específica (AFE - área de folha por unidade de peso de folha $\mathrm{cm}^{2} \mathrm{~g}^{-1}$ );

2) cálculo da altura do dossel em função de um fator (F) que converte biomassa aérea em altura, assumindo que o crescimento vertical termina após o florescimento;

3) cálculo da interceptação relativa de radiação (IRR) em função do IAF e distribuição vertical e horizontal dos dosséis da cultura e árvore; 
4) cálculo da taxa de crescimento para cada dia (TCD) através da multiplicação de IRR pela eficiência relativa de uso da radiação (ERUR - produção de matéria seca por unidade de radiação capturada ao longo do ciclo) e do crescimento máximo potencial da cultura (CMP);

5) cálculo da demanda transpiratória a partir do potencial limitado pela radiação atual (TCD) e de uma eficiência de uso da água potencial (EUAP);

6) cálculo da razão entre demanda e disponibilidade de água (RDA);

7) cálculo similar ao da água para limitação por nitrogênio, calculando-se ao final a razão entre sua demanda e disponibilidade (RDN) e

8) cálculo da produção real de matéria seca em função do crescimento potencial para cada dia (TCD) e o mínimo da limitação por água ou nitrogênio (RDA e RDN).

O crescimento máximo potencial da cultura (CMP) deve ser obtido a partir de experimentos locais com a cultura em condições ideais de crescimento ou através de modelos matemáticos específicos para crescimento de cultura. $\mathrm{O}$ mesmo procedimento deve ser adotado para obtenção dos parâmetros que não são constantes ao longo do ciclo da cultura, isto é, são dependentes do estágio em que a planta se encontra. No WaNuLCAS, estes parâmetros são: área foliar específica (AFE), eficiência relativa de uso da radiação (ERUR), proporção do peso de folha sobre peso de biomassa aérea (PF) e alocação de biomassa para colheita (proporção da biomassa destinada à partes colhidas da cultura - grãos ou tubérculos).

Simulamos uma interface com árvores presentes na Zona 1 e uma faixa de cana-deaçúcar nas Zonas 2, 3 e 4 num comprimento total de 27,5m (Figura 1), representando um SAF em aléias, isto é, faixas de cultura intercaladas com linhas de árvores. Avaliamos as interfaces cana-de-açúcar x seringueira e cana-de-açúcar x eucalipto separadamente por um período de 20 anos (1981 - 2000), desconsiderando-se limitação por nutrientes, nos dois solos mais representativos das terras declivosas da região de Piracicaba: Argissolos Vermelho-Amarelos (PVA) e Neossolos Litólicos (RL); Tabela 1.

O manejo de cada espécie está descrito abaixo e o cronograma simplificado do sistema está na Tabela 2. A distribuição horizontal das zonas simuladas está na Figura 1. 
a) Cana-de-açúcar - plantio de cana-planta em 1 de março do primeiro ano (1981), com corte em 19 de julho do ano seguinte (500 dias de ciclo). Os três anos de soqueiras subsequientes foram simulados como novos plantios anuais efetivados em 23 de julho, com colheita um ano após o plantio. Este ciclo foi repetido por 4 vezes nos 20 anos. A cana-planta foi notada como $\mathrm{P}_{1}, \mathrm{P}_{2}, \mathrm{P}_{3}$ e $\mathrm{P}_{4}$ e a cana-soca foi notada como $\mathrm{S}_{11}, \mathrm{~S}_{12}, \mathrm{~S}_{13}$, $\mathrm{S}_{21}, \ldots, \mathrm{S}_{23}, \ldots, \mathrm{S}_{41}, \ldots, \mathrm{S}_{43}$, sendo o primeiro índice referente à cana-planta original do ciclo.

b) Seringueira - plantio das mudas em 30 de janeiro do primeiro ano (1981) e sangria a partir do momento que atingem o perímetro mínimo de $50 \mathrm{~cm}$ (Bernardes, 2000). Do total de reservas de carboidratos destinadas para crescimento diário da árvore, $10 \%$ foram alocadas à produção de látex. A literatura indica que este valor pode variar de 10 a 40\% (Paardekooper, 1989), e após vários testes foi adotado o valor inferior. Simulamos uma linha de árvores plantadas na Zona 1 com espaçamento de 3 metros entre árvores na linha.

c) Eucalipto - plantio das mudas em 30 de janeiro do primeiro ano (1981), com espaçamento de 2 metros entre árvores na linha. Durante os 20 anos, há 3 colheitas, sendo as 2 últimas a partir da rebrota do primeiro plantio. A simulação das rebrotas foi adaptada com a morte do plantio anterior e um imediato novo plantio, porém com menor densidade de árvores, maior altura e biomassa do toco e reservas de carboidratos das mudas. A primeira e segunda rebrotas tiveram densidade de árvores de $80 \%$ e $62 \%$, respectivamente, do plantio inicial. As colheitas ocorreram em 30 de janeiro de 1987 (ciclo de 6 anos), 30 de janeiro de 1994 (ciclo de 7 anos) e 30 de novembro de 2000 (ciclo de 6 anos e 10 meses). 
Tabela 1. Propriedades dos solos usadas nas Pedotransfer functions do WaNuLCAS

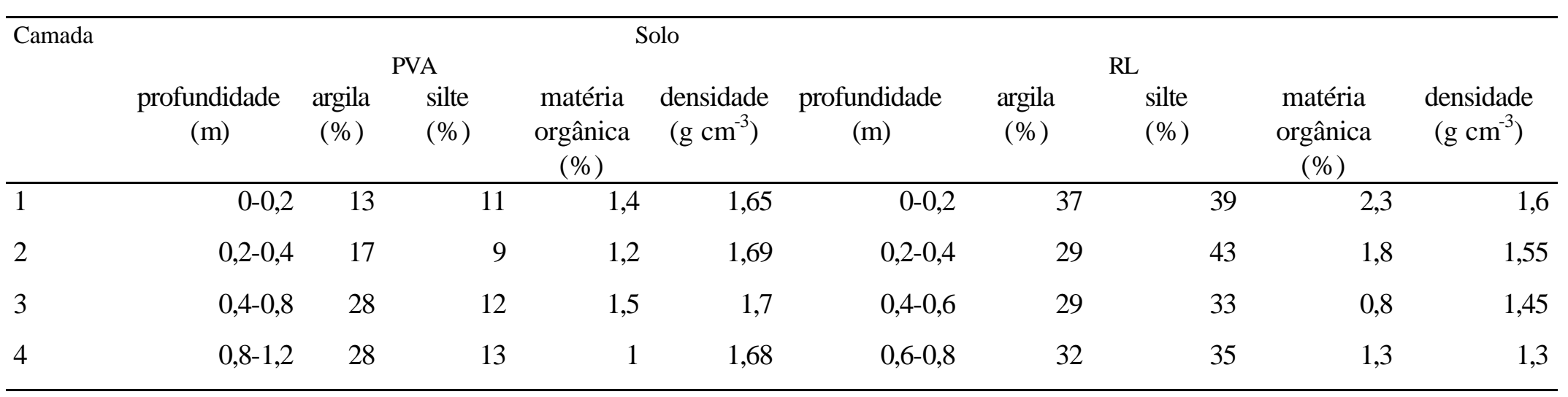

Tabela 2. Cronograma simplificado dos sistemas simulados

\begin{tabular}{|c|c|c|c|c|c|c|c|c|c|c|c|c|c|c|c|c|c|c|c|c|c|c|c|c|c|c|c|c|c|c|c|c|c|c|c|c|c|c|c|c|}
\hline Ano & 81 & & 82 & & 83 & & 84 & & 85 & & 86 & & 87 & & 88 & & 89 & & 90 & & 91 & & 92 & & 93 & & 94 & & 95 & & 96 & & 97 & & 98 & & 99 & & 00 & \\
\hline Semestre & I & II & $\mathrm{I}$ & II & $\mathrm{I}$ & II & $\mathrm{I}$ & II & $\mathrm{I}$ & II & $\mathrm{I}$ & II & $\mathrm{I}$ & II & $\mathrm{I}$ & II & $\mathrm{I}$ & II & $\mathrm{I}$ & II & $\mathrm{I}$ & II & $\mathrm{I}$ & II & $\mathrm{I}$ & II & $\mathrm{I}$ & II & $\mathrm{I}$ & II & I & II & I & II & $\mathrm{I}$ & II & $\mathrm{I}$ & II & $\mathrm{I}$ & II \\
\hline $\begin{array}{l}\text { cana- } \\
\text { planta }\end{array}$ & 1 & 1 & 1 & & & & & & & & 2 & 2 & 2 & & & & & & & & 3 & 3 & 3 & & & & & & & & 4 & 4 & 4 & & & & & & & \\
\hline cana-soca & & & & 11 & 11 & 12 & 12 & 13 & 13 & & & & & 21 & 21 & 22 & 22 & 23 & 23 & & & & & 31 & 31 & 32 & 32 & 33 & 33 & & & & & 41 & 41 & 42 & 42 & 43 & 43 & \\
\hline $\begin{array}{l}\text { Seringueir } \\
\mathrm{a}\end{array}$ & S & S & S & S & $S$ & S & S & S & S & S & S & S & S & S & S & $S$ & $S$ & S & S & & $S$ & S & S & S & S & S & S & $S$ & $S$ & S & S & S & S & $S$ & S & S & $S$ & $S$ & S & S \\
\hline Eucalipto & 1 & 1 & 1 & 1 & 1 & 1 & 1 & 1 & 1 & 1 & 1 & 1 & 2 & 2 & 2 & 2 & 2 & 2 & 2 & 2 & 2 & 2 & 2 & 2 & 2 & 2 & 3 & 3 & 3 & 3 & 3 & 3 & 3 & 3 & 3 & 3 & 3 & 3 & 3 & 3 \\
\hline
\end{tabular}


O modelo foi adaptado para realização das simulações. As principais mudanças se referem à cultura da cana-de-açúcar, já que esta é semi-perene, possui soqueira e colhe-se sua parte vegetativa ao invés de grãos. Assim:

a) o ciclo da cana-de-açúcar foi limitado a uma fase vegetativa. Para o parâmetro referente à fase reprodutiva foi destinado o mínimo tempo necessário para a conclusão do ciclo da cana (3 dias). Para a cana de ano e meio o ciclo vegetativo foi de 497 dias (total 500 dias de ciclo) e para a cana de ano, 362 (365 no total).

b) não houve alocação de biomassa para grãos.

c) a produção da cana-soca é geralmente inferior à cana planta e, segundo Robertson et al. (1996), isto se deve a uma redução por volta de $10 \%$ na eficiência de uso da radiação da soqueira em relação à cana-planta. Essa redução foi adotada nas simulações com canasoca.

d) parâmetros da cana-de-açúcar. Os principais parâmetros de cultura exigidos pelo Wanulcas foram obtidos a partir de dados de experimentos realizados em Piracicaba. O crescimento máximo potencial da cultura $\left(0,026 \mathrm{~kg} \mathrm{~m}^{-2} \mathrm{dia}^{-1}\right)$, área foliar específica $\left(10 \mathrm{~m}^{2} \mathrm{~kg}^{-}\right.$ ${ }^{1}$ ) e proporção massa folha/massa colmo (de 0,7 a 0,1 durante o ciclo) foram obtidos de Machado et al. (1982). O coeficiente de extinção da luz (k) de 0,5 foi o descrito por Van de Berg (2000) a partir do experimento relatado por Machado et al. (1982); o consumo de água para produção de matéria seca $\left(801 \mathrm{~kg}^{-1}\right)$ foi coletado de Barbieri (1981) e a distribuição do sistema radicular foi adaptada de Alvarez et al. (2000). Para a estimativa da produção de colmos, adotou-se o índice de colheita de 80\% (Miocque, 1999). Estes e os demais parâmetros e seus valores estão no Anexo 1.

e) calibração dos parâmetros das árvores, através do programa TreePotGro, auxiliar do Wanulcas para calibração específica das árvores. Nesta fase também optou-se por adotar a opção Functional Branch Analysis para crescimento das árvores. Nesta opção, a partir da biomassa total da planta, equações alométricas calculam o diâmetro da árvore e a partição da biomassa entre tronco, galhos, folhas e liter. O uso do TreePotGro testou os parâmetros coletados no Brasil e definiu as equações alométricas para seringueira e eucalipto. Para a 
seringueira, o crescimento máximo potencial diário e o consumo de água por unidade de biomassa produzida foram $0,01 \mathrm{~kg}$ biomassa $\mathrm{m}^{-2} \mathrm{dia}^{-1}$ (Templeton, 1968) e $4001 \mathrm{H} \mathrm{O} \mathrm{kg}$ biomassa $^{-1}$ (Bernardes, 2001). Eucalipto foi parametrizado para Eucalyptus grandis e os valores foram 0,008 $\mathrm{kg}$ biomassa $\mathrm{m}^{-2} \mathrm{dia}^{-1}$ (Cromer et al., 1993) e $4301 \mathrm{H}_{2} \mathrm{O} \mathrm{kg}$ biomassa ${ }^{-1}$ (Lima, 1993). Os demais parâmetros adotados para as árvores estão nos Anexos 2 e 3.

f) crescimento de raiz - para a cultura, o sistema radicular cresce até atingir o valor máximo no florescimento, definido pelo usuário. Este valor foi definido a partir dos dados de Alvarez et al. (2000). Cada rebrota da cana foi considerado como um novo plantio, portanto, o sistema radicular morre e reinicia o crescimento. Para as árvores a densidade radicular decresce exponencialmente em profundidade e em função da distância da árvore. É constante por camada de solo e zona espacial de interferência durante toda a simulação e seu valor foi adaptado de Bernardes et al. (1998) para seringueira e de Gonçalves \& Mello (2000) para eucalipto. Como o parâmetro obtido para crescimento máximo potencial da cultura não considera biomassa do sistema radicular, não houve alocação de biomassa para a raiz da cultura e das árvores.

g) clima - foram adicionados dados diários reais de Piracicaba para chuva e evapotranspiração potencial para os vinte anos de simulação (1981-2000). Os dados foram coletados do banco de dados da Esalq e a evapotranspiração potencial foi calculada com o uso da equação Penman-Monteith proposta pela FAO (Allen et al., 1998).

Devido ao grande número de parâmetros necessários para alimentar o modelo, é importante identificar os que têm maior importância e necessitam de maior acuracidade em sua obtenção ou definição. Neste sentido, selecionamos alguns parâmetros da planilha "Crop Library" do Wanulcas com o fim de analisar a sensibilidade do modelo a tais parâmetros.

Dos 52 parâmetros desta planilha, selecionamos seis. A análise de sensibilidade foi feita com o aumento e diminuição do valor do parâmetro selecionado e a verificação de seu impacto sobre a biomassa final da cana-de-açúcar (Penning de Vries et al., 1989). Os parâmetros selecionados foram: 1) taxa de crescimento máximo potencial da cultura; 2) coeficiente de extinção; 3) área foliar especifica; 4) potencial máximo da planta; 5) fração de 
carboidratos a serem remobilizados de folhas e 6) eficiência de uso da água. As simulações foram realizadas considerando limitação do crescimento por deficiência hídrica. Os resultados não receberam tratamento estatístico e pretendem somente orientar futuros usuários do modelo. 


\subsection{Resultados e Discussão}

\subsubsection{Crescimento e produção das plantas sem interação entre árvores e cultura}

O sistema radicular das plantas presentes na Zona 1, geralmente árvores, não sofrem efeito do sistema radicular das presentes nas Zonas 2, 3 e 4. Portanto, podemos avaliar o seu crescimento indistintamente da presença da cultura. Para a cana-de-açúcar, inicialmente analisaremos os resultados da Zona 4, onde não há efeito de sombra e a presença do sistema radicular das árvores é muito pequena, como a condição de crescimento e produção sem interação dessa cultura com as árvores. Posteriormente, as interações ocorrendo nas Zonas 2 e 3 serão avaliadas. As Figuras 2 e 3 mostram a evolução da biomassa da parte aérea da cana-de-açúcar (matéria seca de colmo, palmito e folhas) durante os 20 anos nos 4 sistemas simulados. 


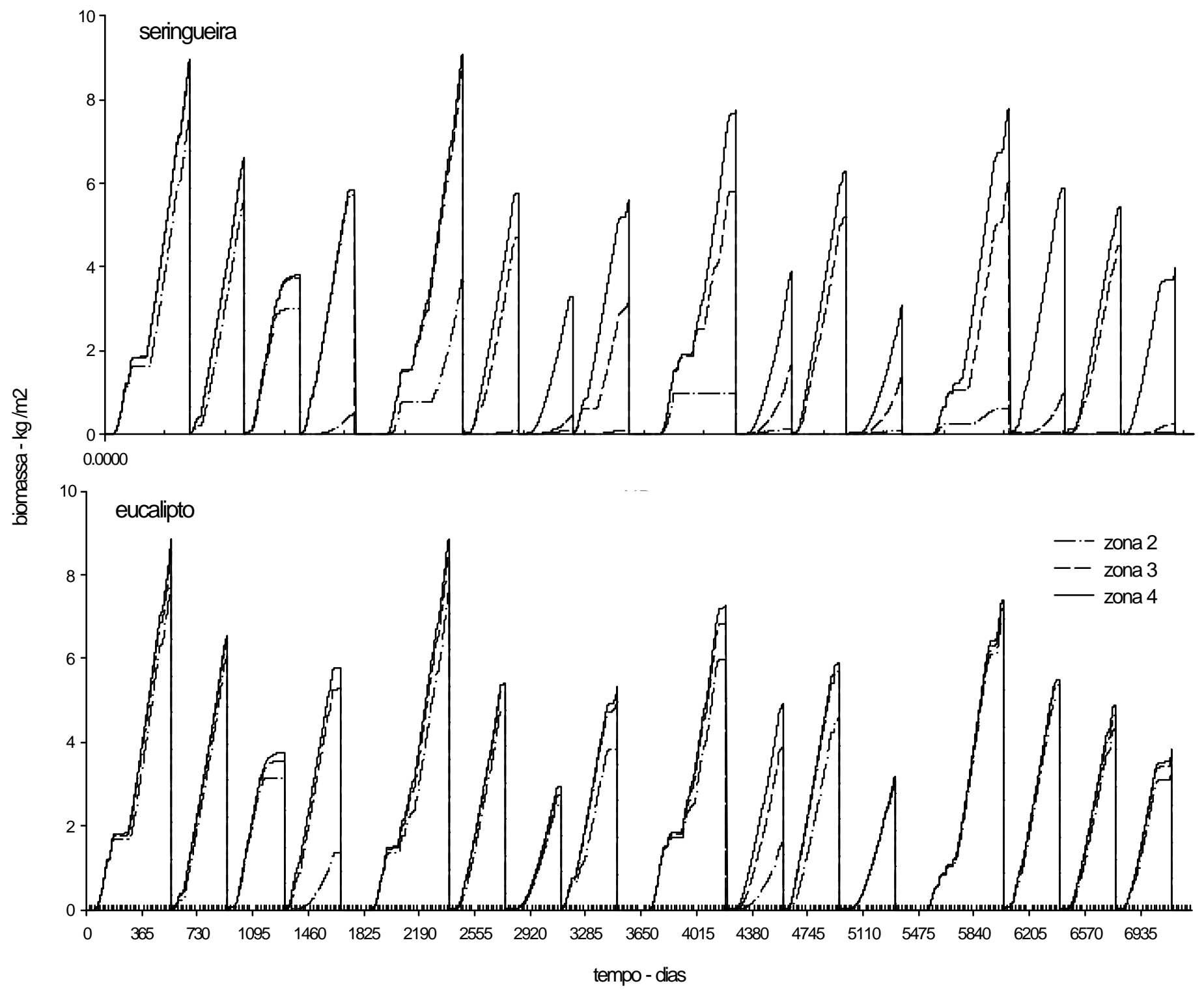

Figura 2 - Evolução da biomassa da cana-de-açúcar no solo PVA, durante os 20 anos de simulação. 


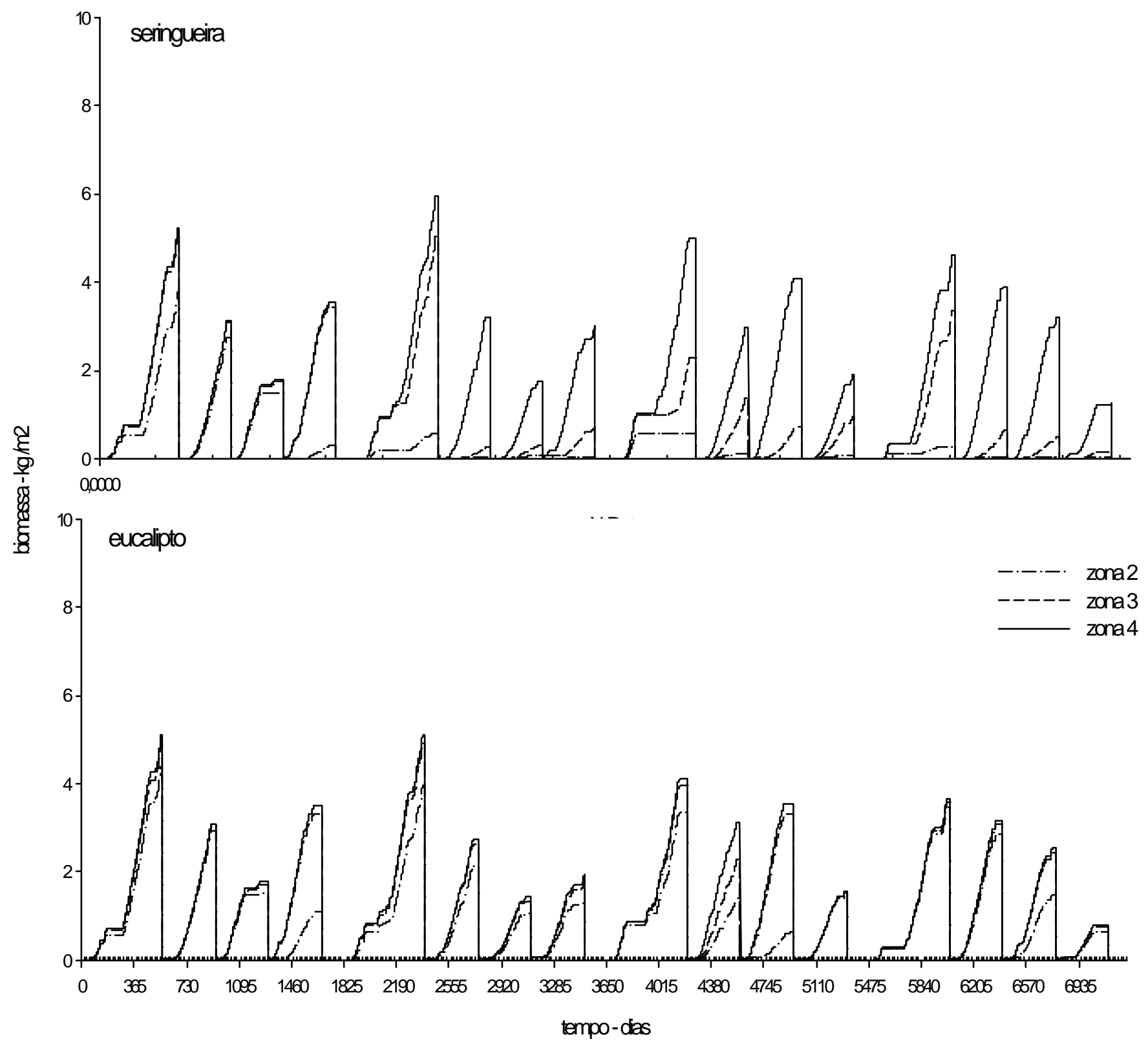

Figura 3 - Evolução da biomassa da cana-de-açúcar no solo RL, durante os 20 anos de simulação. 
Na Zona 4, a cana-planta no Argissolo Vermelho-Amarelo (PVA) produziu biomassa média de $8,38 \mathrm{~kg} \mathrm{~m}^{-2}$, com o valor máximo de $9,09 \mathrm{~kg} \mathrm{~m}^{-2}$, enquanto que no Neossolo Litólico (RL) os valores médio e máximo foram de 5,25 e 5,94 $\mathrm{kg} \mathrm{m}^{-2}$. Para a cana-soca, a biomassa média e máxima foram de 4,96 e 6,06 $\mathrm{kg} \mathrm{m}^{-2}$ para o Argissolo Vermelho-Amarelo e 2,81 e 4,01 $\mathrm{kg} \mathrm{m}^{-2}$ para o Neossolo Litólico. A produção média de colmos no solo PVA foi de $6,7 \mathrm{~kg} \mathrm{~m}^{-2}$ para a cana-planta e $3,97 \mathrm{~kg} \mathrm{~m}^{-2}$ para a soqueira. Já no solo RL a produção média de colmos foi de $4,2 \mathrm{~kg} \mathrm{~m}^{-2}$ para a cana-planta e $2,25 \mathrm{~kg} \mathrm{~m}^{-2}$ para a soqueira. Estes valores estão dentro do limite potencial encontrado na literatura, porém acima dos valores encontrados para a cana-planta na região de Piracicaba e Estado de São Paulo.

Irvine (1983) estimou a produção potencial de biomassa da cana-de-açúcar em $13 \mathrm{~kg}$ $\mathrm{m}^{-2}$ ano $^{-1}$. Muchow et al. (1994) avaliaram o acúmulo de biomassa em Queensland (Austrália) e obtiveram valor de 7,2 $\mathrm{kg} \mathrm{m}^{-2} 445$ dias após o plantio da cultura. Robertson et al. (1996) também avaliaram crescimento em Queensland e reportaram valores máximos de $5,8 \mathrm{~kg} \mathrm{~m}^{-2}$ para cana planta 310 dias após o plantio e $5,55 \mathrm{~kg} \mathrm{~m}^{-2}$ para soqueira 290 dias após o corte anterior. Para a região de Piracicaba, Machado et al. (1982) fizeram avaliação de crescimento de 2 variedades em ciclo de ano e meio em Latossolo Vermelho Amarelo e obtiveram valor médio de 5,3 $\mathrm{kg} \mathrm{m}^{-2}$. Miocque (1999) fez avaliação em área comercial de uma usina em Matão (SP) e obteve valor máximo de $4,9 \mathrm{~kg} \mathrm{~m}^{-2}$ em ciclo de um ano, sendo que a produção média de 10 safras foi de 4,5 $\mathrm{kg} \mathrm{m}^{-2}$. Pereira (1987) simulou o crescimento em Piracicaba com o modelo SIMCANA e obteve produtividade da cultura de $9,72 \mathrm{~kg} \mathrm{~m}^{-2}$ com restrições ambientais e biomassa final da parte aérea de 4,53 $\mathrm{kg} \mathrm{m}^{-2}$. Van de Berg (2000) também simulou o crescimento para as condições de Piracicaba, mas com emprego do modelo WOFOST. Para cana de ano e meio obteve valores ligeiramente abaixo de $5 \mathrm{~kg} \mathrm{~m}^{-2}$ e estimou a produção potencial por volta de $5,3 \mathrm{~kg} \mathrm{~m}^{-2}$. A superestimativa do crescimento da cana-deaçúcar nas simulações do WaNuLCAS deve ser creditada ao fato do modelo não considerar temperatura como um fator determinante do crescimento e desenvolvimento vegetal. Todavia, este é um fator importante para o crescimento desta cultura (Mongelard \& Mimura, 1971), sendo limitante durante parte do ciclo da planta em Piracicaba. Adicionalmente, nas 
simulações o acúmulo de biomassa da parte aérea da cultura ocorre imediatamente ao seu plantio, entretanto, a brotação da cana-de-açúcar pode levar até 30 dias no campo (Casagrande, 1991) e reduzir seu período de crescimento.

O crescimento das árvores também apresentou resultados acima dos obtidos em experimentos de campo na região de Piracicaba ou outras regiões do Estado de São Paulo ou do país. De maneira geral, o modelo apresentou pequena (seringueira) ou nenhuma (eucalipto) sensibilidade das árvores ao déficit hídrico, além de não considerar limitação por temperatura do ar. Adicionalmente, o fato do modelo não considerar a respiração de manutenção, pode levá-lo a superestimar o crescimento, principalmente em simulações de longo prazo. Também é possível que os valores de crescimento potencial utilizados como parâmetros sejam inadequados para simulações em Piracicaba, já que o valor da seringueira foi obtido por Templeton (1968) na Malásia e o do eucalipto foi determinado por Cromer et al. (1996) na Austrália. A análise das árvores também será feita com os resultados das simulações no Argissolo Vermelho-Amarelo, pois o desempenho das árvores nos 2 solos foi semelhante (Tabela 3). 
Tabela 3. Valor final do crescimento das árvores

\begin{tabular}{|c|c|c|c|c|c|c|c|c|}
\hline \multirow{3}{*}{ Variável } & \multicolumn{7}{|c|}{ Solo } & \multirow[b]{3}{*}{ Ser } \\
\hline & \multicolumn{3}{|c|}{ PVA } & & \multicolumn{3}{|c|}{ RL } & \\
\hline & E1 & $\mathrm{E} 2$ & E3 & Ser & E1 & $\mathrm{E} 2$ & E3 & \\
\hline Biomassa $(\mathrm{kg} / \mathrm{m} 2)^{*}$ & 1,70 & 1,75 & 0,74 & 13,41 & 1,73 & 1,79 & 0,74 & 13,74 \\
\hline Diâmetro tronco $(\mathrm{cm})$ & 15,07 & 16,17 & 13,55 & 29,38 & 15,16 & 16,26 & 13,55 & 29,59 \\
\hline Largura máxima da copa (m) & 3,00 & 3,00 & 1,74 & 5,00 & 3,00 & 3,00 & 1,74 & 5,00 \\
\hline IAF máximo ( $\mathrm{m}^{2}$ folha $\mathrm{m}^{-2}$ solo) & 2,86 & 2,68 & 1,74 & 7,00 & 2,91 & 2,75 & 1,74 & 7,13 \\
\hline Altura (m) & 24,05 & 25,38 & 19,19 & 23,11 & 24,16 & 25,46 & 19,19 & 23,25 \\
\hline $\begin{array}{l}\text { Produção madeira - incluindo } \\
\text { casca }(\mathrm{kg} / \mathrm{m} 2)^{*}\end{array}$ & 1,64 & 1,70 & 0,71 & - & 1,67 & 1,72 & 0,71 & - \\
\hline Biomassa total por árvore (kg) & 106,20 & 134,60 & 74,0 & 1210,0 & 108,1 & 137,70 & 74,00 & 1245,5 \\
\hline $\begin{array}{l}\text { Produção acumulada de } \\
\text { borracha seca }(\mathrm{kg} / \mathrm{m} 2)^{*}\end{array}$ & - & - & - & 1,34 & - & - & - & 1,43 \\
\hline $\begin{array}{l}\text { Produção média anual de } \\
\text { borracha seca por árvore - } 16 \\
\text { anos de sangria (kg) }\end{array}$ & - & - & - & 7,50 & - & - & - & 8,12 \\
\hline
\end{tabular}

* os valores se referem à área do campo total simulado no WaNuLCAS

O acúmulo de biomassa das árvores é apresentado na Figura 4. O valor da biomassa da seringueira de $1210 \mathrm{~kg}$ por árvore após 20 anos de crescimento, corresponde a 57,6 kg m ${ }^{2}$ num espaçamento de 7 × $3 \mathrm{~m}$ ou 476 plantas ha ${ }^{-1}$. Este valor está de acordo com a projeção feita por Paardekooper (1989) de que o incremento anual de matéria seca de um seringal seria de $3 \mathrm{~kg} \mathrm{~m}^{-2}$ ou $70 \mathrm{~kg}$ árvore ${ }^{-1}$. Entretanto, estes valores são muito superiores ao estimados por Righi (2000) para um seringal de 15 anos em Piracicaba. Através do emprego da equação alométrica de Shorrocks et al. (1965), o autor estimou a biomassa de cada árvore entre 240 e $370 \mathrm{~kg}$, dependendo do clone. 


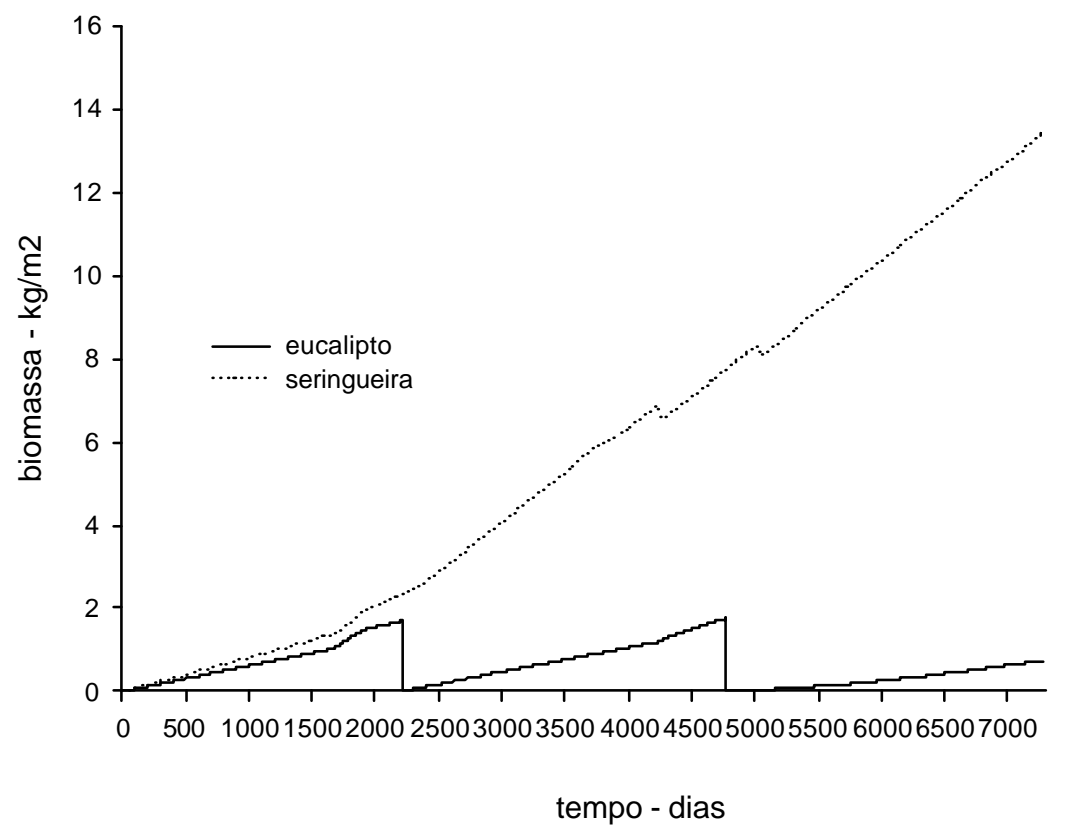

Figura 4 - Acúmulo de biomassa nas árvores

* os valores se referem à área do campo total simulado no WaNuLCAS

O IAF da árvore foi superestimado, atingindo valor final de 7. Este valor está acima do máximo de 5,8 e 6,3 reportados por Templeton (1968) e Shorrocks (1965) e muito acima do valor máximo de 3,17 medido por Righi (2000) em Piracicaba. Isto se deve ao crescimento exagerado da cultura, à partição constante de assimilados simulada pelo WaNuLCAS e à insensibilidade do modelo em reproduzir a senescência periódica das folhas que ocorre na região devido à combinação do efeito de fotoperíodo, temperatura e seca (Moraes, 1977).

O perímetro do tronco de $92 \mathrm{~cm}$ aos 20 anos, o que equivale a um incremento médio de 4,6 $\mathrm{cm} \mathrm{ano}^{-1}$, também está superestimado (Figura 5). Segundo Paardekooper (1989), o incremento pode ser de até $10 \mathrm{~cm} \mathrm{ano}^{-1}$ no início da vida da planta, mas deve cair gradualmente até atingir o valor de $2 \mathrm{~cm}^{2} \mathrm{ano}^{-1}$. Dey \& Joseph (1996) simularam crescimento da seringueira na Índia por 20 anos após a primeira sangria e obtiverem incremento anual médio de 2 a $3 \mathrm{~cm}$ em áreas tradicionais de cultivo. Cortez (1986) estimou o perímetro médio do tronco de seringais comerciais no Estado de São Paulo, no sexto ano após o plantio em 49 
cm. Considerando-se que após o sétimo ano, com o início da sangria, o incremento anual deve ser de $2 \mathrm{~cm}$, estimamos que o perímetro do tronco de uma árvore com 20 anos deva ser ao redor de $77 \mathrm{~cm}$. Righi (2000) reporta um valor máximo de $70 \mathrm{~cm}$ para árvores de 15 anos em sistemas agroflorestais e $62 \mathrm{~cm}$ para árvores na mesma área, porém em monocultivo. Bernardes et al. (1994) mediram o perímetro de seringueiras de $56 \mathrm{~cm} \mathrm{e} 72 \mathrm{~cm}$ aos 7 e aos 10 anos respectivamente. Os mesmo autores simularam o perímetro das árvores empregando o modelo EMB-RUBBER e obtiveram os valores de $56 \mathrm{~cm}$ e $70 \mathrm{~cm}$ para as mesmas datas.

Em função do elevado crescimento simulado, as árvores atingiram perímetro mínimo para o início da sangria no final do quarto ano após o plantio, antes do esperado. Entretanto, atribuímos isto ao crescimento superestimado e não a um ajuste inadequado da equação alométrica calibrada. A produção de borracha das simulações também ficou dentro dos limites da literatura, mas acima do esperado para a região (Figura 5). Além do crescimento, outra razão da produção elevada é que o modelo aloca uma fração da biomassa para borracha, mas não considera as limitações de manejo e o sistema de sangria da árvore, o que influencia a produção de borracha no campo, independentemente do potencial fisiológico. Obtivemos uma produção média anual de 7,5 kg de borracha seca por árvore, considerando-se 16 anos de sangria, o que corresponde uma produção de $3570 \mathrm{~kg} \mathrm{ha}^{-1}$ ano ${ }^{-1}$. Paardekooper (1989) estima a produção máxima fisiológica de borracha seca ao redor de $9000 \mathrm{~kg} \mathrm{ha}^{-1}$ ano ${ }^{-1}$. Dey \& Joseph (1996) obtiveram produção média de $2090 \mathrm{~kg} \mathrm{ha}^{-1}$ ano ${ }^{-1}$ em 20 anos de simulação de sangria em áreas tradicionais da Índia e espera-se uma produção média anual $1500 \mathrm{~kg} \mathrm{ha}^{-1}$ em um seringal no Estado de São Paulo (Castro, 1986). Righi (2000) reporta produção anual de 2,33 e $1,78 \mathrm{~kg}$ de borracha seca por árvore por ano em sistema agroflorestal e em monocultivo respectivamente. 


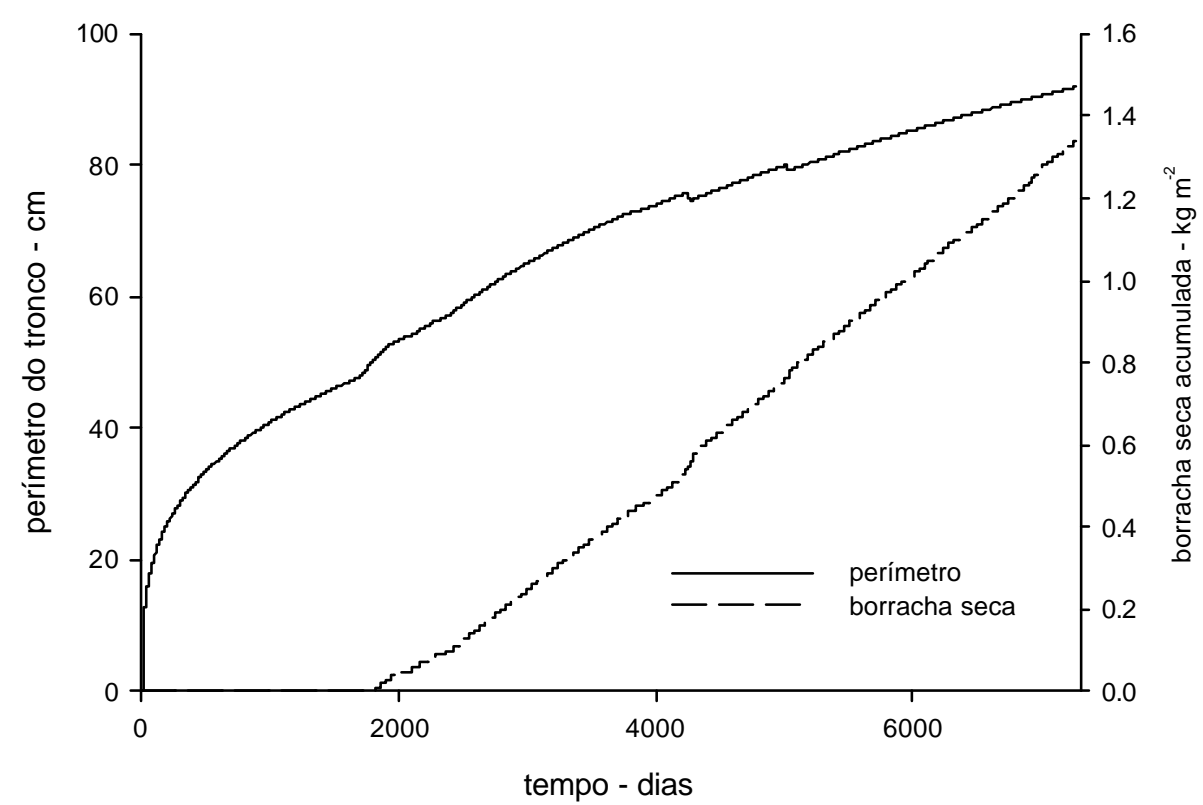

Figura 5 - Evolução do perímetro do tronco da seringueira e produção acumulada de borracha seca.

* os valores da borracha se re ferem à área do campo total simulado no WaNuLCAS

O crescimento do eucalipto também foi superior ao esperado para a região, havendo crescimento contínuo da árvore em toda a simulação, sem haver redução do crescimento por efeito de estresse hídrico (Tabela 3 e Figura 4). Novamente, a partir de um acúmulo de biomassa maior que o esperado, todos os outros parâmetros avaliados ficaram acima dos valores obtidos em experimentos em condições semelhantes às simuladas. Para uma análise detalhada, selecionamos o primeiro ciclo de cultivo no PVA (E1). A biomassa de 106,2 kg árvore $^{-1}$ obtida na simulação no final do primeiro ciclo corresponde a $17,7 \mathrm{~kg} \mathrm{~m}^{-2}$ num espaçamento de 3 x 2 m ou 1660 árvores ha ${ }^{-1}$. Grove et al. (1996) citam uma biomassa de $17,4 \mathrm{~kg} \mathrm{~m}^{-2}$ para um stand de Eucalyptus grandis de 9,25 anos na Austrália. Gonçalves et al. (1999) encontraram valor de $14,03 \mathrm{~kg} \mathrm{~m}^{-2}$ para uma plantação de E. grandis de 7 anos em Itatinga (SP). Leite et al. (1997) mediram 4,80 $\mathrm{kg} \mathrm{m}^{-2}$ em uma plantação de 3 anos de Minas Gerais, sendo que a simulação apresentou valor por volta de $7 \mathrm{~kg} \mathrm{~m}^{-2}$ para o mesmo período. O diâmetro à altura do peito (DAP) simulado de 15,07 cm também foi superior aos $13 \mathrm{~cm}$ 
obtido por Gonçalves et al. (1999). O IAF simulado de 2,86 está abaixo daquele obtido por Leite et al. (1997) de 3,43 em plantação de 3 anos com dossel fechado em Minas Gerais. Dados de Kriedemann \& Cromer (1996), mostram que o IAF máximo de E. grandis pode variar entre 1 e 5 dependendo do uso de fertilizantes na floresta.

\subsubsection{Interações árvore-cultura}

Para avaliar as interações árvore-cultura, analisaremos o desempenho da cana-soca no PVA, pois há maior número de cultivos desta em relação à cana-planta e maior variação de cenários a serem amostrados. Os solos serão avaliados na próxima parte do texto. As Figuras 6a e 7a mostram a biomassa final da cana-soca em cada Zona, indicando a redução do crescimento da Zona com menor (4) para maior (2) intensidade de interação nas duas espécies de árvores. Esta redução refere-se á combinação da competição por radiação solar e água. Para separar as interações abaixo e acima do solo, simulamos os mesmos sistemas sem interação abaixo do solo, eliminando-se o sistema radicular das árvores nas Zonas 2, 3 e 4 (Figuras 6b e 7b). 


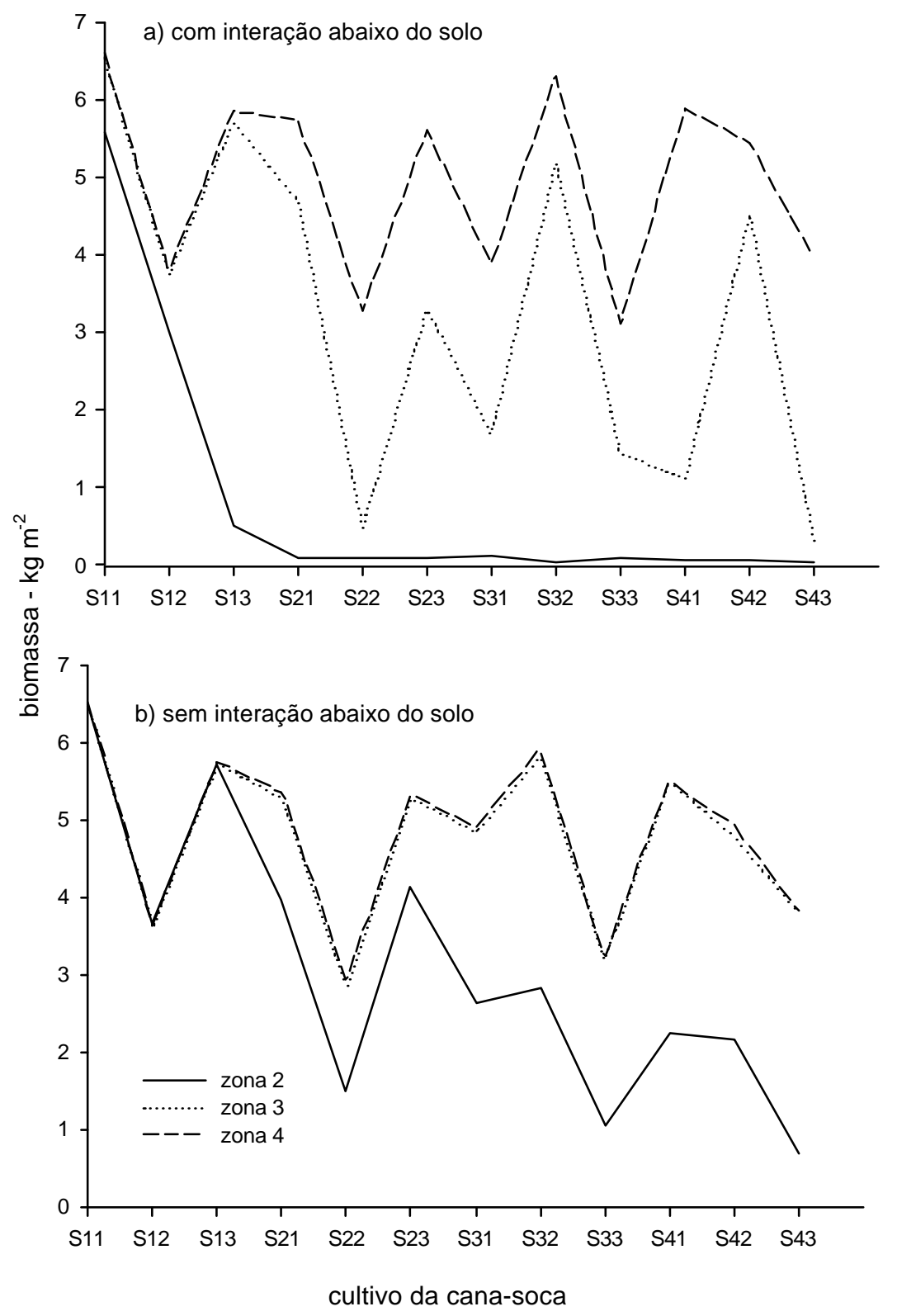

Figura 6 - Evolução da biomassa final da cana-soca no SAF com seringueira no solo PVA, com e sem interação abaixo do solo. 


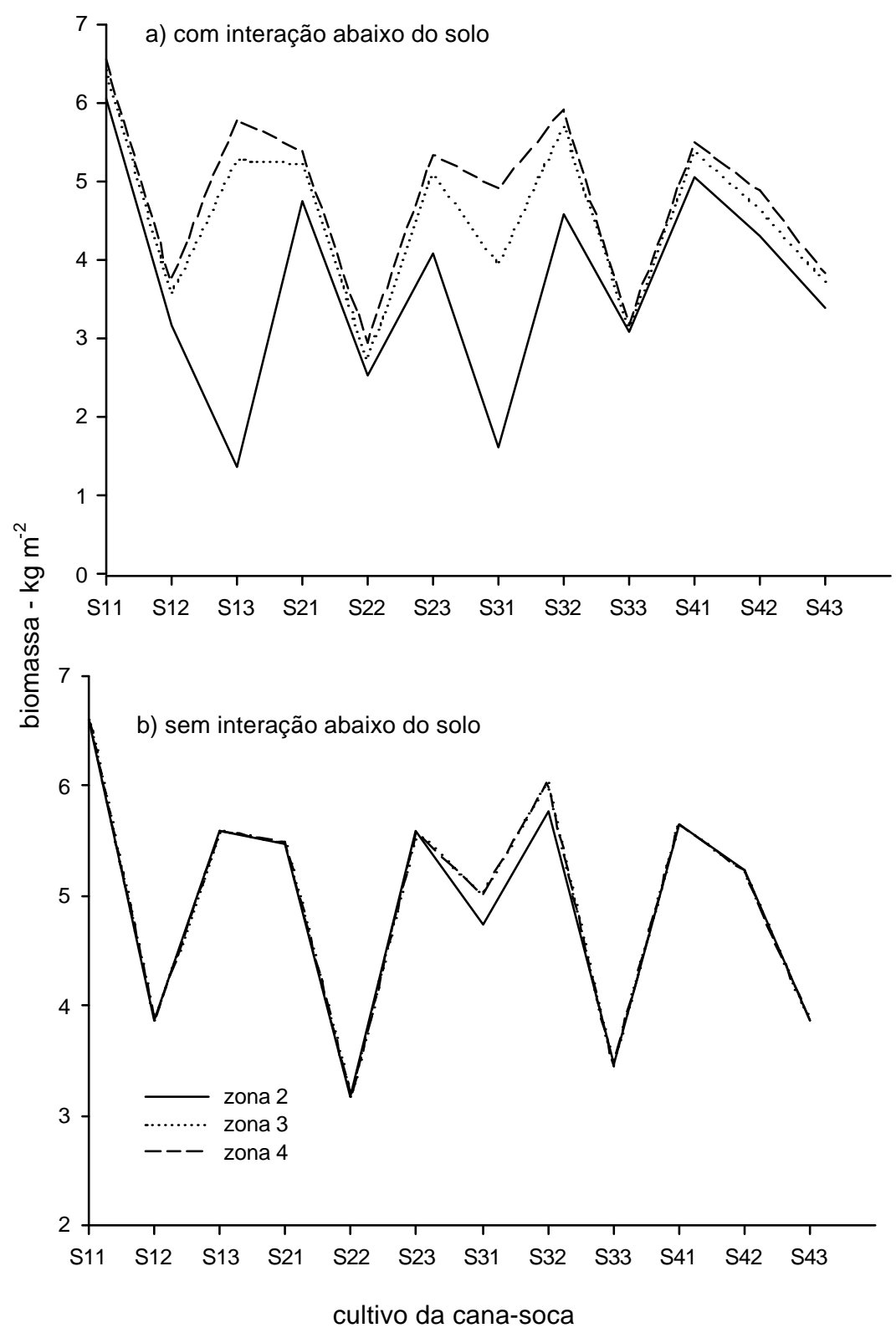

Figura 7 - Evolução da biomassa final da cana-soca no SAF eucalipto no solo PVA, com e sem interação abaixo do solo.

Verifica-se que a competição por luz somente ocorre na Zona 2, sendo intensa e crescente na seringueira e branda e esporádica no eucalipto. A diferença entre espécies se deve às características já descritas anteriormente: a seringueira possui copa mais larga e IAF 
maior. Além disso, o eucalipto é cortado a cada 6-7 anos e, conseqüentemente, sua copa é eliminada periodicamente. Assim, a copa do eucalipto sombreia a Zona 2 com muito menor intensidade que a seringueira (Figura 8). Ressaltamos que o sombreamento da seringueira está superestimado devido ao alto valor de IAF simulado. Além disso, o modelo apenas considera a direção vertical da radiação, o que superestima a sombra na Zona 2 e a subestima na Zona 3.

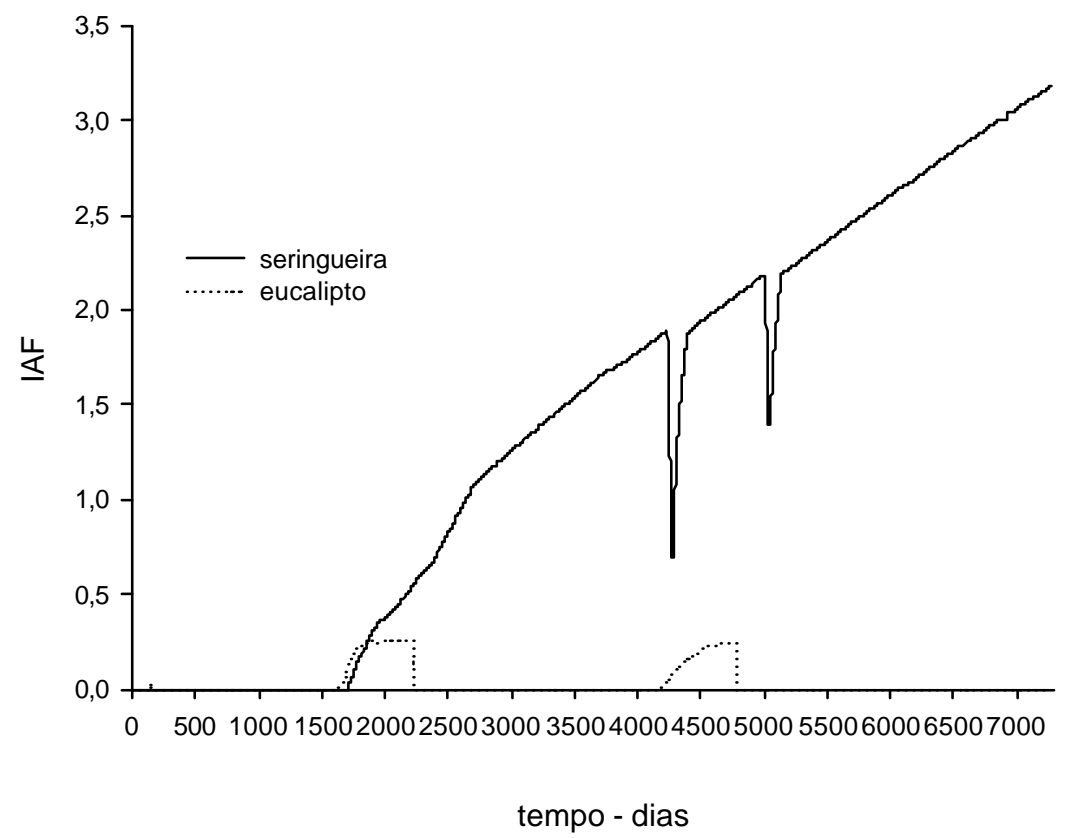

Figura 8 - IAF das árvores na zona 2 da cultura no PVA

A competição por água é grande nas Zonas 2 e 3, sendo mais forte na seringueira, apesar do sistema radicular do eucalipto ser um pouco mais denso que o da seringueira nessas Zonas (Figura 9). Do total da água usada, a seringueira absorveu 53\%, 36\%, $10 \%$ e 1\% nas zonas 1, 2, 3 e 4 respectivamente. O eucalipto teve um padrão semelhante, com 51\%, 32\%, $14 \%$ e $3 \%$. Entretanto, a principal causa da maior competição na seringueira se deve à quantidade absoluta de água absorvida, fator influenciado basicamente pelo manejo de cada espécie. O balanço hídrico geral dos sistemas (Tabela 4) mostra que a seringueira absorveu 3 
vezes mais água que o eucalipto. A primeira foi definida com um potencial de crescimento ligeiramente superior e uma demanda de água por unidade de matéria seca produzida pouco inferior que o eucalipto. Entretanto, a seringueira teve um crescimento contínuo e uma conseqüente crescente demanda de água durante a simulação. Já o eucalipto, por ter o crescimento reiniciado a cada ciclo de corte, tem a demanda absoluta de água inferior ms fases iniciais de crescimento. A Figura 7 indica que a competição por água é maior nas soqueiras $S_{13}$ e $S_{31}$, em que o eucalipto está próximo do corte (com maior biomassa e maior demanda absoluta de água) e que o inverso ocorre nas soqueiras $S_{22}$ e $S_{33}$, posteriores ao corte e com plantas pequenas. Este quadro está de acordo com os resultados de Ong et al. (2000) e Lott et al. (2000), que verificaram em um experimento de longo prazo, que a intensidade da competição por água de Grevillea com as culturas aumentava progressivamente com o crescimento das árvores e a maturidade do sistema. As demais variações entre ciclos da cana devem-se à quantidade e distribuição da chuva. 
a) seringueira

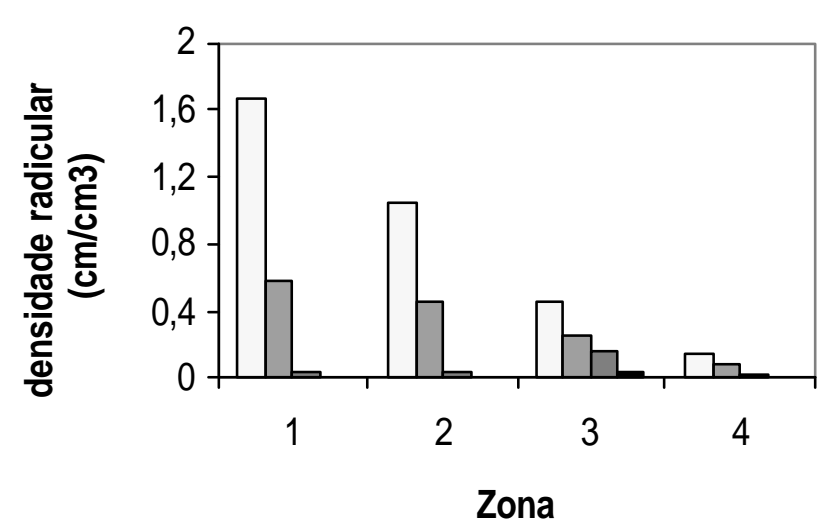

b) eucalipto

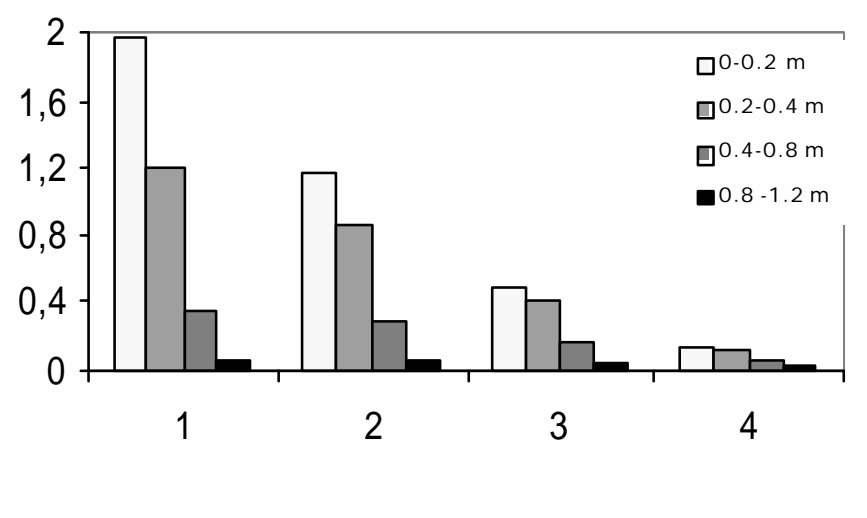

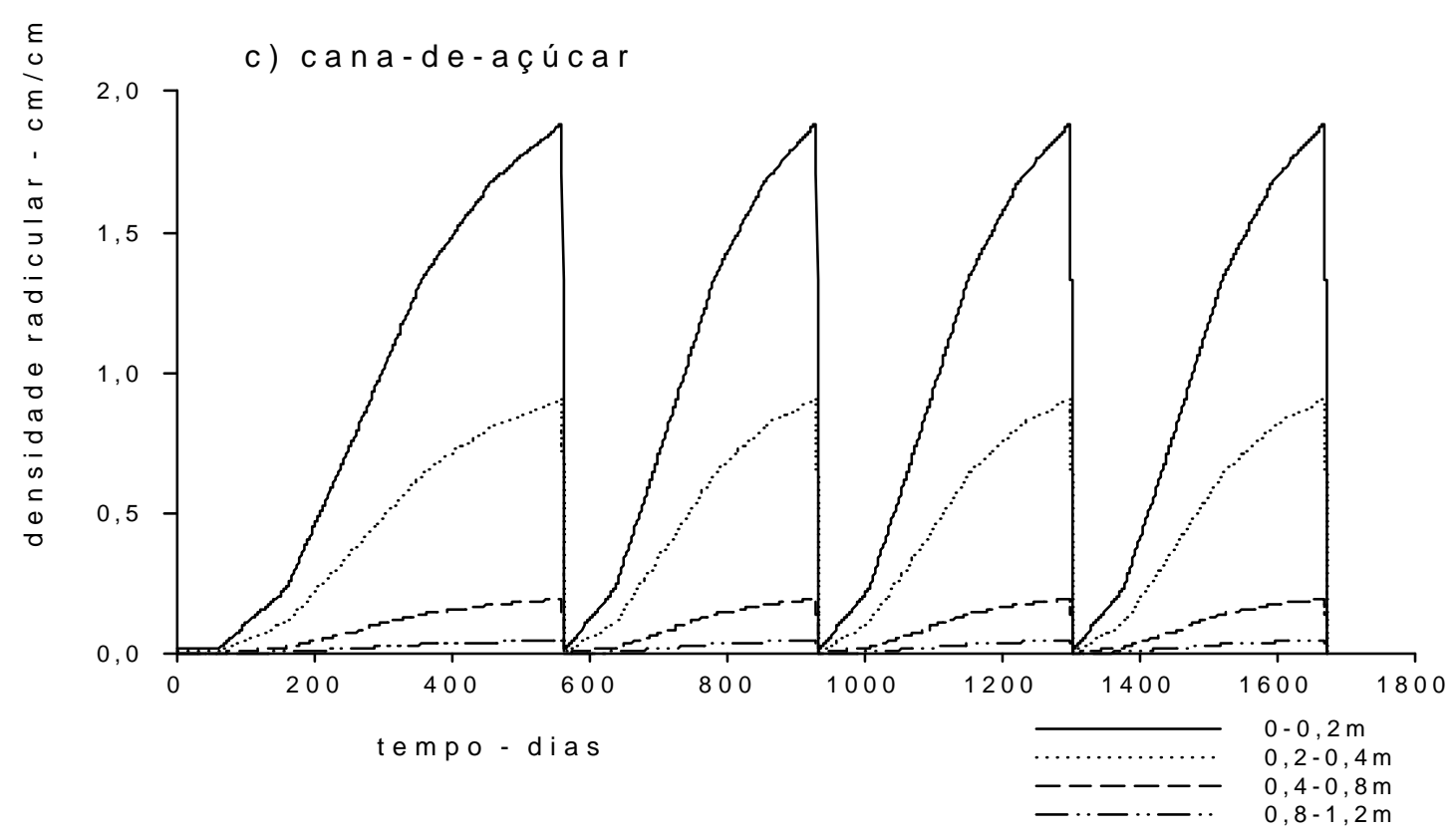

Figura 9 - Distribuição do sistema radicular das plantas no PVA

Para melhor ilustrar o discutido acima, amostramos 4 ciclos da cana-soca do sistema com seringueira no PVA. Pela Tabela 5 percebe-se que as árvores absorvem quantidade significativa de água das Zonas 2 e 3 e que isto se intensifica com seu crescimento. Nas Zonas 2 e 3 das soqueiras $S_{11}$ e $S_{13}$ e na Zona 3 das soqueiras $S_{41}$ e $S_{42}$, a diminuição na transpiração e a conseqüente redução do crescimento da cultura se devem exclusivamente à 
competição por água, pois a copa das árvores não sombreia a cultura. Na Zona 2 das soqueiras $S_{41}$ e $S_{42}$, a redução se deve á interações abaixo e acima do solo. A competição também se deve à quantidade e distribuição da chuva, como pode ser visto comparando-se a Zona 3 das soqueiras $S_{41}$ e $S_{42}$. A árvore absorveu quantidade similar de água na Zona 3, mas a maior precipitação na soqueira $S_{42}$ forneceu maior disponibilidade de água para a cultura, o que não foi suficiente para compensar os efeitos negativos das interações abaixo e acima do solo no crescimento da cultura na Zona 2. 
Tabela 4. Balanço hídrico geral dos 20 anos de simulação

\begin{tabular}{|c|c|c|c|c|c|c|c|c|}
\hline \multirow[t]{3}{*}{ Componentes } & \multicolumn{4}{|c|}{ solo RL } & \multicolumn{4}{|c|}{ solo PVA } \\
\hline & \multicolumn{3}{|c|}{ SAF seringueira } & \multirow{2}{*}{$\begin{array}{c}\text { SAF eucalipto } \\
\text { saída } \\
\text { (mm) }\end{array}$} & \multicolumn{2}{|c|}{ SAF seringueira } & \multicolumn{2}{|c|}{ SAF eucalipto } \\
\hline & $\begin{array}{l}\text { entrada } \\
(\mathrm{mm})\end{array}$ & $\begin{array}{l}\text { saída } \\
(\mathrm{mm})\end{array}$ & $\begin{array}{l}\text { entrada } \\
(\mathrm{mm})\end{array}$ & & $\begin{array}{l}\text { entrada } \\
(\mathrm{mm})\end{array}$ & $\begin{array}{l}\text { saída } \\
(\mathrm{mm})\end{array}$ & $\begin{array}{l}\text { entrada } \\
\text { (mm) }\end{array}$ & $\begin{array}{l}\text { saída } \\
(\mathrm{mm})\end{array}$ \\
\hline Estoque inicial no solo & 91,8 & & 91,8 & & 148,0 & & 148,0 & \\
\hline Precipitação & $28.106,8$ & & $28.106,8$ & & $28.106,8$ & & $28.106,8$ & \\
\hline $\begin{array}{l}\text { Evaporação por interce } \\
\text { plantas }\end{array}$ & & 1885,1 & & $2.215,9$ & & $3.366,9$ & & 4045,3 \\
\hline Evaporação do solo & & 9511,1 & & $11.697,0$ & & $6.909,0$ & & 7999,6 \\
\hline Absorção pela cultura & & 2655,9 & & $3.311,8$ & & $5.238,4$ & & $6.512,3$ \\
\hline Absorção pela árvore & & 6321,6 & & 2041,5 & & $6.156,3$ & & 2006,6 \\
\hline Escoamento superficial & & 915,0 & & 1434,3 & & 661,1 & & 1023,4 \\
\hline Drenagem & & $6.655,6$ & & $7.202,9$ & & $5.622,4$ & & 6315,5 \\
\hline Estoque final no solo & & 254,3 & & 295,1 & & 300,6 & & 351,9 \\
\hline Balanço & $28.198,6$ & $28.198,6$ & $28.198,6$ & $28.198,5$ & $28.254,8$ & $28.254,7$ & $28.254,8$ & $28.254,6$ \\
\hline
\end{tabular}


Tabela 5. Biomassa da cultura e uso de água pela cultura e árvore no SAF com seringueira, solo PVA

\begin{tabular}{|c|c|c|c|c|c|c|c|c|c|c|}
\hline \multirow{2}{*}{$\begin{array}{l}\text { Ciclo } \\
\text { cana- } \\
\text { soca }\end{array}$} & \multirow{2}{*}{$\begin{array}{l}\text { Precipitação } \\
(\mathrm{mm})\end{array}$} & & Zona 2 & & & Zona 3 & & & Zona 4 & \\
\hline & & $\begin{array}{l}\text { biomass } \\
\qquad \mathrm{a} \\
\mathrm{da} \\
\text { cultura } \\
\left(\mathrm{kg} \mathrm{m}^{2}\right)\end{array}$ & $\begin{array}{l}\text { transpiração } \\
\text { da cultura } \\
\left(1 \mathrm{~m}^{-2}\right)\end{array}$ & $\begin{array}{c}\text { água } \\
\text { absorvida } \\
\text { pela árvore } \\
\left(1 \mathrm{~m}^{-2}\right)\end{array}$ & $\begin{array}{l}\text { biomassa } \\
\text { da cultura } \\
\left(\mathrm{kg} \mathrm{m}^{2}{ }^{2}\right)\end{array}$ & $\begin{array}{c}\text { transpiração } \\
\text { da cultura } \\
\left(1 \mathrm{~m}^{-2}\right)\end{array}$ & $\begin{array}{c}\text { água } \\
\text { absorvida } \\
\text { pela árvore } \\
\left(1 \mathrm{~m}^{-2}\right)\end{array}$ & $\begin{array}{c}\text { biomassa } \\
\text { da cultura } \\
\left(\mathrm{kg} \mathrm{m}^{2}{ }^{2}\right)\end{array}$ & $\begin{array}{l}\text { transpiração } \\
\text { da cultura } \\
\left(1 \mathrm{~m}^{-2}\right)\end{array}$ & $\begin{array}{c}\text { água } \\
\text { absorvida } \\
\text { pela árvore } \\
\left(1 \mathrm{~m}^{-2}\right)\end{array}$ \\
\hline S11 & 2176,07 & 5,58 & 475,53 & 257,65 & 6,54 & 552,91 & 9,87 & 6,6 & 558,41 & 0 \\
\hline S13 & 1265,61 & 0,49 & 39,31 & 303,23 & 5,71 & 479,85 & 20,5 & 5,85 & 493,12 & 0,02 \\
\hline S41 & 1462,61 & 0,06 & 2,98 & 973,7 & 1,1 & 91,47 & 268,42 & 5,88 & 495,74 & 14,92 \\
\hline S42 & 1617,99 & 0,06 & 2,93 & 914,81 & 4,52 & 384,35 & 267,29 & 5,44 & 455,8 & 2,9 \\
\hline
\end{tabular}




\subsubsection{Balanço hídrico e solos}

Com o balanço hídrico geral dos sistemas, ao final de cada simulação, foi possível verificar as diferenças entre o desempenho em cada solo selecionado (Tabela 4). O PVA é um solo mais profundo e com propriedades físicas distintas do RL (Tabela 1), o que o confere maior capacidade de armazenamento de água. As características hidráulicas dos solos são calculadas no modelo através das Pedotransfer Functions com parâmetros derivados das equações de Van Genuchten adaptadas por Wosten et al. (1995). Desta forma, no PVA há maior absorção de água e conseqüente maior crescimento da cultura e perda de evaporação por interceptação do dossel das plantas, ponderado entre cultura e árvores (Tabela 4 e Figuras 2 e 3). No RL, há menor absorção de água pela cultura e menor crescimento desta, havendo maiores perdas por drenagem, escoamento superficial e evaporação do solo. Assim, a biomassa final da cana-de-açúcar no PVA foi por volta de $60 \%$ maior que no RL. Contudo, no RL há absorção de água e crescimento das árvores (Tabelas 3 e 4) ligeiramente superior aos simulados no PVA, provavelmente por um aproveitamento da água que não seria usada pela cultura e seria perdida por drenagem. Esta maior disponibilidade de água provavelmente seria oriunda da menor perda por evaporação por interceptação do dossel das plantas, já que há menor biomassa da cultura e conseqüente menor IAF.

A principal diferença do balanço hídrico entre as espécies de árvores (Tabela 4), refere-se ao uso de água 3 vezes maior da seringueira que o eucalipto, determinando menor absorção de água e crescimento da cultura nas Zonas de interferência.

Para a cana-de-açúcar, houve menor perda de produção relativa nas Zonas 2 e 3 no PVA para ambas as espécies de árvores (Tabela 6). Estas diferenças foram mais acentuadas na Zona 3 da seringueira e na Zona 2 do eucalipto, exatamente nas Zonas onde a competição por água é mais intensa para cada árvore 
Tabela 6. Biomassa média da cana-soca em relação à Zona 4 de cada sistema simulado

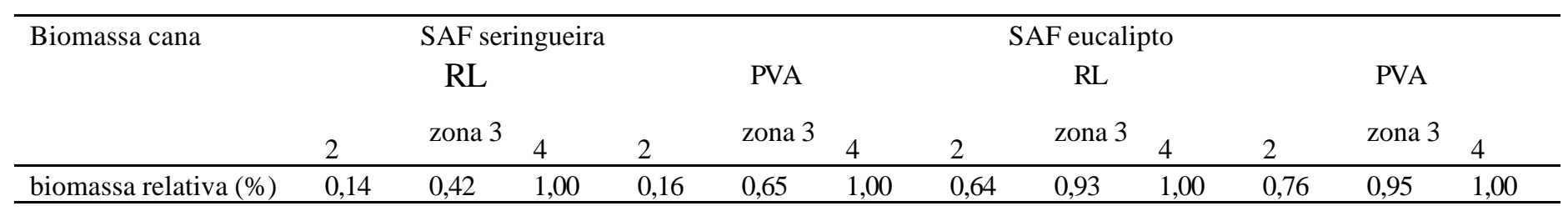




\subsubsection{Análise de sensibilidade}

As Figuras 10 a 16 mostram o resultado das simulações, sendo possível verificar a disparidade de importância relativa de cada parâmetro. Os parâmetros taxa de crescimento máximo potencial da cultura, coeficiente de extinção, área foliar especifica e eficiência de uso da água são sensíveis a mudanças e suas alterações repercutem em significativas mudanças nos resultados das simulações. Todavia, os parâmetros fração de carboidratos a serem remobilizados pelas folhas e potencial máximo da planta pouco respondem a variações em seus valores, até mesmo se adotados com valores extremos.

No caso de parâmetros de solo, verificou-se que as simulações nos 2 solos com propriedades diferentes, Argissolo Vermelho Amarelo (PVA) e Neossolo Litólico (RL), resultaram em resultados diferentes de crescimento da cultura e balanço hídrico (Tabela 7 e Figura 16). No solo com maior limitação física para armazenamento de água (RL), as perdas foram maiores, principalmente por evaporação do solo e drenagem, resultando numa menor absorção de água pela cultura com consequente menor crescimento da cultura e menor evaporação por interceptação do dossel. 
Tabela 7. Balanço hídrico da simulação do Wanulcas para dois solos

\begin{tabular}{lrrrr}
\hline Componente & \multicolumn{2}{c}{ Entrada (mm) } & \multicolumn{2}{c}{ Saída (mm) } \\
& PVA & RL & PV & RL \\
\hline Estoque inicial no solo & 148,0 & 98,0 & & \\
Precipitação & 1962,7 & 1962,7 & & \\
Evaporação do solo & & & 649,1 & 964,9 \\
Absorção pela planta & & 592,3 & 295,6 \\
Evaporação por interceptação & & & \\
do dossel & & 330,2 & 185,5 \\
Drenagem & & & 284,7 & 368,7 \\
Estoque final no solo & & 254,4 & 246,0 \\
Total & 2110,7 & 2060,7 & 2110,7 & 2060,7 \\
\hline
\end{tabular}

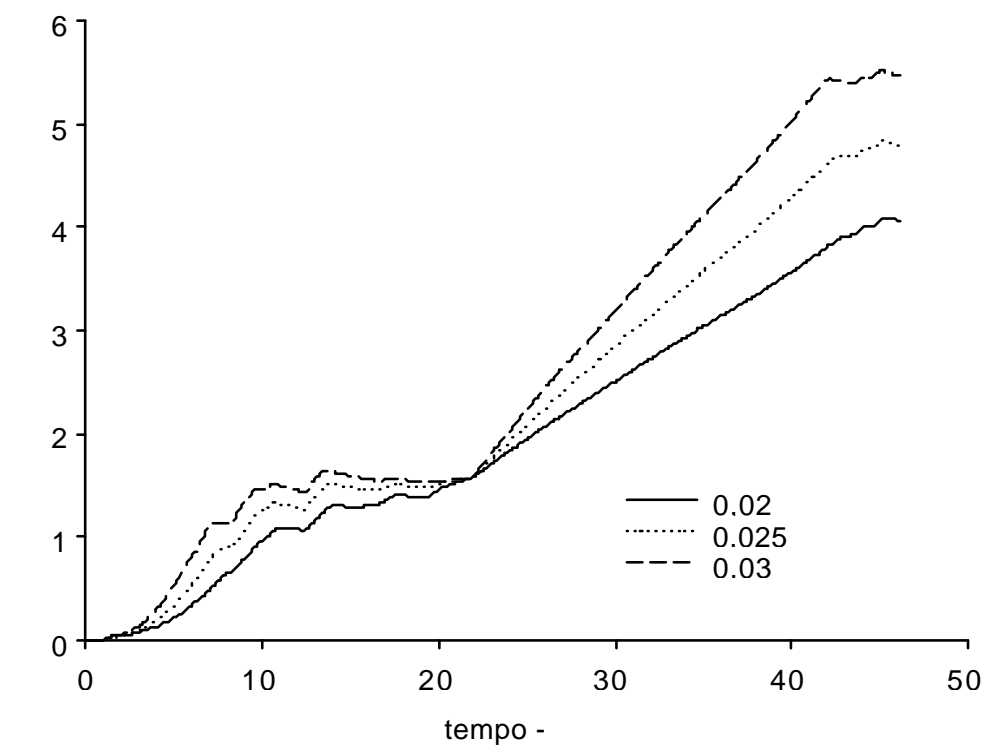

Figura 10 - Evolução da biomassa para distintas taxas de crescimento máximo da cultura 


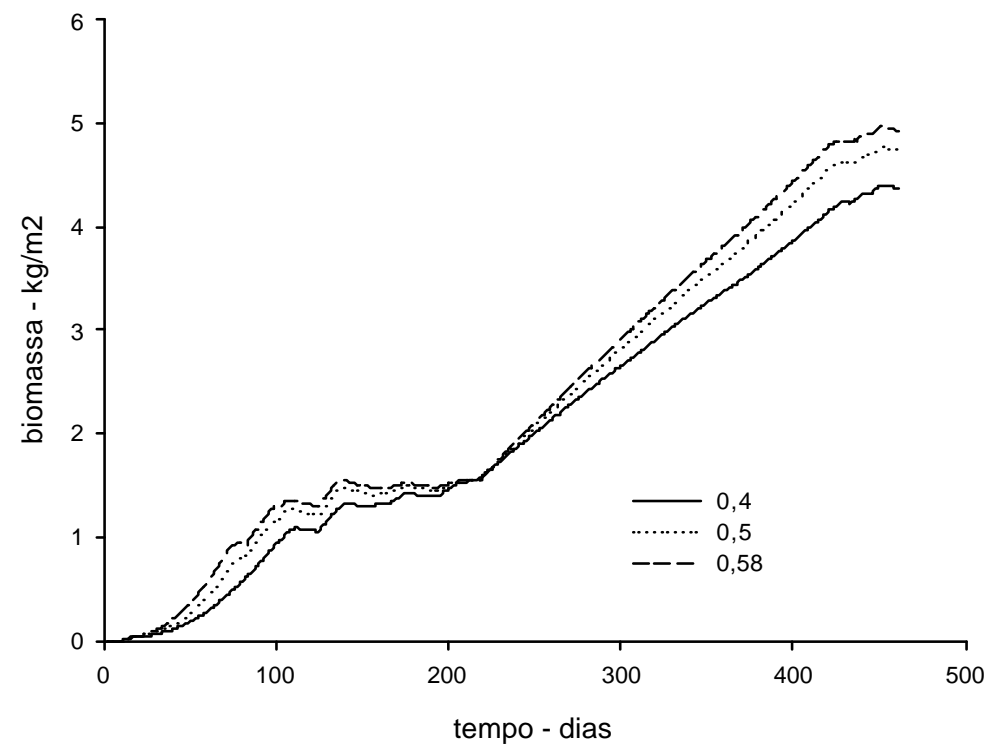

Figura 11 - Evolução da biomassa para distintos valores de coeficiente de extinção

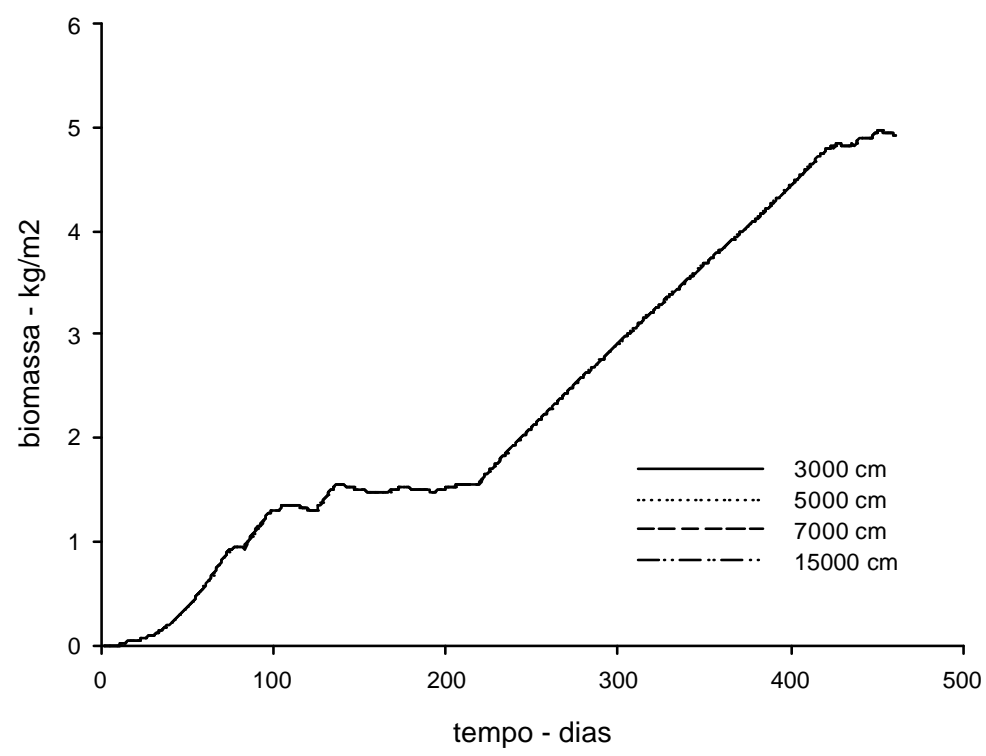

Figura 12 - Evolução da biomassa para distintos valores de potencial máximo da planta 


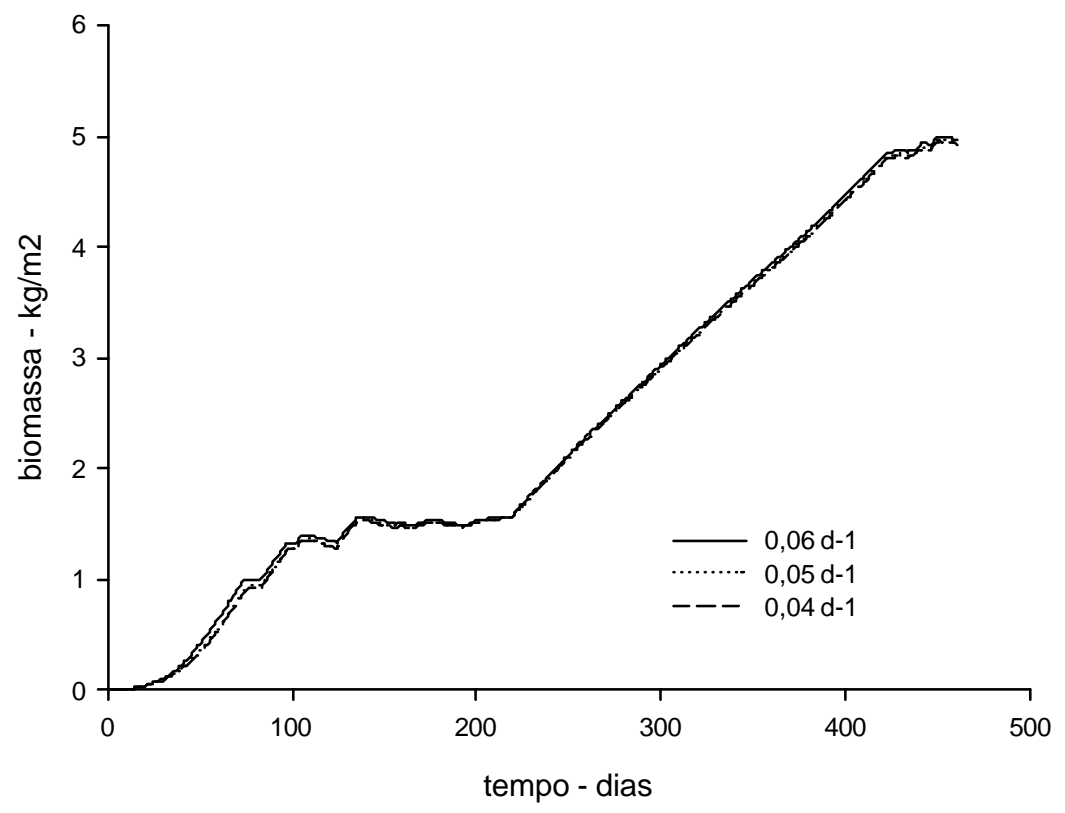

Figura 13 - Evolução da biomassa para distintos valores de fração de carboidratos remobilizados das folhas 


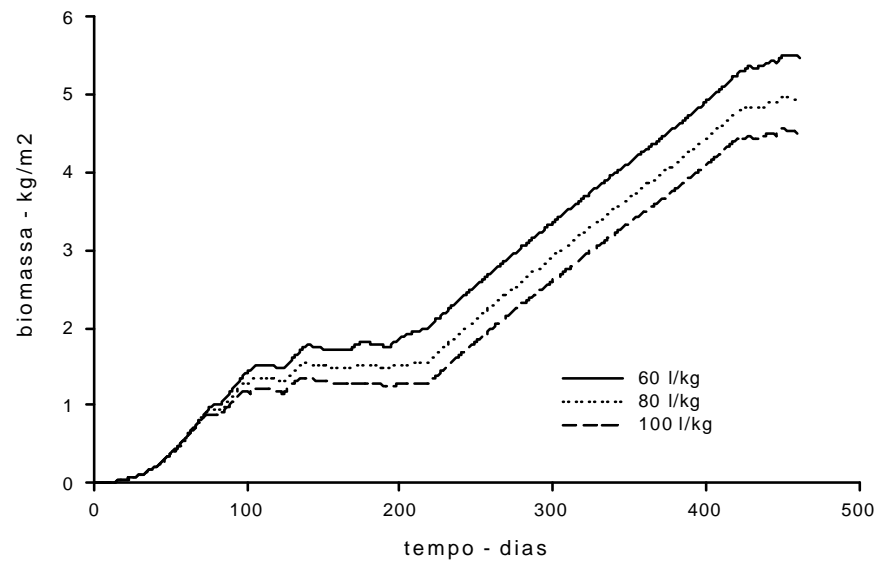

Figura 14 - Evolução da biomassa para distintos valores de eficiência de uso da água

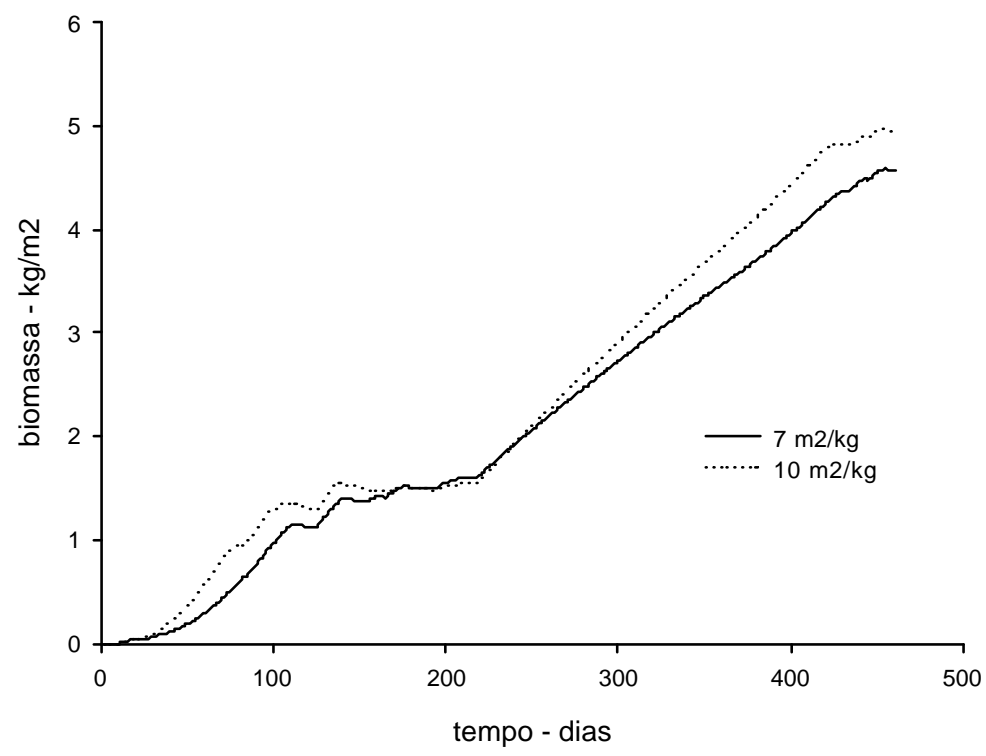

Figura 15 - Evolução da biomassa para distintos valores de área foliar especifica 


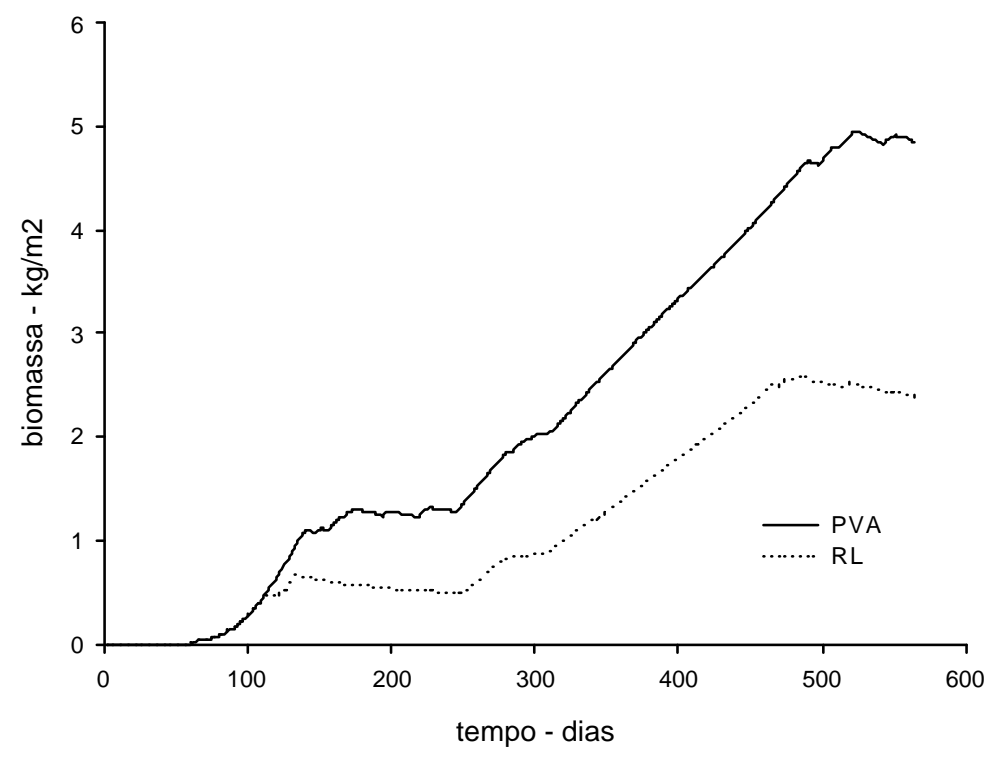

Figura 16 - Evolução da biomassa para dois tipos de solos

\subsubsection{Considerações finais}

No sistema com eucalipto a competição parece ser menos intensa do que com a seringueira devido principalmente á sua copa mais rala propiciando maior disponibilidade de luz para a cultura e ao seu manejo, onde o corte e os novos ciclos de crescimento diminuem significativamente tanto as interações abaixo como acima do solo. Logo, a água parece ser o fator mais limitante para o sistema com eucalipto e tanto luz como água para a seringueira. Portanto, embora espere-se que a luz seja o principal fator limitante para associação de plantas (Monteith et al., 1991), especialmente no caso de árvores altas associadas à culturas $\mathrm{C}_{4}$ como a cana-de-açúcar, deve-se atentar para todos os fatores envolvidos. Analisando todos os fatores em SAF de milho com árvores de grande porte, como a castanha negra (Juglans nigra) e carvalho vermelho (Quercus rubra), Gillespie et al. (2000) verificaram que a água era fator mais limitante que luz para o desempenho do sistema. Portanto, os resultados confirmam Huxley (1999) que apontou que tanto as características de manejo como as biológicas das árvores (copa, sistema radicular e demanda por água) determinam a intensidade das interações e o desempenho das culturas associadas. 
Do ponto de vista dos solos, a simulação sugere maior complementaridade do uso de recursos no PVA, já que a redução relativa na produção das árvores (2-3\% menor) seria compensada por uma produção significativamente maior da cultura nas Zonas onde a competição por água é mais severa. Logo, pode-se inferir que o LER (índice de equivalência de área - Ong, 1996) seria maior no PVA que no RL. Assim, apenas do ponto de vista biofísico, o sistema com eucalipto parece mais interessante do que o com seringueira, assim como o PVA em relação ao RL. Porém, somente após uma avaliação econômica detalhada, que considere o rendimento conjunto de todo o SAF será possível realizar uma indicação consistente sobre cada sistema. Esta avaliação deve também ser somada a realização de experimentos de campo que testem as hipóteses e indicações sugeridas pelas simulações.

O emprego do WaNuLCAS mostrou ser uma importante ferramenta para explorar potenciais e restrições dos SAFs propostos para cana-de-açúcar em Piracicaba. Foi possível realizar grande número de combinações de plantas com rapidez, testar alternativas de manejo, separar interações abaixo e acima do solo, testar diversos cenários e hipóteses e verificar os recursos mais limitantes em cada situação.

Entretanto, os futuros experimentos devem considerar as limitações do modelo e as possíveis lacunas entre os resultados simulados e os esperados no campo. Assim, deve-se considerar as limitações para avaliação da competição por luz, já que o modelo somente considera a radiação com origem zenital. Isto superestima o sombreamento às culturas sob a projeção da copa das árvores e negligencia totalmente o sombreamento às culturas fora desta área. Deve-se também atentar para uma possível superestimativa da competição por água, já que o sistema radicular das árvores apresenta densidade e distribuição vertical e horizontal constante durante toda a simulação. O modelo também superestimou o crescimento das plantas em geral, por não considerar temperatura do ar como fator determinante do crescimento vegetal. Especificamente, as árvores tiveram pouca sensibilidade ao estresse hídrico e o hábito decíduo não pôde ser representado adequadamente, o que possivelmente também superestimou o efeito negativo das árvores sobre as culturas e o crescimento daquelas. Assim, parece ser necessário efetuar modificações no WaNuLCAS que 
contemplem a realidade desta e outras simulações de crescimento de longo prazo, com árvores de grande porte e em clima sub-tropical.

No atual estágio de desenvolvimento do modelo, as modificações microclimáticas decorrentes da associação de árvores e culturas não são contempladas, havendo uma tendência de enfatizar as interações de natureza competitiva acima do solo em detrimento das complementares. Estas modificações em muitas situações são responsáveis pela complementaridade do uso de recursos e das vantagens relativas dos SAFs frente ao monocultivo (Wallace, 1996) e devem ser consideradas no aprimoramento do modelo. Desta forma, o desempenho dos sistemas simulados é o mínimo do que poderia ser atingido no campo e o modelo contribui mais para uma avaliação qualitativa do que quantitativa do sistema proposto.

Este trabalho também procurou colaborar para um futuro maior uso dos modelos agroflorestais, testando o WaNuLCAS em situações originais e acrescentando ao seu banco de dados parâmetros de uma nova cultura e de duas espécies de árvores, assim como dois novos solos e dados diários de 20 anos de clima de uma região sub-tropical do Brasil. 


\subsection{Conclusões}

As indicações dos resultados das simulações permitem concluir que:

1) SAFs em aléias com cana-de-açúcar e seringueira e eucalipto são viáveis e devem ser avaliados no campo.

2) Há aumento da competição entre as árvores e a cultura de acordo com o crescimento das árvores e a maturidade do sistema.

3) A competição por luz e água são limitantes ao crescimento da cultura.

4) O emprego do WaNuLCAS permitiu avaliar os SAFs e direcionar a experimentação de campo.

5) O modelo tem limitações para simulações em ambientes sub-tropicais e de crescimento de árvores altas e em longo prazo.

6) Modelo enfatiza interações competitivas acima do solo, minimizando os benefícios relativos de SAFs frente a monocultivos. 


\title{
5 CRESCIMENTO E PRODUÇÃO DE PLANTAS EM INTERFACES CANA-DE- AÇÚCAR X SERINGUEIRA E CANA-DE-AÇÚCAR X EUCALIPTO
}

\author{
Autor: LUÍS FERNANDO GUEDES PINTO \\ Orientador: Prof. Dr. MARCOS SILVEIRA BERNARDES
}

\section{RESUMO}

As interações biofísicas determinam o crescimento e a produção das plantas associadas em sistemas agroflorestais (SAFs); sendo que a medida da produção ao longo de um transecto na interface árvore-cultura é um método indicado para avaliar as interações em condições de campo. SAFs de aléias em contorno foram indicados como uma alternativa de uso da terra para produção de cana-de-açúcar, contudo há falta de experimentos de campo das interfaces cana-de-açúcar x árvore. Neste trabalho avaliamos a produção de plantas nas interfaces cana-de-açúcar x seringueira e cana-de-açúcar x eucalipto em dois estudos em áreas de campos comerciais, onde medimos parâmetros biométricos e tecnológicos da canade-açúcar em transectos ao longo da interface. Simulamos a disponibilidade de radiação solar para a cultura ao longo do transecto em cada estudo e testamos seu efeito sobre a produção de matéria seca da cana-de-açúcar. Posteriormente, simulamos o ciclo de 7 anos de dois SAFs cana-de-açúcar x eucalipto. Os resultados de campo indicaram que as árvores foram beneficiadas no SAF e o crescimento e produção da cultura foram afetados negativamente, quanto menor a distância das árvores. As simulações indicaram que radiação solar e interações abaixo do solo são causadoras da redução do crescimento da cultura e que a importância relativa de cada fator depende da distância das árvores. Os SAFs simulados com eucalipto têm produção similar ao monocultivo das espécies isoladas.

Palavras-chave: IAF, interações, luz, modelo, sistemas agroflorestais 


\title{
PLANT GROWTH AND YIELD IN SUGARCANE-RUBBER AND SUGARCANE- EUCALYPTUS INTERFACES
}

\author{
Author: LUÍS FERNANDO GUEDES PINTO \\ Adviser: Prof. Dr. MARCOS SILVEIRA BERNARDES
}

\section{SUMMARY}

Biophysical interactions determine plant growth and yield in agroforestry systems (AFs) and the measurement of yield in a transect in the tree-crop interface is indicated as a method to evaluate interactions in on-farm conditions. Contourhedgerows were indicated as a land use alternative for sugarcane cultivation, however, there is lack of field experiments of plant performance in these conditions. In this work we assessed yield in the interfaces sugarcanerubber and sugarcane-eucalyptus in two on-farm experiments where we measured biometric and technological sugarcane parameters in transects in the interfaces. We simulated the availability of solar radiation for the crop along the transect in each experiment and tested its effect over sugarcane dry matter production. Afterwards, we simulated the 7 years cycle two sugarcane-eucalyptus AFs. Field results indicated that trees were benefited in the AFs and crop growth and yield were negatively affected by distance of the trees. Simulations indicated that solar radiation and below ground interactions determine reduction in crop growth and that the relative importance of each variable depends on the distance from the trees. The simulated AFs with have similar production of the monocropping of each specie.

Key-words: interactions, LER, light, model, agroforestry 


\subsection{Introdução}

As interações biofísicas acima e abaixo do solo em sistemas agroflorestais (SAFs) determinam a partilha e a eficiência do uso de recursos por culturas e árvores, influenciando o crescimento e produção das plantas (Ong et al., 1991). As interações podem ser de natureza competitiva ou complementar no uso de radiação solar, água e nutrientes e o recurso mais limitante será definido pela combinação das características das plantas, clima, solo e manejo do sistema (Rao et al., 1997). Além disso, as interações podem alterar a alocação de recursos nas plantas, afetando o índice de colheita e a produção (Huxley, 1999).

Um método simples e eficaz para avaliar as interações é medir a produção ao longo de um transecto na interface árvore-cultura, especialmente em condições de campo, onde é difícil encontrar interfaces controladas (Ong, 1996). Neste sentido, Rao \& Cole (1991) afirmaram que a pesquisa em áreas comerciais tem um papel fundamental no desenvolvimento de pesquisas de sistemas agroflorestais. Esta pode ser usada no diagnóstico de oportunidades e limitações, seleção de prioridades de pesquisa e avaliação dos componentes do SAF e suas interações (Scherr, 1991).

Modelos de simulação são representações simplificadas de sistemas e sua aplicação pode levar a um uso mais eficaz do conhecimento e pesquisa agronômica e experimentação. Podem também ser usados para extrapolação do desempenho de sistemas agrícolas de escala de campo para regiões (Penning de Vries et al., 1989).

SAFs de aléias em contorno foram indicados como uma alternativa de uso da terra para produção de cana-de-açúcar (Sacharum officinarum) em áreas declivosas de Piracicaba, SP (Pinto et al, 2001). No capítulo anterior sugerimos sua viabilidade com eucalipto (Eucalyptus spp) e seringueira (Hevea brasiliensis) através de simulações com o modelo agroflorestal WaNuLCAS (Van Noordwijk \& Lusiana, 1999). Entretanto, apesar do potencial apontado, há falta de experimentos de campo das interfaces cana-de-açúcar x árvore. Contudo, na região de Piracicaba há cultivo significativo de árvores, e entre ela,s 
seringueira e eucalipto ao longo de canaviais, fornecendo condições para avaliações do desempenho de plantas na interface das árvores com a cana-de-açúcar.

Aliado aos trabalhos já executados anteriormente, as medidas de campo e o uso de modelos matemáticos simples, que busquem relações universais, permitirão extrapolar os resultados para outras condições da região e fornecer subsídios para a pesquisa e políticas de adoção dos SAFs na região. Desta forma, visamos avaliar o crescimento e a produção da cana-de-açúcar nas suas interfaces com seringueira e eucalipto. 


\subsection{Material e Métodos}

\subsubsection{Estudo 1 - interface cana-de-açúcar x seringueira}

\section{Descrição da área}

A interface cana-de-açúcar x seringueira localizava-se na Fazenda São José ( $22^{\circ} 15^{\prime}$ S, $47^{\circ} 45^{\prime} \mathrm{W}, 657 \mathrm{~m}$ de altitude) no município de Rio Claro, SP. Nesta há monocultivo comercial de seringueira e cana-de-açúcar, porém com diversas interfaces entre as culturas. A região possui clima Cwa (sub-tropical úmido, com verão chuvoso e seca de inverno). A temperatura média anual é $20,1^{\circ} \mathrm{C}$, a média do mês mais quente, $22,8^{\circ} \mathrm{C}$ (dezembro), e a do mês mais frio, $16,7^{\circ} \mathrm{C}$ (julho). A precipitação média anual é de $1376 \mathrm{~mm}$, sendo a do mês mais seco $24 \mathrm{~mm}$ (julho) e a do mais úmido $238 \mathrm{~mm}$ (janeiro). A interface situava-se numa área plana de Latossolo Vermelho Amarelo. As linhas de seringueira estavam plantadas na direção norte-sul e o canavial encontrava-se na face oeste.

O seringal foi plantado em 1983 com o clone RRIM 600, no espaçamento de 7 x 3 m. Até 1997 a área ocupada com cana-de-açúcar era uma plantação de eucalipto. O canavial era separado do seringal por um carreador de terra e as primeiras plantas de cana-de-açúcar ficavam a 6,60 m da primeira linha de seringueiras, formando-se um ângulo de $60^{\circ}$ entre as linhas de seringueira e de cana-de-açúcar. O canavial foi plantado em 16 de março de 2001 com a variedade SP83-2847 e espaçamento de 1,4 m entre as linhas. A adubação no plantio foi de $120 \mathrm{Kg} \mathrm{N} \mathrm{ha}^{-1}$ e $144 \mathrm{~kg} \mathrm{~K}_{2} \mathrm{O} \mathrm{ha}{ }^{-1}$.

\section{Delineamento e medidas}

$\mathrm{Na}$ interface, selecionamos um trecho homogêneo de $40 \mathrm{~m}$ para amostragem, onde medimos a linha exterior de seringueira e transectos no canavial no dia 22 de maio de 2002; três dias após um evento de ventos de até 90 km h-1 que danificou os canaviais. Amostramos 11 árvores consecutivas de seringueira (abrangendo 33 metros) e medimos: i) altura total e altura do início da copa; ii) diâmetro à altura do peito (DAP); iii) largura da copa no sentido do canavial e iv) índice de área foliar (IAF $-\mathrm{m}^{2}$ folha $\mathrm{m}^{-2}$ solo). As alturas foram medidas com 
hipsômetro de Haga. O IAF foi estimado com analisador de dossel LI-COR LAI 2000, usado no período da manhã em dia nublado, obtendo-se a média de três medidas, sendo que cada uma foi resultante da amostragem em 8 posições no interior do seringal.

$\mathrm{Na}$ área de cana-de-açúcar, amostramos 6 posições em função de distâncias do seringal, com 4 repetições, sendo cada repetição um transecto. As posições, definidas pela avaliação visual do canavial, foram a 7,5 m; 9 m; 12,5 m; 16 m; 21,5 m e 36,5 m das árvores externas do seringal. A distância relativa de cada posição foi obtida pelo quociente da distância da posição pela altura da árvore.

Para amostragem da cana-de-açúcar e sua posterior avaliação biométrica, utilizamos método adaptado de Machado et al. (1982) e Landell et al. (1999). Em cada posição, coletamos todos as perfilhos de dois metros lineares. Destes, no campo, medimos: i) número de perfilhos; ii) altura da planta e do colmo e iii) biomassa aérea fresca dividida em colmo, ponta, folha verde e folha seca. Dois perfilhos por posição (divididos em colmo, ponta e folha verde) e duas amostras de folhas secas de toda a área foram pesados separadamente para análise de peso seco. $\mathrm{O}$ material foi seco em estufa a $70^{\circ} \mathrm{C}$ por 7 dias, exceto os colmos que permaneceram 15 dias na estufa após serem picados e cortados no sentido do comprimento. Dos colmos secos também contamos o número de entre-nós. Em cada posição coletamos um disco de área conhecida $\left(76,51 \mathrm{~mm}^{2}\right)$ de 10 folhas. Os discos foram secos em estufa e a partir de suas massas determinamos a Área Foliar Específica (AFE, $\mathrm{m}^{2} \mathrm{~kg}^{-1}$ ) e, combinado com a massa total de folhas verdes, determinamos o IAF. De cada posição foram amostrados dois colmos para análise tecnológica, onde determinou-se o teor de ATR (açúcar total reduzido) e fibra total.

Os dados foram submetidos à análise de variância e as variáveis com médias com diferenças significativas foram submetidas à análise de regressão. As variáveis com tendência de aumento assintótico de seu valor em função da distância das árvores, foram analisadas com regressão logarítmica $\left(\mathrm{y}=\mathrm{b}_{0}+\mathrm{b}_{1} \ln \mathrm{x}\right)$. As com tendência de diminuição do valor no mesmo sentido, foram analisadas com regressão exponencial negativa. Para tal, utilizamos o programa SPSS 10 para Windows e Excel. 
Posteriormente utilizamos o modelo matemático proposto por Goudriaan (1977) e adaptado por Bernardes et al. (1998), que simula a disponibilidade de radiação solar para culturas intercalares em função da distância das árvores e da geometria de suas copas (equação 1):

$$
\operatorname{Ir}=0.5(\operatorname{sen}(\operatorname{arctg}((\mathrm{d}-(\mathrm{cw} * \mathrm{cw} / \mathrm{d})) / \mathrm{hr})+\mathrm{s})+1) \mathrm{I}_{0}
$$

onde $\mathrm{Ir}=$ irradiância diária que atinge o dossel da cultura intercalar $\left(\mathrm{MJ} \mathrm{m}^{-2} \mathrm{dia}^{-1}\right) ; \mathrm{d}=$ distância das árvores (m); I0 = irradiância diária numa superfície horizontal acima da copa das árvores $\left(\mathrm{MJ} \mathrm{m}^{-2} \operatorname{dia}^{-1}\right) ; \mathrm{cw}=$ raio da copa $(\mathrm{m}) ; \mathrm{s}=$ declividade to terreno (radianos); $\mathrm{hr}=$ altura relativa das árvores (m), obtida pela diferença da altura das árvores pela da cultura. Como calculamos a irradiância relativa, adotamos $\mathrm{I}_{0}=1$.

Em seguida testamos o efeito da disponibilidade relativa de radiação sobre a produção relativa de matéria seca com o emprego de análise de regressão.

\subsubsection{Estudo 2 - interface cana-de-açúcar $x$ eucalipto}

\section{Descrição da área}

A interface cana-de-açúcar x eucalipto localizava-se no município de Piracicaba, SP (S 22 42'30', W 47 38'01'"; altitude de 554m) com clima Cwa, segundo a classificação de Koeppen. O clima é sub-tropical úmido, com verão chuvoso e seca de inverno. A temperatura média anual é de $21,4{ }^{\circ} \mathrm{C}$, com temperaturas médias mensais de $24,8{ }^{\circ} \mathrm{C}$ no verão e $17,1{ }^{\circ} \mathrm{C}$ no inverno e precipitação média anual de $1278 \mathrm{~mm}$. Identificamos no município um canavial vizinho a uma plantação comercial de eucalipto (Eucalyptus grandis), presente em área plana de Latossolo Vermelho Amarelo. As linhas de eucalipto estavam plantadas paralelamente às de cana-de-açúcar na orientação sudeste-noroeste, com a cana presente na face nordeste. 
O eucalipto foi plantado em julho de 1997 com espaçamento 3,00 x 1,25 m, sendo separado do canavial por um carreador de terra, com as primeiras linha de cana-de-açúcar e eucalipto distantes $6,00 \mathrm{~m}$. O canavial foi plantado em março de $2001 \mathrm{com}$ a variedade SP 80-1816 e espaçamento de 1,4 m entre as linhas. A adubação de plantio e cobertura foram de $500 \mathrm{~kg} \mathrm{ha}^{-1}$ e $460 \mathrm{~kg} \mathrm{ha}^{-1}$ respectivamente da fórmula 5-20-20.

\section{Delineamento e medidas}

Ao longo da interface selecionamos um trecho homogêneo de $40 \mathrm{~m}$ para amostragem, onde medimos a linha exterior e a primeira linha interior do eucalipto e transectos no canavial no dia 8 de maio de 2002 (as árvores tinham aproximadamente cinco anos e a cana 11 meses

de idade). Amostramos 10 árvores consecutivas de cada linha (abrangendo 12,5 metros) e medimos: i) altura total; ii) diâmetro à altura do peito (DAP); iii) largura da copa no sentido do canavial, iv) índice de área foliar (IAF) e v) estimamos o volume total de madeira com casca, com o emprego da equação volumétrica indicada por Stape \& Itria (1996) - equação 2:

$$
\begin{aligned}
& \text { Volume }=\exp (-9,766237+1,703300 * \ln (\text { DAP })+1,101996 * \ln (\text { Altura })) ;(\text { Eq. } 2) \\
& \text { sendo volume }\left(\mathrm{m}^{3}\right), \text { DAP }(\mathrm{cm}) \text { e altura }(\mathrm{m}) .
\end{aligned}
$$

Para as medidas utilizamos os mesmos materiais e métodos do Experimento 1. Para comparação das duas linhas de eucalipto amostradas realizamos Análise de Variância, com nível de significância de 0,05, assumindo-se que a linha externa do plantio representaria uma situação de SAF e a interior, a de um plantio em monocultivo.

Para a cana-de-açúcar o delineamento experimental, a análise estatística e a aplicação do modelo de irradiância foram iguais às do Estudo 1. As exceções foram a pesagem de folhas secas, determinação da AFE da cana e análise tecnológica dos colmos, que não foram realizadas neste estudo. Além disso, devido ao paralelismo entre as linhas de cana e eucalipto, usamos outra adaptação dos métodos de Machado et al. (1982) e Landell et al. (1999): 
a) as posições amostradas situavam-se a $6,0 \mathrm{~m} ; 8,8 \mathrm{~m} ; 11,6 \mathrm{~m} ; 15,8 \mathrm{~m} ; 20,0 \mathrm{~m}$ e 28,4 m da primeira linha de eucaliptos.

b) em cada posição, contamos o número de perfilhos de cinco metros lineares e coletamos os 10 primeiros para pesagem da massa aérea fresca.

c) O IAF foi determinado diretamente com uso do LI-COR LAI 2000. Cada medida foi resultado da amostragem de quatro posições, sendo duas na linha e duas na entre-linha.

\section{Simulação do ciclo do SAF cana-de-açúcar x eucalipto}

Verificada a acuracidade do modelo em estimar a irradiância relativa e sua relação com a produção de matéria seca, utilizamo-lo para simular o ciclo de dois SAFs de eucalipto e cana-de-açúcar, desde o plantio até o primeiro corte das árvores, com o fim de comparar suas produções relativas com a dos monocultivos da cultura e da espécie florestal. A altura média das árvores em cada ano foi adaptada de Stape (1995) e a largura média das copas foi baseada em Stape \& Itria (1996) - Tabela 1. Assumimos o valor de dois metros para altura média do dossel da cana-de-açúcar. 
Tabela 1. Valores de altura da árvore e largura da copa no ciclo de Eucalyptus grandis.

\begin{tabular}{lcc}
\hline Ano & Altura da árvore $(\mathrm{m})$ & Largura da copa $(\mathrm{m})$ \\
\hline 1 & 4 & 1,5 \\
2 & 9 & 1,5 \\
3 & 12 & 2,0 \\
4 & 15 & 2,0 \\
5 & 19 & 2,5 \\
6 & 20 & 3,0 \\
7 & 21 & 3,0 \\
\hline
\end{tabular}

A partir dos resultados das medidas de campo, a faixa cultivada com cana-de-açúcar foi dividida em quatro zonas com irradiância relativa e produção de matéria seca relativa homogêneas, a primeira estimada pelo modelo de irradiância e a segunda pela equação de regressão irradiância relativa x matéria seca relativa. Aplicando o modelo com os dados da Tabela acima, estimamos a irradiância relativa disponível para cada zona, no seu ponto central, em cada ano. Em seguida, estimamos a produção relativa de matéria seca em cada zona, considerando a área relativa da faixa ocupada por cada zona. Posteriormente, somamos o valor da produção relativa de cada zona, obtendo-se a produção relativa de toda a faixa de cana-de-açúcar. Assim, a produção relativa máxima de cada zona seria a proporção de sua área na faixa e a produção relativa máxima da faixa seria igual a um (1). Finalmente, com a produção relativa da faixa de cana-de-açúcar por ano, calculamos o componente da cultura no índice de equivalência de área (IEA), pelo método proposto por Ong (1996) e calculado pela equação 4. IEA maior que um (1), representa um SAF com ganhos de produção frente ao monocultivo isolado de seus componentes.

$$
\mathrm{IEA}=\mathrm{Xsaf} / \mathrm{Xmono}+\mathrm{Ysaf} / \mathrm{Ymono}
$$


sendo Xsaf, a produção da cultura em SAF e Xmono, a produção da cultura em monocultivo; analogamente para Y, sendo este o índice referente à árvore.

O valor de Xsaf do ciclo foi obtido da média aritmética dos Xsaf de cada ano da cana-de-açúcar e Xmono foi igual a um (1). Ysaf e Ymono foram obtidos dos valores de volume de madeira medidos no experimento de campo. 


\subsection{Resultados}

\subsection{1 Árvores}

A Tabela 2 mostra os resultados dos parâmetros medidos na linha externa do seringal, indicando que as árvores eram mais baixas, porém com maior diâmetro e largura da copa que as de eucalipto. O seringal possuiu IAF superior que da plantação de eucalipto.

Assumimos que as árvores externas do plantio de eucalipto representam as de um sistema agroflorestal em aléias, e as da linha interna, as de um monocultivo. Assim, verificamos que as árvores em SAF foram beneficiadas e tiveram crescimento superior que as em monocultivo, já que todos os parâmetros medidos (exceto altura) tiveram diferença significativa entre os dois tratamentos (Tabela 3). $\mathrm{O}$ volume de madeira por árvore estimado foi significativamente maior $(\mathrm{P}<0,01)$ nas árvores em SAF, correspondendo a uma produção de madeira com casca de $777,41 \mathrm{~m}^{3} \mathrm{ha}^{-1}$ contra $406,71 \mathrm{~m}^{3} \mathrm{ha}^{-1}$ para as em monocultivo. $\mathrm{O}$ principal fator para a produção superior foi o diâmetro das árvores, sendo o valor de 13,06 cm obtido no monocultivo, similar ao da plantação de Eucalyptus grandis avaliada por Gonçalves et al. (1999) em Itatinga (SP). O maior crescimento e produção de madeira das árvores em SAF devem ser atribuídos principalmente à ausência de competição entre árvores na direção da cultura, com um maior crescimento lateral da copa e maior aproveitamento da radiação disponível (Monteith et al., 1991) e uso de água e nutrientes da área da cultura da cana-de-açúcar. 
Tabela 2. Média e desvio padrão das variáveis medidas nas árvores de seringueira

\begin{tabular}{lc}
\hline Variável & média (desvio padrão) \\
\hline altura total $(\mathrm{m})$ & $12,94(1,39)$ \\
altura da copa $(\mathrm{m})$ & $10,36(1,23)$ \\
largura da copa $(\mathrm{m})$ & $4,60(0,51)$ \\
diâmetro $(\mathrm{cm})$ & $19,82(2,41)$ \\
IAF geral da plantação & $1,58(0,06)$ \\
$\left(\mathrm{m}^{2}\right.$ folha m & \\
\hline
\end{tabular}

Tabela 3. Média e desvio padrão das variáveis medidas nas árvores de eucalipto

\begin{tabular}{lrr}
\hline Variável & \multicolumn{1}{l}{ Linha 1 } & \multicolumn{1}{l}{ Linha 2 } \\
\hline altura total $(\mathrm{m})$ & $24,61(1,58)$ & $23,47(2,69)$ \\
diâmetro $(\mathrm{cm})$ & $18,34(4,96) *$ & $13,06(4,81)$ \\
largura da copa $(\mathrm{m})$ & $3,09(1,19) *$ & $1,49(0,36)$ \\
volume de madeira com casca $\left(\mathrm{m}^{3}\right.$ & $0,29(0,04)^{*}$ & $0,15(0,03)$ \\
arvore $\left.{ }^{-1}\right)$ & & \\
IAF geral da plantação $\left(\mathrm{m}^{2}\right.$ folha $\mathrm{m}^{-2}$ & 1,08 & \\
solo) & & \\
\hline
\end{tabular}

* médias com diferença significativa $(\mathrm{P}<0,05)$

\subsubsection{Cana-de-açúcar}

Houve efeito da distância das árvores sobre o crescimento da cultura nos dois estudos. Todas as variáveis relacionadas ao crescimento (matéria seca, palha, massa colmos, altura, número de perfilhos, IAF e comprimento de entre-nós) tiveram análise de variância significativa $(\mathrm{P}<0,01)$ e de médio a alto coeficiente de correlação com a distância nas regressões (Tabelas 4 a 7 e Figuras 1 e 2). 
Tabela 4. Média e desvio padrão das variáveis de cana-de-açúcar medidas no estudo com seringueira

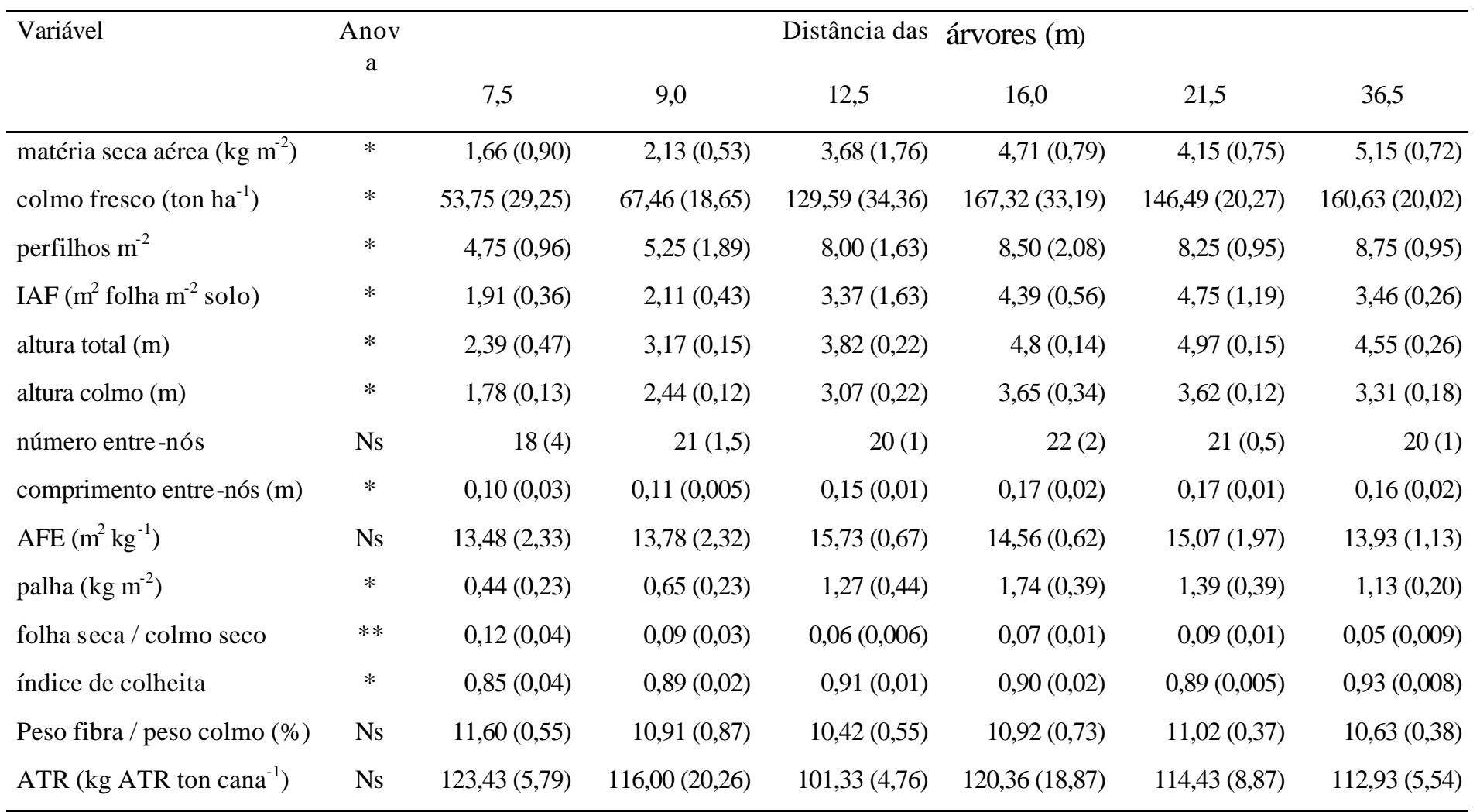

Nível de significância da variável * - P < 0,01; ** - 0,01< $\mathrm{P}<0,05 ;$ ns - não significativo 
Tabela 5. Regressão das variáveis significativas de cana-de-açúcar medidas no estudo com seringueira, em função da distância das árvores.

\begin{tabular}{llc}
\hline Variável & Tipo regressão & $\mathrm{R}^{2}$ \\
\hline matéria seca aérea $\left(\mathrm{kg} \mathrm{m}^{-2}\right)$ & logarítmica & $0,57^{*}$ \\
colmo fresco $\left(\right.$ ton $^{-1} \mathrm{~h}^{-1}$ & logarítmica & $0,68^{*}$ \\
perfilhos $\mathrm{m}^{-2}$ & logarítmica & $0,53^{*}$ \\
$\mathrm{IAF}\left(\mathrm{m}^{2}\right.$ folha m${ }^{-2}$ solo) & logarítmica & $0,45^{*}$ \\
altura total (m) & logarítmica & $0,86^{*}$ \\
altura colmo (m) & logarítmica & $0,82^{*}$ \\
comprimento entre-nós (m) & logarítmica & $0,64^{*}$ \\
palha $\left(\mathrm{kg} \mathrm{m} \mathrm{m}^{-2}\right)$ & logarítmica & $0,44^{*}$ \\
folha seca / colmo seco & exponencial & $0,33^{*}$ \\
índice de colheita & logarítmica & $0,45^{*}$ \\
\hline
\end{tabular}

Nível de significância da regressão: * - P $<0,01$ 
Tabela 6. Média e desvio padrão das variáveis de cana-de-açúcar medidas no estudo com eucalipto

\begin{tabular}{|c|c|c|c|c|c|c|c|}
\hline \multirow[t]{2}{*}{ Variável } & \multirow[t]{2}{*}{ Anova } & \multicolumn{6}{|c|}{ Distância das árvores (m) } \\
\hline & & 6,0 & 8,8 & 11,6 & 15,8 & 20,0 & 28,4 \\
\hline matéria seca aérea $\left(\mathrm{kg} \mathrm{m}^{-2}\right)$ & $*$ & $0,87(0,29)$ & $0,98(0,07)$ & $1,80(0,41)$ & $3,42(0,34)$ & $3,51(0,36)$ & $2,93(1,10)$ \\
\hline Colmo fresco (ton $\mathrm{ha}^{-1}$ ) & $*$ & $28,77(7,94)$ & $37,39(1,45)$ & $64,05(16,66)$ & $125,24(16,55)$ & $123,66(14,61)$ & $118,37(18,14)$ \\
\hline perfilhos $\mathrm{m}^{-2}$ & $*$ & $3,50(0,58)$ & $4,00(0,00)$ & $5,25(0,95)$ & $8,25(0,50)$ & $8,25(0,50)$ & $7,75(0,96)$ \\
\hline $\operatorname{IAF}\left(\mathrm{m}^{2}\right.$ folha $\mathrm{m}^{-2}$ solo $)$ & $*$ & $0,45(0,11)$ & $0,77(0,11)$ & $0,93(0,04)$ & $1,30(0,04)$ & $1,29(0,11)$ & $1,40(0,19)$ \\
\hline altura total (m) & $*$ & $3,46(0,25)$ & $3,78(0,21)$ & $4,30(0,18)$ & $4,6(0,12)$ & $4,72(0,11)$ & $4,82(0,14)$ \\
\hline altura colmo (m) & $*$ & $1,79(0,48)$ & $2,06(0,09)$ & $2,61(0,16)$ & $3,02(0,22)$ & $3,09(0,07)$ & $3,10(0,07)$ \\
\hline número entre-nós & $*$ & $13(2)$ & $12(1,5)$ & $15(1)$ & $16(1)$ & $16(1)$ & $15(2)$ \\
\hline comprimento entre-nós (m) & $*$ & $0,13(0,02)$ & $0,18(0,03)$ & $0,17(0,009)$ & $0,18(0,02)$ & $0,19(0,008)$ & $0,20(0,02)$ \\
\hline folha seca / colmo seco & $\mathrm{ns}$ & $0,15(0,01)$ & $0,18(0,04)$ & $0,15(0,04)$ & $0,10(0,02)$ & $0,12(0,02)$ & $0,13(0,06)$ \\
\hline Índice de colheita & $\mathrm{ns}$ & $0,81(0,01)$ & $0,79(0,04)$ & $0,82(0,04)$ & $0,86(0,02)$ & $0,84(0,02)$ & $0,84(0,05)$ \\
\hline
\end{tabular}

Nível de significância da variável: * $\mathrm{P}<0,01 ; * *-0,01<\mathrm{P}<0,05 ;$ ns - não significativo. 
Tabela 7. Regressão das variáveis significativas de cana-de-açúcar medidas no estudo com eucalipto, em função da distância das árvores.

\begin{tabular}{llc}
\hline Variável & tipo regressão & $\mathrm{R}^{2}$ \\
\hline matéria seca aérea $\left(\mathrm{kg} \mathrm{m}^{-2}\right)$ & logarítmica & $0,63^{*}$ \\
colmo fresco $\left(\right.$ ton $\left.^{-1}\right)$ & logarítmica & $0,76^{*}$ \\
perfilhos $\mathrm{m}^{-2}$ & logarítmica & $0,76^{*}$ \\
$\mathrm{IAF}\left(\mathrm{m}^{2}\right.$ folha m${ }^{-2}$ solo) & logarítmica & $0,89^{*}$ \\
altura total (m) & logarítmica & $0,89^{*}$ \\
altura colmo (m) & logarítmica & $0,82^{*}$ \\
número entre-nós & logarítmica & $0,33^{*}$ \\
comprimento entre-nós (m) & logarítmica & $0,58^{*}$ \\
\hline
\end{tabular}

Nível de significância da regressão: * $\mathrm{P}<0,01$ 


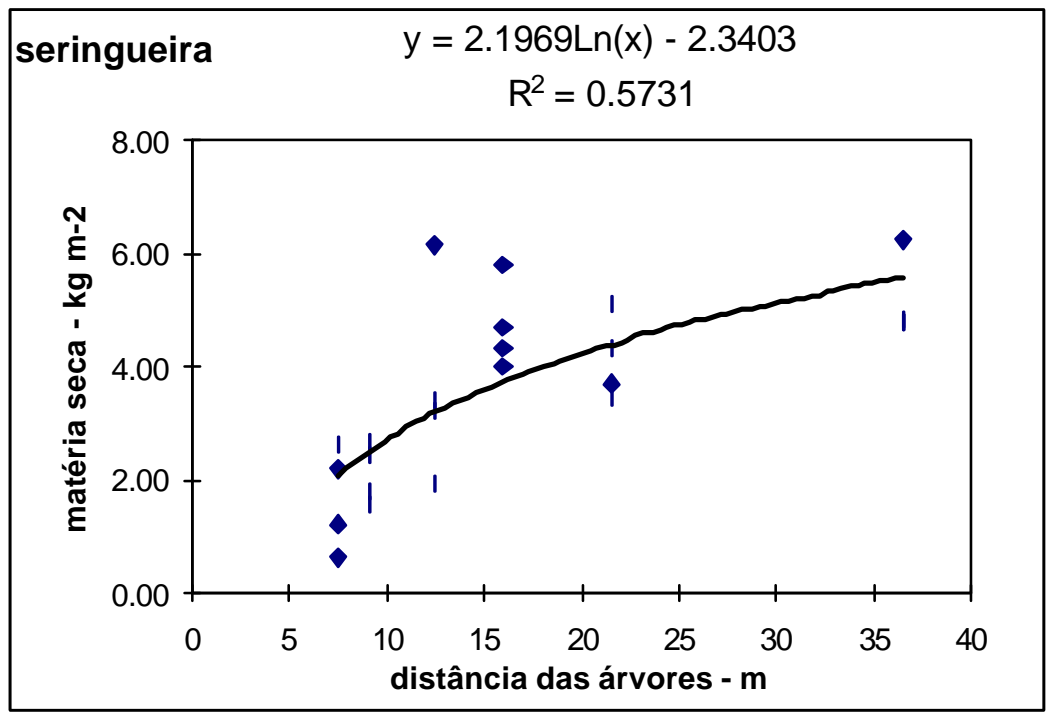

Figura 1 - Regressão não-linear da matéria seca da cana-de-açúcar em função da distância das árvores de seringueira

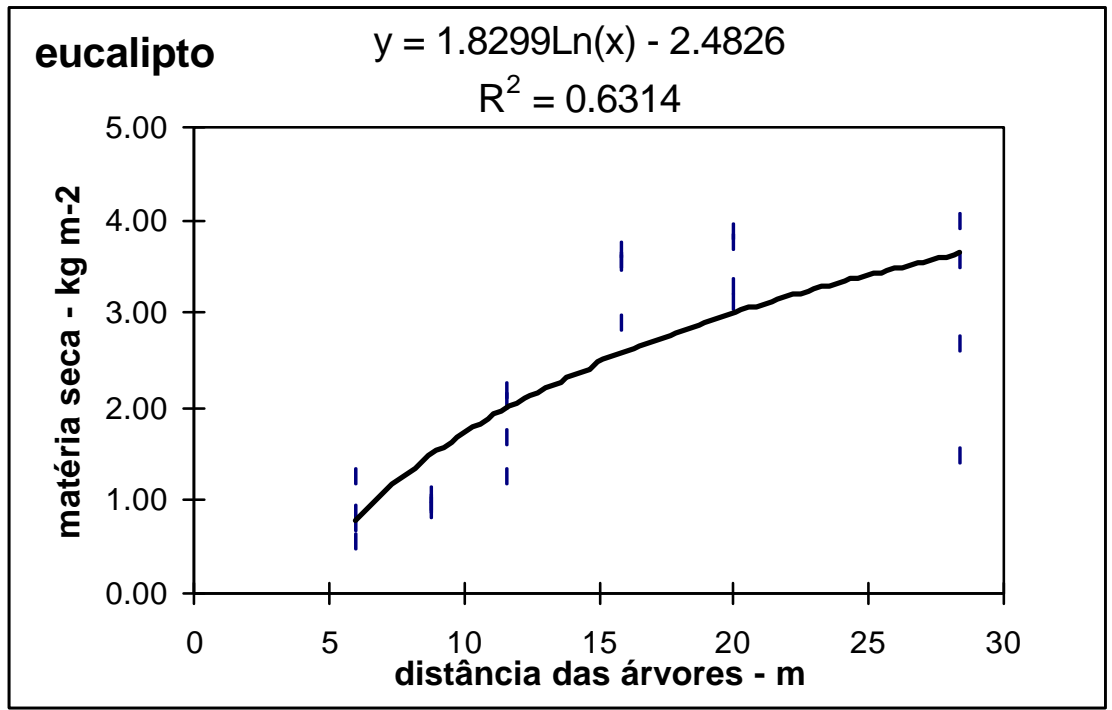

Figura 2 - Regressão não-linear da matéria seca da cana-de-açúcar em função da distância das árvores de eucalipto

O menor crescimento da cultura nas posições mais próximas das árvores deve-se à interações biofísicas abaixo e acima do solo entre as árvores e a cultura, em acordo com Rao et al. (1998). A presença das copas das árvores e seu consequente sombreamento reduz a 
disponibilidade de radiação para a cultura e causa uma diminuição na temperatura do ar e do solo quanto mais se aproxima das árvores (Monteith et al., 1991). A diminuição da radiação e da temperatura do solo reduzem a brotação e o perfilhamento da cana-de-açúcar (Casagrande, 1991), justificando a menor densidade de perfilhos próximo às árvores. Já o menor crescimento da cultura deve-se à provável menor disponibilidade de radiação e temperatura do ar, pois a cana-de-açúcar é uma planta $\mathrm{C}_{4}$, com resposta fotossintética positiva a estes dois fatores (Irvine, 1983). Segundo Black \& Ong (2000) o acúmulo de biomassa pode ser linearmente relacionado com a interceptação de radiação solar pelo dossel da cultura, sendo a última determinada pelo IAF (Loomis \& Connor, 1992). Isto pôde ser confirmado pelas regressões lineares altamente significativas $(\mathrm{P}<0,01)$ entre matéria seca e IAF em cada posição nas Figuras 3 e 4; ressaltando-se que os maiores valores de IAF estão relacionados à maior população de plantas (Irvine, 1983). Segundo Irvine (1983), o crescimento da cana-de-açúcar pode ser determinado pela elongação dos colmos, sendo que a temperatura do ar é o fator mais diretamente relacionado ao processo; o que explica o menor comprimento médio de entre-nós e de altura da planta e do colmo próximo às árvores. Um menor IAF, contudo, resulta em maior disponibilidade de luz nas porções inferiores do dossel da planta e causa menor taxa de senescência de folhas de cana (Bull \& Glasziou, 1975). Menores temperaturas do ar também aumentam o período de duração de uma folha e diminuem a taxa de senescência (Squire, 1993), contribuindo para a maior produção de palha nas posições com maior IAF e mais afastadas das árvores. 


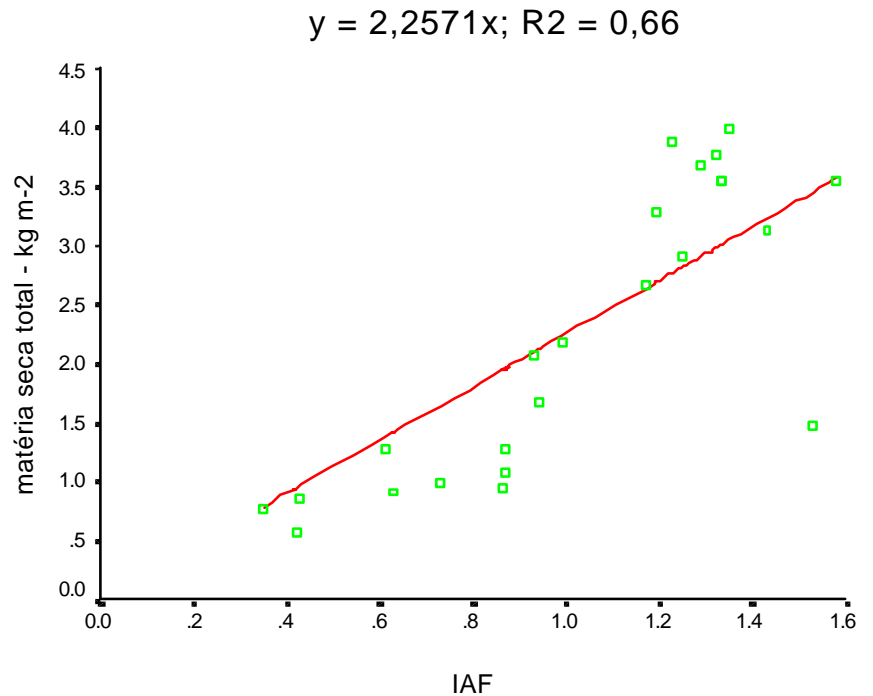

Figura 3 - Regressão linear IAF x matéria seca total da cana-de-açúcar no experimento com eucalipto

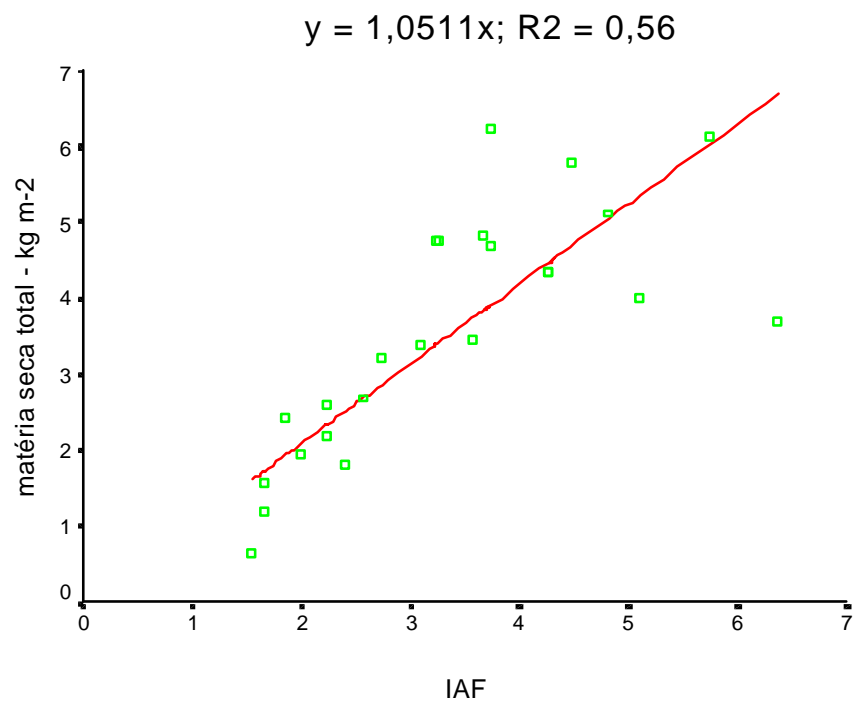

Figura 4 - Regressão linear IAF x matéria seca total da cana-de-açúcar no experimento com seringueira

Não houve efeito conclusivo sobre o efeito das interações no desenvolvimento da cultura. O número de entre-nós não apresentou diferença significativa entre as posições no estudo com seringueira, mas houve efeito no eucalipto, com regressão indicando tendência da 
diminuição de seu número próximo das árvores. O mesmo ocorreu para variáveis relativas à partição de assimilados. O índice de colheita e relação massa folha seca / massa colmo seco não foram significativos no estudo com eucalipto, mas foram no com seringueira. A regressão indicou tendência de diminuição do índice de colheita próximo às árvores e aumento da proporção folha / colmo na mesma direção. Segundo Brenner (1996) o efeito da sombra e da alteração da temperatura do ar e umidade do solo e do ar sobre a partição de assimilados e desenvolvimento da planta e o índice de colheita varia entre espécies, geralmente favorecendo as culturas em que colhe-se folhas em detrimento de grãos. A relação folha / colmo variou de 0,7 para 0,1 durante o ciclo da cana no experimento realizado por Machado et al. (1982) e o índice de colheita atingiu valor máximo de 0,85 em experimentos conduzidos na Austrália e África do Sul por Inman-Bamber et al. (2002). No experimento com seringueira a área foliar específica (AFE) não apresentou diferença significativa e foi superior ao valor de $10 \mathrm{~m}^{2} \mathrm{~kg}^{-1}$ medido por Machado et al. (1982). Todavia, esperávamos um aumento da AFE como uma adaptação à menor intensidade de radiação, como indicado por Huxley (1999) e observado por Righi (2000) em feijoeiro.

No experimento com seringueira, também não houve diferença significativa dos parâmetros tecnológicos, embora esperássemos uma maior concentração de açúcar no colmo na sombra, devido à menor temperatura do ar (Irvine, 1983). Todos as posições tiveram teor de fibra abaixo dos 12,57\% definidos como limite pela indústria, mas somente a posição um (1) atingiu o valor padrão mínimo de $121,96 \mathrm{~kg}$ ATR tonelada cana ${ }^{-1}$.

O valor de $5,3 \mathrm{~kg} \mathrm{~m}^{-2}$ de matéria seca obtido por Machado et al. (1982) para canaplanta de 18 meses em Piracicaba é semelhante à média máxima de $5,15 \mathrm{~kg} \mathrm{~m}^{-2}$ na seringueira e superior aos $3,51 \mathrm{~kg} \mathrm{~m}^{-2}$ do experimento com eucalipto. Quanto à produção de colmos frescos, manteve-se um valor superior na seringueira, acima do máximo de $140 \mathrm{t} \mathrm{ha}^{-1}$ obtido por Alleoni \& Beauclair (1995) em experimento em Piracicaba.

Analisando-se a matéria seca final, é possível identificar 3 zonas homogêneas ao longo dos transectos nos dois estudos. No eucalipto, as zonas seriam no intervalo das posições 1-2, 3 e 4-6. Isto equivale às respectivas distâncias absolutas e relativas das árvores de: 6-11,6 m 
$(0,24-0,47) ; 11,6-15,8 \mathrm{~m}(0,47-0,64)$ e 15,8-28,4 m (0,64-1,15). Na seringueira, as zonas seriam no intervalo das posições 1-2, 3 e 4-6, equivalendo às distâncias absolutas e relativas das árvores de: 7,5-12,5 m (0,58-0,96); 12,5-16,0 m (0,96-1,23) e 16,0-36,5 m (1,232,82). Seringueiras com altura de 14 metros afetaram a produção de feijão até a distância de 10 metros (Righi, 2000) e de milho e soja até 9 metros (Bernardes et al., 1998). De todo modo, os estudos foram realizados com árvores adultas, no máximo de seu crescimento e da intensidade de competição com a cana-de-açúcar. Assim, o desempenho da cultura pode ser considerado o mais negativo possível de um eventual SAF de cana-de-açúcar com eucalipto ou seringueira.

No estudo com seringueira observa-se, de maneira geral, um alto valor relativo do desvio padrão nas posições mais próximas das árvores, com sua diminuição ao longo do transecto (Tabela 4). Já no experimento com eucalipto, o desvio padrão se manteve baixo e constante ao longo do transecto (Tabela 6). Isto pode ser atribuído ao paralelismo das linhas de plantio de cana-de-açúcar em relação às árvores de eucalipto neste experimento. Isto não ocorreu na seringueira e forçou que a parcela de amostragem em cada posição fosse quase perpendicular às linhas de árvores.

\subsubsection{Simulações}

A Tabela 8 mostra a distância relativa e a irradiância relativa calculada para cada posição. Percebemos que seria necessário amostrar mais uma posição de cana-de-açúcar no eucalipto, para obter-se uma situação de ausência de competição por radiação solar com as árvores.

As Figuras 5 e 6 apresentam as regressões da matéria seca relativa em função da irradiância relativa nos dois estudos, onde verificamos a correlação entre as variáveis com regressões com alta significância $(\mathrm{P}<0,01)$, como obtido por Benardes et al. (1998), Righi (2000) e Moraes (2002). Isto indica que o modelo pode ser usado para extrapolação de resultados experimentais para outras condições. Entretanto, os trabalhos citados obtiveram 
correlação superior que este e relação próxima a 1:1 entre as variáveis, pois foram realizados em condições experimentais controladas, visando a minimização das interações abaixo do solo, com irrigação e adubação abundantes em solo de alta fertilidade e alta capacidade de retenção de água. Todavia, os presentes estudos foram realizados em solos com baixa fertilidade e capacidade de retenção de água, com adubação convencional para as culturas e sem irrigação. Ressaltamos também o efeito causado pela sombra à cana-de-açúcar, espécie $\mathrm{C}_{4}$ com grande resposta fotossintética positiva à radiação (Irvine, 1983), o que deve ter colaborado para o desvio da curva da relação 1:1.

Adicionalmente, as regressões com coeficiente linear $\left(b_{0}\right)$ menor que um (1) indicam que, a partir de uma certa proximidade das árvores, mesmo com disponibilidade de radiação, não há produção de matéria seca. Atribuímos este resultado à maior intensidade das interações abaixo do solo, superando as acima do solo a partir de certa distância. O maior valor do coeficiente linear $\left(\mathrm{b}_{0}\right)$ para eucalipto, mesmo tendo IAF maior que o da seringueira, sugere que esta espécie é mais competitiva que a seringueira. Esta evidência também reforça a importância do efeito da competição abaixo do solo nas condições estudadas.

Tabela 8. Distância relativa, irradiância relativa estimada para cada posição nos dois experimentos e zona homogênea de cada posição

\begin{tabular}{lcccc}
\hline Posição & \multicolumn{2}{c}{ Seringueira } & \multicolumn{2}{c}{ Eucalipto } \\
& & $\begin{array}{c}\text { distância relativa } \\
\text { irradiância relativa } \\
\text { (zona) }\end{array}$ & $\begin{array}{l}\text { distância relativa } \\
\text { (zona) }\end{array}$ \\
\hline 1 & 0,58 & $0,70(1)$ & 0,24 & $0,60(1)$ \\
2 & 0,69 & $0,78(1)$ & 0,35 & $0,67(1)$ \\
3 & 0,96 & $0,88(2)$ & 0,47 & $0,73(2)$ \\
4 & 1,23 & $0,94(3)$ & 0,64 & $0,80(3)$ \\
5 & 1,66 & $0,97(3)$ & 0,81 & $0,85(3)$ \\
6 & 2,82 & $0,99(3)$ & 1,15 & $0,91(3)$ \\
\hline
\end{tabular}




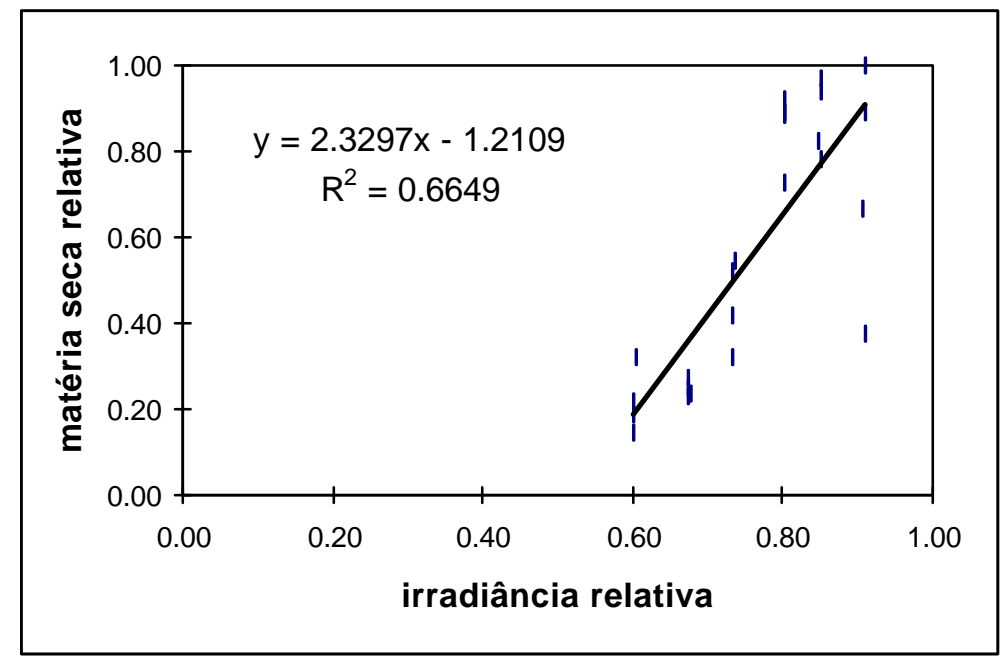

Figura 5 - Regressão linear da irradiância relativa x matéria seca total relativa da canade-açúcar no experimento com eucalipto

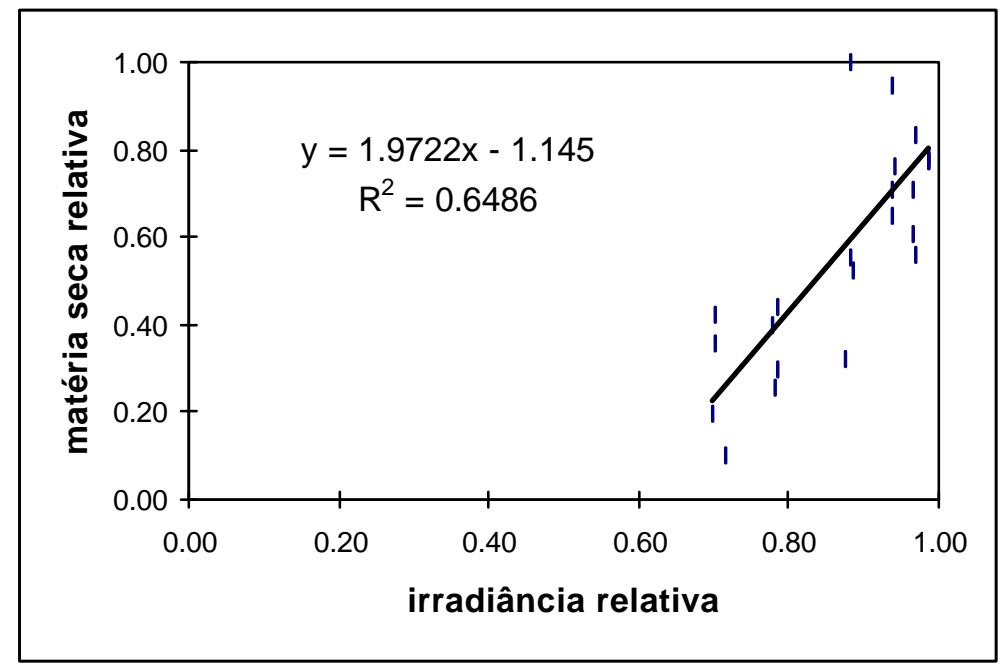

Figura 6 - Regressão linear da irradiância relativa x matéria seca total relativa da canade-açúcar no experimento com seringueira

\subsubsection{Simulação do ciclo do SAF cana-de-açúcar $x$ eucalipto}

Com os resultados do estudo de campo, os SAFs em aléias simulados consistiriam de renques duplos de Eucalyptus grandis, com espaçamento $3 \mathrm{~m} \mathrm{x} \mathrm{1,25} \mathrm{m,} \mathrm{intercalados} \mathrm{por}$ 
uma faixa de cana-de-açúcar. A diferença entre os dois SAFs foi a distância entre os renques de eucalipto e o comprimento da faixa de cana. O SAF 100m teve distância 100 metros entre os renques e o SAF 75m, 75 metros, causada somente pela redução da zona 4. Em ambos, a primeira linha de cana seria plantada a quatro metros do renque de eucalipto, totalizando uma faixa plantada de cana de 92 metros, no caso do SAF 100m. A faixa inicial de quatro metros foi subdividida em duas para cálculo do IEA: a primeira de 1,5 m, referente à área ocupada pelo eucalipto e a segunda, de $2,5 \mathrm{~m}$, mesmo sem plantio, foi contabilizada como área da cana-de-açúcar. Esta nova zona de cana-de-açúcar será denominada zona 0 (zero). Como as análises são relativas e assumimos simetria do sistema, apresentaremos o resultado de meio SAF, isto é, um renque de eucalipto e plantio de 46 metros de cana, para o SAF $100 \mathrm{~m}$ (Figura 7). Cada ano do ciclo teve a sequência de cálculo da Tabela 9, com a posterior síntese anual e do ciclo da produção de cana (Tabela 10).

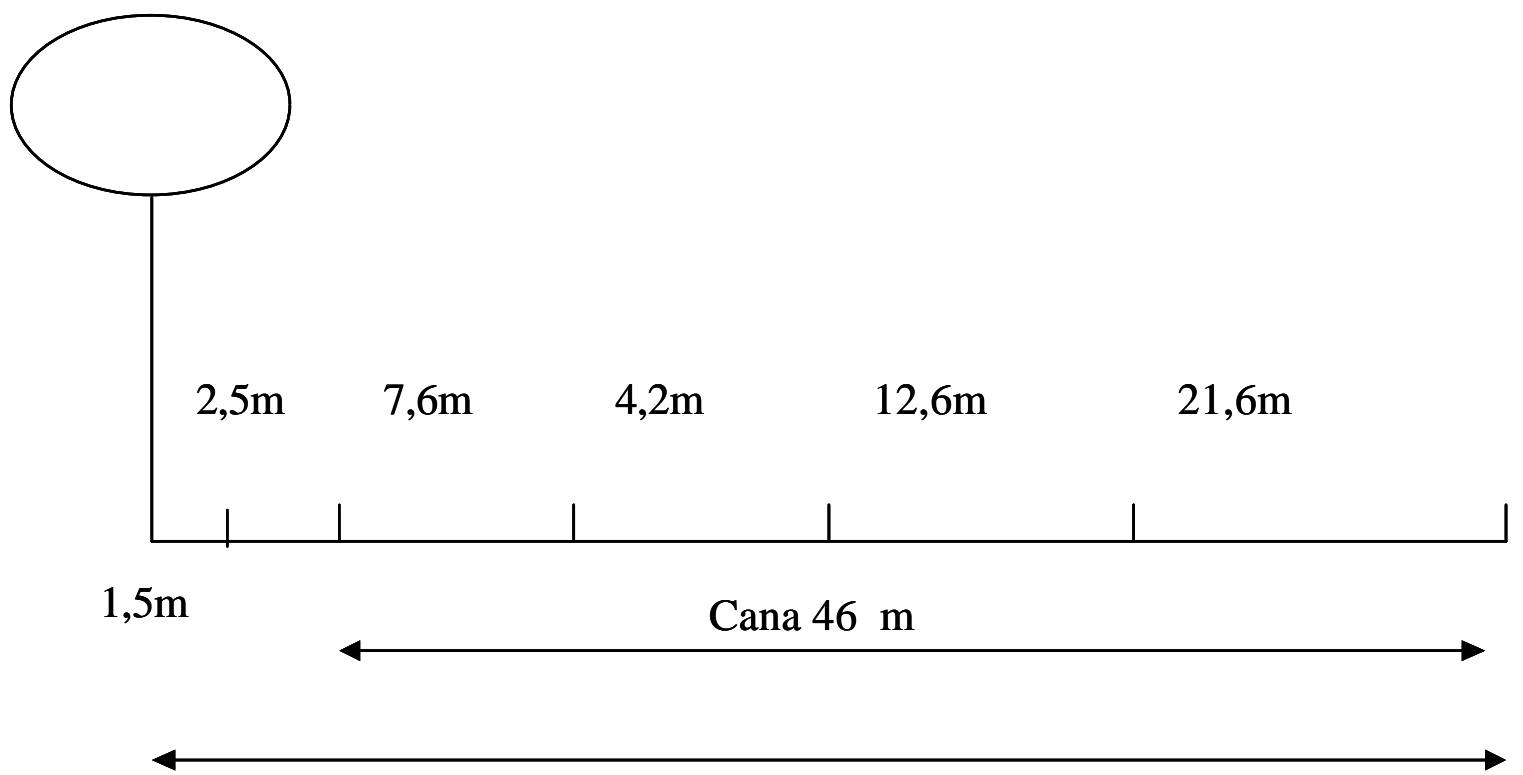

SAF $50 \mathrm{~m}$

Figura 7 - Representação (fora de escala) do SAF 100m. 
Tabela 9. Cálculo anual da produção relativa da cana-de-açúcar. ex.: SAF 100m, ano 5.

\begin{tabular}{lcccc}
\hline Zona & $\begin{array}{c}\text { irradiância } \\
\text { relativa }\end{array}$ & $\begin{array}{c}\text { matéria seca } \\
\text { relativa }\end{array}$ & $\begin{array}{l}\text { produção relativa } \\
\text { da cana }\end{array}$ & $\begin{array}{l}\text { produção relativa } \\
\text { da cana em } \\
\text { monocultivo* }\end{array}$ \\
\hline 0 & - & - & 0 & 0,05 \\
1 & 0.70 & 0,41 & 0,06 & 0,16 \\
2 & 0.81 & 0,68 & 0,06 & 0,09 \\
3 & 0.88 & 0,84 & 0,22 & 0,26 \\
4 & 0.96 & 1,00 & 0,44 & 0,44 \\
Produção & & & & \\
relativa da faixa & & & & \\
de cana & & & 0,78 & 1,00 \\
\hline
\end{tabular}

* produção máxima possível, calculada em função da área relativa de cada zona na faixa de cana-de-açúcar.

Tabela 10. Componente da cana-de-açúcar no IEA do sistema

\begin{tabular}{lccc}
\hline Ano & SAF 100m & SAF 75 m & monocultivo \\
\hline 1 & 0,93 & 0,97 & 1 \\
2 & 0,89 & 0,87 & 1 \\
3 & 0,86 & 0,81 & 1 \\
4 & 0,81 & 0,75 & 1 \\
5 & 0,76 & 0,68 & 1 \\
6 & 0,75 & 0,66 & 1 \\
7 & 0,74 & 0,65 & 1 \\
Média & $\mathbf{0 , 8 2}$ & $\mathbf{0 , 7 7}$ & $\mathbf{1}$ \\
\hline
\end{tabular}

Novamente, verificamos que a diminuição relativa da produção da cana em SAF se acentua da Zona 4 para a Zona 1 (Tabela 9), ou seja, quanto mais próximo da árvore, assim como a produção relativa da faixa de cana-de-açúcar diminui de acordo com o crescimento das árvores de eucalipto (Tabela 10).

Finalmente, a contribuição do eucalipto para o IEA do SAF 100m foi de 0,14 e 0,19 no SAF 75m. O IEA final do ciclo foi de 0,96 para ambos, com produção total próxima à dos monocultivos isolados das espécies. Entre os SAFs, a diminuição da produção da cana-deaçúcar no SAF 75m, devido à redução de sua zona de produção máxima, foi compensada pelo aumento da proporção da área do SAF ocupada pelo eucalipto, espécie beneficiada pela 
associação. Como a produção da cana-de-açúcar foi muito prejudicada pela árvore na Zona 1, sugerimos a substituição da cultura por culturas ou espécies arbóreas tolerantes ao sombreamento nesta área, como sugerido no capítulo 3. Assim, deve-se contribuir para um aumento do IEA e da diversidade do sistema. Righi (2000) obteve IEAs de 0,91 e 1,28 para dois plantios de feijão associados com seringueira, o primeiro realizado no inverno e o segundo no verão. Ong (1996) revisou o resultado de vários experimentos de SAFs com leucena e culturas anuais na Índia, que resultaram em IEA de 1,17 a 2,36 e Lott et al (2000) obtiveram valores entre 1 e 1,5 em vários anos de cultivo dos SAFs grevilea x milho e grevilea x feijão caupi no Quênia.

Finalmente, embora tenha ocorrido ligeira diminuição da produção do SAF em relação ao monocultivo, os benefícios esperados de conservação do solo (Young, 1997) reforçam a vantagem relativa do SAF para cultivo de cana-de-açúcar em Piracicaba. Novos estudos devem verificar espaçamentos ótimos entre os renques e a combinação de outras espécies arbóreas na zona próxima ao renque de árvores, buscando-se a otimização do IEA. Deve-se também considerar o risco de erosão em diferentes classes de declividade e a avaliação econômica dos sistemas. 


\subsection{Conclusões}

1) Houve efeito positivo do crescimento e produção do eucalipto em sistemas agroflorestais, quando comparado a seu monocultivo.

2) Nos dois experimentos houve efeito negativo e inversamente proporcional à distância das árvores no crescimento e produção da cana-de-açúcar.

3) O crescimento da cultura foi influenciado pela combinação da competição acima e abaixo do solo. A importância de cada fator depende da distância das árvores.

4) O SAF cana-de-açúcar x eucalipto tem produção similar aos monocultivos de cada espécie.

5) O modelo de irradiância forneceu subsídios para a compreensão das interações no SAF, identificou erros nos experimentos, permitiu orientar experimentos futuros e possibilitou extrapolar os resultados para uma nova escala temporal de avaliação. 


\section{CONCLUSÕES}

1) SAFs em aléias em contorno são alternativa viável para cultivo de cana-de-açúcar no município de Piracicaba, especialmente nos solos com alta suscetibilidade à erosão, havendo diversas espécies arbóreas exóticas e nativas que podem compor estes SAFs, destacando-se seringueira e eucalipto.

2) A competição por luz e água são limitantes ao crescimento da cultura e há aumento da competição entre as árvores e a cultura de acordo com o crescimento das árvores. A importância relativa entre competição abaixo e acima do solo depende da distância das árvores.

3) O emprego do WaNuLCAS permitiu avaliar qualitativamente os SAFs e direcionar a experimentação de campo, mas apresentou limitações nas avaliações quantitativas.

4) Há efeito negativo e inversamente proporcional à distância das árvores no crescimento e produção da cana-de-açúcar, mas o SAF cana-de-açúcar x eucalipto tem produção similar ao monocultivo de cada espécie, pois a árvore é beneficiada pela associação.

5) O modelo de irradiância forneceu subsídios para a compreensão das interações no SAF cana-de-açúcar x eucalipto, orientou o presente e permite orientar futuros experimentos e possibilitou extrapolar os resultados dos trabalhos de campo.

6) As indicações das simulações devem verificadas em experimentos de campo e a recomendação dos SAFs deve ser feita após análise econômica dos mesmos. 
ANEXOS 
Anexo 1. Parâmetros modificados para cana-de-açúcar (Saccharum officinarum L.)

\begin{tabular}{|c|c|c|c|c|}
\hline Definição & Unidade & Cana-planta & Cana-soca & Fonte \\
\hline Length of generative stage & dias & 3 & 3 & \\
\hline Length of vegetative stage & dias & 498 & 362 & \\
\hline Earliest day to flower in a year & dia Juliano & 91 & & $\begin{array}{l}\text { Casagrande } \\
\text { (1991) }\end{array}$ \\
\hline Latest day to flower in a year & dia Juliano & 181 & 181 & $\begin{array}{l}\text { Casagrande } \\
\text { (1991) }\end{array}$ \\
\hline Production of dry matter per day & $\mathrm{kg} /(\mathrm{m} 2$.day) & 0.026 & 0.026 & $\begin{array}{l}\text { Machado et al. } \\
\text { (1982) }\end{array}$ \\
\hline Seed weight & $\mathrm{kg} / \mathrm{m} 2$ & 0.02 & 0.02 & Bernardes (2000) \\
\hline Water for dry matter production & $\mathrm{l} / \mathrm{kg}$ & 80 & 80 & Barbieri (1981) \\
\hline Conversion factor & $\mathrm{m} 3 / \mathrm{kg} 2$ & 0.7 & 0.7 & 7 empírico \\
\hline Extinction light coefficient & adimensional & 0.5 & 0.5 & $\begin{array}{l}\text { Van de Berg } \\
(2000)\end{array}$ \\
\hline Max. root length density in layer1 & $\mathrm{cm} / \mathrm{cm} 3$ & 1.881 & 1.881 & $\begin{array}{l}\text { adaptado de } \\
\text { Alvarez et al. } \\
(2000)\end{array}$ \\
\hline Max. root length density in layer2 & $\mathrm{cm} / \mathrm{cm} 3$ & 0.906 & & $\begin{array}{l}\text { adaptado de } \\
\text { Alvarez et al. } \\
(2000)\end{array}$ \\
\hline Max. root length density in layer3 & $\mathrm{cm} / \mathrm{cm} 3$ & 0.2 & & $\begin{array}{l}\text { adaptado de } \\
\text { Alvarez et al. } \\
(2000)\end{array}$ \\
\hline Max. root length density in layer4 & $\mathrm{cm} / \mathrm{cm} 3$ & 0.05 & 0.05 & $\begin{array}{l}\text { adaptado de } \\
\text { Alvarez et al. } \\
(2000)\end{array}$ \\
\hline
\end{tabular}

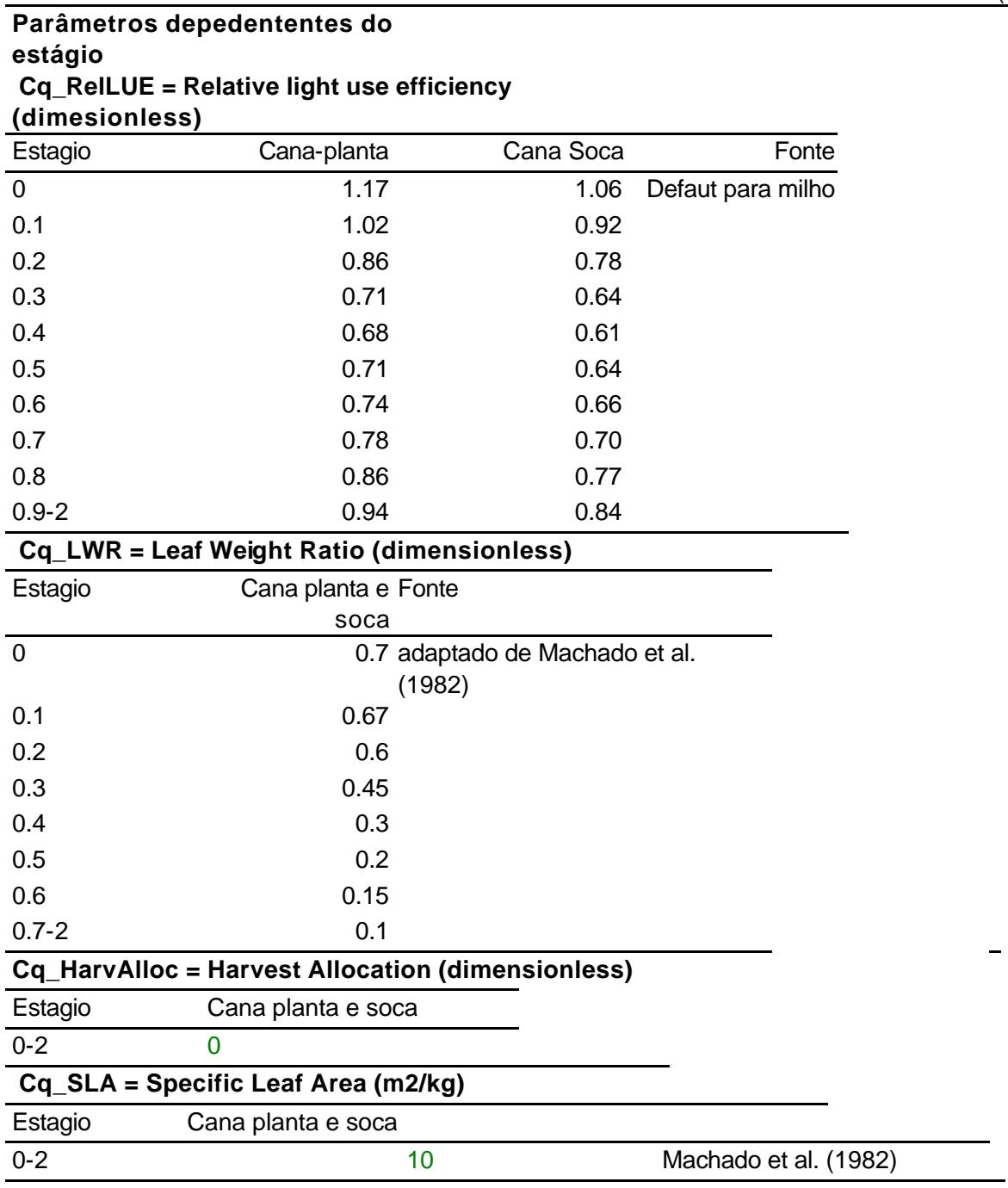


Anexo 2. Parâmetros modificados para seringueira (Hevea brasiliensis Muell. Arg.)

\begin{tabular}{|c|c|c|c|c|c|}
\hline & & Parâmetro & Unidade & Valor & Fonte \\
\hline \multicolumn{2}{|c|}{ Growth Stage } & Length of vegetative cycle & days & 2555 & Bernardes (2000) \\
\hline & & Length of generative cycle & days & 150 & Bernardes (2000) \\
\hline & & Earliest day to flower in a year & Julian day & 244 & Bernardes (2000) \\
\hline & & Latest day to flower in a year & Julian day & 288 & Bernardes (2000) \\
\hline \multirow[t]{4}{*}{ Growth } & & Max. growth rate & $\mathrm{kg} \mathrm{m}-2$ & 0.01 & Templeton (1968) \\
\hline & & Leaf weight ratio & [] & 0.1 & \begin{tabular}{|l|} 
adaptado de \\
Templeton (1968) e \\
Conceição et al. \\
$(1986)$ \\
\end{tabular} \\
\hline & & Specific leaf area & $\mathrm{m} 2 / \mathrm{kg}$ & 10 & $\begin{array}{l}\text { adaptado de } \\
\text { Conceição et al. } \\
(1986)\end{array}$ \\
\hline & & Water for dry matter production & I kg-1 & 400 & Bernardes (2000) \\
\hline \multirow[t]{5}{*}{ Canopy } & & Max. canopy height above bare stem & $m$ & 12 & $\begin{array}{l}\text { adaptado de Leong } \\
(1980)\end{array}$ \\
\hline & & Ratio between canopy width and height & [] & 0.5 & \begin{tabular}{|l} 
adaptado de Leong \\
$(1980)$
\end{tabular} \\
\hline & & Max. canopy radius & $\mathrm{m}$ & 5 & \begin{tabular}{|l|} 
adaptado de Leong \\
(1980) e Righi (2000)
\end{tabular} \\
\hline & & Maximum leaf area index & [] & 6 & Leong (2000) \\
\hline & & Ratio leaf area index min. and max. & [] & 0.4 & $\begin{array}{l}\text { adaptado de Leong } \\
(2000)\end{array}$ \\
\hline $\begin{array}{l}\text { Light } \\
\text { capture }\end{array}$ & & Extinction light coefficient & [] & 0.7 & Bernardes (2000) \\
\hline \multicolumn{2}{|c|}{ Rain interception } & Rainfall water stored at leaf surface & $\mathrm{mm}$ & 0.3 & Lima (1996) \\
\hline \multirow[t]{2}{*}{ Litterfall } & & Litterfall caused by drought & day-1 & 0.2 & empírico \\
\hline & & Treeshold value for litterfall due to drought & [] & 0.3 & empírico \\
\hline \multicolumn{2}{|c|}{ Allometric Branching } & Intercept for total biomass equation & $\mathrm{kg}$ & 0.0209603 & $\begin{array}{l}\text { adaptado de } \\
\text { Shorrocks et al. } \\
(1965)\end{array}$ \\
\hline & & Power for total biomass equation & $\mathrm{cm}-1$ & 3.45 & \begin{tabular}{|l} 
adaptado de \\
Shorrocks et al. \\
$(1965)$
\end{tabular} \\
\hline & & Intercept for branch biomass equation & $\mathrm{kg}$ & 0.001064482 & empírico \\
\hline & & Power for branch biomass equation & $\mathrm{cm}-1$ & 3.8 & empírico \\
\hline & & Intercept for Leaf\&twig biomass equation & $\mathrm{kg}$ & 0.02295764 & empírico \\
\hline & & Power for Leaf\&twig biomass equation & $\mathrm{cm}-1$ & 2.7 & empírico \\
\hline & & Intercept for litterfall equation & $\mathrm{kg}$ & 0.000268829 & empírico \\
\hline & & Power for litterfall equation & $\mathrm{cm}-1$ & 4.5 & empírico \\
\hline & & Wood density & $\mathrm{kg} \mathrm{m}-3$ & 5500 & adaptação irreal \\
\hline \multirow[t]{4}{*}{ Roots } & All Type & Root tip diameter & $\mathrm{cm}$ & 0.1 & default \\
\hline & Type 1 & Total root length per unit area $(x=0)$ & $\mathrm{cm} \mathrm{cm}-2$ & 1 & \begin{tabular}{|l} 
adaptado de \\
Bernardes et al. \\
$(1998)$
\end{tabular} \\
\hline & Type1 \& 2 & Tree root distribution shape & $m-1$ & 0.1 & \begin{tabular}{|l} 
adaptado de \\
Bernardes et al. \\
$(1998)$
\end{tabular} \\
\hline & & Decrease of root with depth & $m-1$ & 3 & \begin{tabular}{|l} 
adaptado de \\
Bernardes et al. \\
$(1998)$
\end{tabular} \\
\hline
\end{tabular}


Anexo 3.- Parâmetros modificados para eucalipto (Eucalyptus grandis Hill ex Maiden)

\begin{tabular}{|c|c|c|c|c|c|}
\hline & & Parâmetro & Unidade & Valor & Fonte \\
\hline \multirow{6}{*}{\multicolumn{2}{|c|}{ Growth Stage }} & Length of vegetative cycle & days & 7400 & $\begin{array}{l}\text { adaptação irreal para evitar } \\
\text { florescimento }\end{array}$ \\
\hline & & Length of generative cycle & days & 270 & IPEF (2000) \\
\hline & & Earliest day to flower in a year & Julian day & 1 & IPEF (2000) \\
\hline & & Latest day to flower in a year & Julian day & 60 & IPEF (2000) \\
\hline & & Initial stage & dimensionless & 0.25 & default \\
\hline & & Stage after pruning & dimensionless & 0.2 & default \\
\hline \multirow{5}{*}{\multicolumn{2}{|c|}{ Growth }} & Max. growth rate & $\mathrm{kg} \mathrm{m}-2$ & 0.008 & Cromer et al. (1993) \\
\hline & & Fraction of growth reserve & dimensionless & 0.05 & default \\
\hline & & Leaf weight ratio & dimensionless & 0.45 & $\begin{array}{l}\text { adaptado de Gonçalves et al. } \\
\text { (1999) e Leite et al. (1997) }\end{array}$ \\
\hline & & Specific leaf area & $\mathrm{m} 2 / \mathrm{kg}$ & 15 & $\begin{array}{l}\text { adaptado de Leite et al. (1997) e } \\
\text { Cromer et al. (1993) }\end{array}$ \\
\hline & & Water for dry matter production & I kg-1 & 430 & Lima (1993) \\
\hline \multirow{5}{*}{\multicolumn{2}{|c|}{ Canopy }} & $\begin{array}{l}\text { Max. canopy height above bare } \\
\text { stem }\end{array}$ & $\mathrm{m}$ & 12 & adaptado de Leite et al. (1997) \\
\hline & & $\begin{array}{l}\text { Ratio between canopy width and } \\
\text { height }\end{array}$ & dimensionless & 0.2 & empírico \\
\hline & & Max. canopy radius & $\mathrm{m}$ & 3 & adaptado de Leite et al. (1997) \\
\hline & & Maximum leaf area index & dimensionless & 5 & Kriedemann \& Cromer (1996) \\
\hline & & $\begin{array}{l}\text { Ratio leaf area index min. and } \\
\text { max. }\end{array}$ & dimensionless & 0.5 & empírico \\
\hline \multicolumn{2}{|c|}{$\begin{array}{c}\text { Rain } \\
\text { interception }\end{array}$} & $\begin{array}{l}\text { Rainfall water stored at leaf } \\
\text { surface }\end{array}$ & $\mathrm{mm}$ & 0.3 & Lima (1993) \\
\hline \multirow{2}{*}{\multicolumn{2}{|c|}{$\begin{array}{l}\text { Light } \\
\text { capture }\end{array}$}} & $\begin{array}{l}\text { Light intensity affecting tree } \\
\text { growth }\end{array}$ & dim.less & 1 & \\
\hline & & Extinction light coefficient & dim.less & 0.8 & \\
\hline \multirow{9}{*}{\multicolumn{2}{|c|}{$\begin{array}{l}\text { Allometric } \\
\text { Branching }\end{array}$}} & $\begin{array}{l}\text { Intercept for total biomass } \\
\text { equation }\end{array}$ & $\mathrm{kg}$ & 0.0209603 & $\begin{array}{l}\text { empírico a partir de Gonçalves } \\
\text { et al. (1999) e Leite et al. (1997) }\end{array}$ \\
\hline & & Power for total biomass equation & $\mathrm{cm}-1$ & 3.4 & $\begin{array}{l}\text { empírico a partir de Gonçalves } \\
\text { et al. (1999) e Leite et al. (1997) }\end{array}$ \\
\hline & & $\begin{array}{l}\text { Intercept for branch biomass } \\
\text { equation }\end{array}$ & $\mathrm{kg}$ & 0.0010645 & $\begin{array}{l}\text { empírico a partir de Gonçalves } \\
\text { et al. (1999) e Leite et al. (1997) }\end{array}$ \\
\hline & & $\begin{array}{l}\text { Power for branch biomass } \\
\text { equation }\end{array}$ & $\mathrm{cm}-1$ & 3.2 & $\begin{array}{l}\text { empírico a partir de Gonçalves } \\
\text { et al. (1999) e Leite et al. (1997) }\end{array}$ \\
\hline & & $\begin{array}{l}\text { Intercept for Leaf\&twig biomass } \\
\text { equation }\end{array}$ & $\mathrm{kg}$ & 0.0229576 & $\begin{array}{l}\text { empírico a partir de Gonçalves } \\
\text { et al. (1999) e Leite et al. (1997) }\end{array}$ \\
\hline & & $\begin{array}{l}\text { Power for Leaf\&twig biomass } \\
\text { equation }\end{array}$ & $\mathrm{cm}-1$ & 2 & $\begin{array}{l}\text { empírico a partir de Gonçalves } \\
\text { et al. (1999) e Leite et al. (1997) }\end{array}$ \\
\hline & & Intercept for litterfall equation & $\mathrm{kg}$ & 0.0002688 & $\begin{array}{l}\text { empírico a partir de Gonçalves } \\
\text { et al. (1999) e Leite et al. (1997) }\end{array}$ \\
\hline & & Power for litterfall equation & $\mathrm{cm}-1$ & 4.1 & $\begin{array}{l}\text { empírico a partir de Gonçalves } \\
\text { et al. (1999) e Leite et al. (1997) }\end{array}$ \\
\hline & & Wood density & $\mathrm{kg} \mathrm{m}-3$ & 2000 & adaptação irreal \\
\hline \multirow[t]{4}{*}{ Roots } & $\begin{array}{l}\text { All } \\
\text { Ty } \\
\text { pe }\end{array}$ & Root tip diameter & $\mathrm{cm}$ & 0.1 & $\begin{array}{l}\text { adaptado de Gonçalves e Mello } \\
(2000)\end{array}$ \\
\hline & \begin{tabular}{|c|} 
Ty \\
pe \\
1 \\
\end{tabular} & $\begin{array}{l}\text { Total root length per unit area } \\
(x=0)\end{array}$ & & 1 & $\begin{array}{l}\text { adaptado de Gonçalves e Mello } \\
(2000)\end{array}$ \\
\hline & \multirow[t]{2}{*}{\begin{tabular}{|c|} 
Ty \\
pe \\
1 \\
$\&$ \\
2 \\
\end{tabular}} & Tree root distribution shape & $m-1$ & 0.05 & $\begin{array}{l}\text { adaptado de Gonçalves e Mello } \\
(2000)\end{array}$ \\
\hline & & Decrease of root with depth & $m-1$ & 3 & $\begin{array}{l}\text { adaptado de Gonçalves e Mello } \\
(2000)\end{array}$ \\
\hline
\end{tabular}




\section{REFERÊNCIAS BIBLIOGRÁFICAS}

ALLEN, R.G.; PEREIRA, L.S.; RAES, D.; SMITH, M. Crop evapotranspiration: guidelines for computing crop water requirements. Roma: FAO, 1998. 300p. (FAO irrigation and drainage papers, 56).

ALLEONI, L.R.F.; BEAUCLAIR, E.G.F. Cana-de-açúcar cultivada após milho e amendoim, com diferentes doses de adubo. Scientia Agricola. v. 53, n. 3, p. 409415. 1995

ALVAREZ, I.A.; CASTRO, P.R. DE C.; NOGUEIRA, M.C.S. Crescimento de raízes de cana crua e queimada em dois ciclos. Scientia Agrícola, v.7, n.4, p.653-659, 2000 .

ANDERSON, L.S.; SINCLAIR, F.L. Ecological interactions in agroforestry systems. Agroforestry Abstracts. v.6, n.2, p.57-91, 1993.

BARBIERI, V. Medidas e estimativas de consumo hídrico em cana-de-açúcar (Saccharum spp). Piracicaba, 1981. 82p. Dissertação (Mestrado) Escola Superior de Agricultura “Luiz de Queiroz", Universidade de São Paulo.

BENJAMIN, T.J., HOOVER, W.L., SEIFERT, J.R, GILLESPIE, A.R. Defining competition vectors in a temperate alley cropping system in the midwestern USA. 4. The economic return of ecological knowledge. Agroforestry Systems. v.48, p.79-93, 2000. 
BERNARDES, M. S.; FÚRIA, L. R. R.; TERAMOTO, E. R.; BERNARDO, K.T. Interações abaixo da superfície do solo em sistema agroflorestal de seringueira (Hevea brasiliensis) e milho (Zea mays). In: CONGRESSO BRASILEIRO EM SISTEMAS AGROFLORESTAIS, 2., Belém, 1998. Resumos expandidos. Belém: Embrapa-CPATU, 1998. p. 14-16.

BERNARDES, M.S; SPAROVEK, G. Sistemas de produção para áreas com restrições à colheita mecanizada de cana-de-açúcar.. Depto. de Agricultura e Ciência do Solo - ESALQ, Piracicaba: 1998. 27p. (Projeto de Pesquisa)

BERNARDES, M.S. (2001). comunicação pessoal.

BERNARDES, M.S. (ed.) Sangria da seringueira. 2. ed. ver. ampl. Piracicaba: o editor, 2000. $405 \mathrm{p}$.

BERNARDES, M.S.; FANCELLI, A.L. Seringueira como uma possível cultura intercalar para os pomares de Citrus. In: SIMPÓSIO DA CULTURA DA SERINGUEIRA, 2., Piracicaba, 1987. Anais. Piracicaba: ESALQ, Depto de Agricultura, 1990. p.223-252.

BERNARDES, M.S.; GOUDRIAAN, J.; DOURADO-NETO, D.; CÂMARA, G.M.S. Tree-crop interactions in agroforestry system of rubber with soybean and maize. In: CONGRESS OF THE EUROPEAN SOCIETY FOR AGRONOMY, 5., Nitra / Eslováquia, 1998. Short communications. Eslováquia:ESA, 1998. p. 125-126. v.2.

BERNARDES, M.S.; GOUDRIAAN, J.; CASTRO, P.R.C.; CASTRO, A.M.G.; BRUMMER, B.M. Evaluation of the "EMB-RUBBER" model for estimating growth and yield. In: CONGRESS OF THE EUROPEAN SOCIETY FOR AGRONOMY, 3., Abano-Padova, 1994. Proceedings. Colmar Cedex: ESA, 1994. p. 314-315. 
BERNARDES, M.S; SPAROVEK, G.; ROSSETTO, R.; FARAHT, M.; VICCINO, J.R., STAPE, J.L., FILHO, V.A.C.; HAMMERSCHLAG, N. Sistemas de produção para áreas com restrições à colheita mecanizada de cana-de-açúcar. In: SEMANA DE CANA-DE-AÇÚCAR DE PIRACICABA, 3., Piracicaba, 1998. Anais. Piracicaba: Stab, 1998. p.35-37.

BLACK, C.; ONG, C. Utilisation of light and water in tropical agriculture. Agricultural and Forest Meteorology. v.104, p.25-47. 2000

BOVI, M.L.A. Palmito pupunha: Informações básicas para o cultivo. In: ENCONTRO SOBRE PRODUÇÃO DE PALMITO, 1., Piracicaba, 1993. Anais. Piracicaba: Calq-Depto de Agricultura, 1993. p. 12-23.

BRENNER, A.J. Microclimatic modifications in agroforestry. In: ONG, C.K.; HUXLEY, P. (Ed.) Tree-crop interactions: a physiological approach. Wallingford: CAB \& ICRAF, 1996. cap.5, p.159-187.

BUll, T.A., GLASZIOU, K.T. Sugarcane. In: EVANS, L.T. Crop Physiology. London: Cambridge press. p.51-72. 1975

BURESH, R. Agroforestry research for integrated land use: nutrient management research in agroforestry. Nairobi : ICRAF, 1995. 28p.

CANNELL, M.G.R.; VAN NOORDWIJK; M, ONG, C.K. The central agroforestry hypothesis: the trees must acquire resources that the crop would not otherwise acquire. Agroforestry Systems . v.33, p.1-5, 1996.

CARVALHO, P.E.R. Espécies florestais brasileiras: recomendações silviculturais, potencialidades e uso da madeira. Brasília: Embrapa, 1994. 640p.

CASAGRANDE, A.A. Tópicos de morfologia e fisiologia de cana-de-açúcar. Jaboticabal: FUNEP, 1991. 157p.

CASTRO, P.R. de C. Fisiologia da seringueira. In: SIMPÓSIO SOBRE A CULTURA DA SERINGUEIRA NO ESTADO DE SÃO PAULO, 1., Piracicaba, 1986. Anais. Campinas: Fundação Cargill, 1986. p.252-268. 
COORDENADORIA DE ASSISTÊNCIA TÉCNICA INTEGRAL. Levantamento subjetivo a nível de município. Piracicaba: Secretaria de Agricultura do Estado de São Paulo, 1997.

CONCEIÇÃO, H. E.O. da; OLIVA, M.A.; LOPES, N.F Resistência da seca à seringueira. II. Crescimento e partição de assimilados em clones submetidos à déficit hídrico. Pesquisa Agropecuária Brasileira. v.21, n.2, p.141-153. 1986.

CORTEZ, J.V. Histórico e expansão da cultura da seringueira no Estado de São Paulo. In: SIMPÓSIO SOBRE A CULTURA DA SERINGUEIRA NO ESTADO DE SÃO PAUlO, 1., Piracicaba, 1986. Anais. Campinas: Fundação Cargill, 1986. p.1-10.

CRESTANA, S. Técnicas recentes de determinação de características do solo. In: REUNIÃO BRASILEIRA DE MANEJO E CONSERVAÇÃO DO SOLO E DA ÁGUA, 10., Florianópolis, 1994. Resumos. Florianópolis: SBCS, 1994. p. 86-97.

CROMER, R.N.; CAMERON, D.M.; RANCE, S.J.; RYAN, P.A.; BROWN, M. Response to nutrients in Eucalyptus grandis. 1. Biomass accumulation. Forest Ecology and Management, v.62, p.211-230, 1993.

DAILY, G.; DASGUPTA, P. BOLIN, B.; CROSSON, P.; GUERNY, J. du, EHRLICH, P.; FOLKE, C.; JANSSON, A. M.; JANSSON, B; KAUTSKY, N.; KINZIG, A.; LEVIN, S.; MALER, K.; PINSTRUP-ANDERSEN, P.; SINISCALCO, D.; WALKER, B. Food production, population growth, and the environment. Science, v.281, p.1291-1292, 1998.

DEY, S.K.; JOSEPH, T. Agro-ecological zoning for productivity of rubber in India and economic analysis of tapping systems. Wageningen: AB-DLO, 1996.

EASTMAN, J. R. Idrisi - user's guide. Worcester: Clark University, 1992.

EMBRAPA. Sistema Brasileiro de Classificação de Solos. Rio de Janeiro: Embrapa, 1999. 412p. 
FAO. FAO Yearbook 1998 - production. v.52. Rome: FAO, 1999. 233p.

FERRETTI, A.R.; KAGEYAMA, P.Y.; ARBOEZ, G.F.; SANTOS, J.D.; BARROS, M.I.A.; LORZA, R.F.; OLIVEIRA,C. Classificação de espécies arbóreas em grupos ecológicos para revegetação com nativas no Estado de São Paulo. Florestar Estatístico, v.3, n.7, p.73-77, 1995.

FNP CONSULTORIA \& COMÉRCIO. Agrianual 1998: Anuário de agricultura brasileira. São Paulo: Argos, 1997. 540p.

FNP CONSULTORIA \& COMÉRCIO. Agrianual 1999: Anuário de agricultura brasileira. São Paulo: Argos, 1998. 535p.

FNP CONSULTORIA \& COMÉRCIO. Agrianual 2000: Anuário de agricultura brasileira. São Paulo: Argos, 1999. 546p.

FUJISAKA, S. Sense and nonsense: contour hedgerows for soil erosion control. Agroforestry Forum. v.8, n.4, p.8-11, 1997.

GARRITY, D. P. Tree-soil-crop interactions on slopes. In: ONG, C.K.; HUXLEY, P. (Ed.) Tree-crop interactions: a physiological approach. Wallingford: CAB \& ICRAF, 1996. cap.8, p.299-318.

GILlESPIE, A.R.; JOSE, S.; MENGEL, D.B.; HOOVER, W.L.; POPE, P.E.; SEIFERT, J.R.; BIEHLE, D.J.; STALL, T.; BENJAMIN, T.J. Defining compettion vectors in a temperate alley cropping system in the midwestern USA. I. Production physiology. Agroforestry Systems. v.48., p.25-40, 2000.

GONÇALVES, J.L. DE M.; MELLO, S.L. DE M. O sistema radicular das árvores. In: GONÇALVES, J.L. DE M; BENEDETTI, V.(Ed) Nutrição e fertilização florestal. Piracicaba: IPEF, 2000. p.219-267.

GONÇALVES, J.L.de M.; POGIANI, F.; STAPE, J.L.; MELLO, S.L.de M.; MENDES, K.C.F.S.; GAVA, J.L.; BENEDETTI, V. Eucalypt plantation in the humid tropics: São Paulo, Brazil. In: NAMBIAR, E.K.S.; COSSALTER, C.; TIARKS, A. (Ed.) Site management and productivity in tropical plantation forests.Workshop Proceedings. Pietermaritzburg: CIFOR, 1999. p. 5-12. 
GONÇALVES, J.S.; SOUZA, S.A.M. Proibição da queima no Estado de São Paulo: simulações dos efeitos por área cultivada e na demanda pela força de trabalho. Informações econômicas. v.28, n.3, p.21-40, 1998a.

GONÇALVES, J.S.; SOUZA, S.A.M. Alternativas econômicas para áreas com restrição à colheita mecanizada da cana-de-açúcar, na região de Piracicaba-SP. In: SEMANA DE CANA-DE-AÇÚCAR DE PIRACICABA, 3., Piracicaba, 1998. Anais. Piracicaba: Stab, 1998b. p.4-8.

GOUDRIAAN, J. Crop micrometeorlogy: a simulation study. Wageningen: PUDOC, 1977. 249p. (Simulation monographs).

GOVINDEN, N. Intercropping of sugarcane with potato in Mauritius - a successful cropping system. Field Crops Research. v.25, n.1/2, p.99-110, 1990.

GROVE, T.S.; THOMSON, B.D.; MALAJCZUK, N. (1996). In: ATTIWILL, P.M.; ADAMS, M.A. (Ed.) Nutrition of Eucalypts. Australia: CSIRO, 1996. p.77108.

HANNON, B.; RUT, M. Modelling dynamic biological systems. New York: Springer, 1997. 397p.

HUXLEY, P. Biological factors affecting form and function in woody-non-woody plant mixtures. In: ONG, C.K.; HUXLEY, P. (Ed.) Tree-crop interactions: a physiological approach. Wallingford: CAB \& ICRAF, 1996. cap.7, p.235-298.

HUXLEY, P. Tropical agroforestry. Oxford: Blackwell Science, 1999. 371p.

INMAN-BAMBER, N.G.; MUCHOW, R.C.; ROBERTSON, M.J. Dry matter partitioning of sugarcane in Australia and South Africa. Field crops research. v. 76, n.1, p. 71-84. 2002.

IRVINE, J.E. Sugarcane. In: In: BANTA, S.J.; SMITH, W.H. (Ed). Potential productivity of field crops under different environments. Philippines: International Rice Research Institute, 1983. p.361-381. 
KRIEDEMANN, P.E.; CROMER, R.N. The nutritional physiology of the Eucalypts nutrition and growth. In: ATTIWILL, P.M.; ADAMS, M.A. (Ed.) Nutrition of Eucalypts. Australia: CSIRO, 1996. p.109-121.

KWONG, K.F.N.; UMRIT, G.; DEVILLE, J. Nitrogen fertilization of sugarcane in an intercropping system with maize and potato in the humid tropical climate of mauritius. Experimental Agriculture. v.32, n.2, p.213-218, 1996.

LAL, R. Myths and scientific realities of agroforestry as a strategy for sustainable management for soils in the tropics. Advances in Soil Science, v.15. New York: Springer-Verlag, 1991. p.91-137.

LANDELL, M.G. DE A.; VASCONCELOS, A.C.M. DE; SILVA, M.A.; PERECIN, D.; CARVAlHO, R.S.R. DE; BARBOSA, V.; PENNA, M.J. Validação de métodos de amostragem para estimativa de produção de cana-de-açúcar em áreas de colheita mecanizada. STAB. v.18, n.2, p. 39-51. 1999.

LEITE, F.P.; BARROS, N.F. de; NOVAIS, R.F. de; SANS, L.M.A.; FABRES, A.S. Crescimento de Eucalyptus grandis em diferentes densidades populacionais. Árvore. v.21, n.3, p.313-321, 1997.

LEONG, W. Canopy modification and its effect on the growth and yield of Hevea Brasiliensis Muell. Arg. Bélgica, 1980. 283p. Thesis (Doutorado). Faculty of Agricultural Sciences, Bélgica.

LIMA, W de P. Impacto ambiental do eucalipto. São Paulo: EDUSP, 1993. 301p.

LOOMIS, R.S.; CONNOR, D.J. Crop ecology: productivity and management in agricultural systems. Cambridge University Press, Cambridge, UK. 1992. 538p.

LOTT, J.E.; HOWARD, S.B.; ONG, C.K.; BLACK, C.R. Long-term productivity of a Grevillea robusta-based overstorey agroforestry system in semi-arid Kenya - II. Crop growth and system performance. Forest ecology and management. v.139 n.1/3. p.187-201, 2000. 
MACHADO, E.C.; PEREIRA, A.R.; FAHL, J.I.; ARRUDA, H.V.; CIONE, J. Índices biométricos de duas variedades de cana-de-açúcar. Pesquisa Agropecuária Brasileira. v.17, n.9, p.1323-1329, 1982.

McDONALD, M.A.; STEVENS, P.A.; HEALEY, J.R.; DEVI PRASAD, P.V.. Maintenance of soil fertility on steeplands in the Blue Mountains of Jamaica: the role of contour hedgerows. Agroforestry Forum, v.8, n.4, p.21-25, 1997.

MIALHE, L.G.; RIPOLI, T.C.; MILAN, M. Algumas considerações sobre o formato e espaçamento de plantio. Álcool \& Açúcar. v.3, n.11 p.28-42, 1983.

MIOCQUE, J. Avaliação de crescimento e de produtividade de matéria verde da canade-açúcar na região de Araraquara - SP. Stab. v.17, n.4, p.45-47, 1999.

MOBBS, D.C.; CANNELL, CROUT, N.M.J.; M.G.R., LAWSON, G.J. Complementarity of light and water use in tropical agroforests. I. Theoretical model outline, performance and sensitivity. Forest Ecology and Management. v.102 p.259-274, 1998.

MONGELARD, J.C.; MIMURA, L. Growth studies on the sugarcane plant. I. Effects of temperature. Crop Science. v.11, p.795-800, 1971.

MONTEITH, J.L.; ONG, C.K.; CORLETT, J.E. Microclimatic interactions in agroforestry systems. Forest Ecology and management. v.45, p.31-44, 1991.

MORAES, C.R.A. Radiação solar, desenvolvimento e produção de palmitos de pupunha (Bactris gasipaes H.B.K.) em sistemas agroflorestais na Amazônia ocidental. Piracicaba, 2002. 86p. Tese (Doutorado) Escola Superior de Agricultura "Luiz de Queiroz", Universidade de São Paulo.

MORAES, V.H. de F. Rubber. In: ALVIM, P.T.; KOZLOWSKI, T.T. (Ed.) Ecophysiology of tropical crops. Nova Iorque: Academic Press, 1977. cap 11, p.315-331.

MUCHOW, R.C.; SPILLMAN, M.F.; WOOD, A.W.; THOMAS, M.R. Radiation interception and biomass accumulation in a sugarcane crop grown under irrigated 
tropical conditions. Australian Journal of Agricultural Research. v.45, p.3749, 1994.

MUETZELFELDT, R.I.; SINCLAIR, F.L. Ecological modelling of agroforestry systems. Forestry Abstracts. v.54, n.12, p.1103-1143, 1993.

NAIR, P.K.R. Agroforestry systems in the tropics. London: Kluwer, 1989. 664p.

OLIVEIRA, J.B. Solos do Estado de São Paulo: descrição das classes registradas no mapa pedológico. Boletim Científico, 45. Campinas: IAC, 1999. 112p.

OLIVEIRA, J.B.; CAMARGO, M.N.; ROSSI, M.; CALDERANO-FILHO, B. Mapa Pedológico do Estado de São Paulo. Embrapa-IAC, 1999.

OLIVEIRA, J.B.; PRADO, H. Carta pedológica semidetalhada do Estado de São

Paulo; quadrícula de Piracicaba. Escala 1:100.000. Secretaria de Agricultura e Abastecimento do Estado de São Paulo, Coordenadoria de Pesquisa Agropecuária, Campinas: Instituto Agronômico, 1989.

ONG, C.K. A framework for quantifying the various effects of tree-crop interactions. In: ONG, C.K.; HUXLEY, P. (Ed.) Tree-crop interactions: a physiological approach. Wallingford: CAB \& ICRAF, 1996. cap.1, p.1-24.

ONG, C.K.; HUXLEY, P. Tree-crop interactions: a physiological approach. Wallingford: CAB \& ICRAF, 1996. 386p.

ONG, C.K.; CORLETT,J.E.; SINGH, R.P.; BLACK, C.R. Above and below ground interactions in agroforestry systems. Forest ecology and management. v.45, p.45-57, 1991.

ONG, C.K.; BLACK, C.R.; WALLACE, J.S.; KHAN, A.A.H.; LOTT, J.E.; JACKSON, N.A.; HOWARD, S.B.; SMITH, D.M. Productivity, microclimate and water use in Grevillea robusta-based agroforestry systems on hillslopes in semiarid Kenya. Agriculture Ecosystems \& Environment. v.80 n.1/2 p.121-141, 2000. 
ORGANIZAÇÃO DOS PLANTADORES DE CANA-DE-AÇÚCAR DO ESTADO DE SÃO PAULO. Queima da cana-de-açúcar, informações disponíveis. Câmara Paulista do Setor Sucroalcooleiro, Piracicaba: Orplana, 1996. 18p. (Boletim).

PAARDEKOOPER, E.C. Exploitation of the rubber tree. IN: WEBSTER, C.C.; BAULKWILL, W.J. (Ed.) Rubber. England: Longman, 1989. p.349-414. (Tropical agricultural series).

PARTON, W.J.; OJIMA, D.S.; COLE, C.V.; SCHIMEL, D.S. A general model for soil organic matter dynamics: sensitivity to litter chemistry, texture and management. Soil Science Society of America v.39, p147-167, 1994.

PASSOS, E.E.M. Ecofisiologia do coqueiro. In: FERREIRA, J.M.S.; WARWICK, D.R.N.; SIQUEIRA, L.A. (Ed.) A cultura do coqueiro no Brasil. Brasilia: Embrapa, 1998a. cap.3, p.65-72.

PASSOS, E.E.M. Morfologia do coqueiro. In: FERREIRA, J.M.S.; WARWICK, D.R.N.; SIQUEIRA, L.A. (Ed.) A cultura do coqueiro no Brasil. Brasilia: Embrapa, 1998b. cap.2, p. 57-64.

PENNING de VRIES, F.W.T.; JANSEN, D.M.; ten BERGE, H.F.M.; BAKERNA, A. Simulation of ecophysiological processes of growth in several annual crops. Pudoc: Wagenigen. 271p. 1989.

PEREIRA, A.R. Balanço de carbono: uso de modelos e simulação. In: CROCOMO, O.J.; SILVEIRA, J.A.G. da (Ed.) SEMINÁRIO DE BIOTECNOLOGIA AGRÍCOLA, 5., Piracicaba, 1987. Anais. Piracicaba: CEBTEC/FEALQ, 1987. p. 189-207.

PEREIRA, A.R. Mathematical modelling. Agricultural and Forest Meteorology. v.31,p.217-218, 1984. (Editorial)

PIMENTEL, D.; STACHOW, U.; TAKACS, D.A.; BRUBAKER, H.W; DUMAS, A.R.; MEANEY, J.J.; O’NEIL, J.A.S.; ONSI, D.E.; CORZILIUS, D.B. Conserving biological diversity in agricultural/forestry systems. BioScience, v.42, n.5, p.354-362, 1992. 
PINTO, L.F.G., BERNARDES, M.S.; SPAROVEK, G; CÃMARA, G.M de S. Feasibility of agroforestry for sugarcane production and soil conservation in Brazil. In: STOTT, D.E.; MOHTAR, R.H.; STEINHARDT, G.C. (Eds). Sustaining the Global Farm. In: INTERNATIONAL SOIL CONSERVATION ORGANIZATION MEETING, 10., West Lafayette, 2001 papers West Lafayette, ISCO/USDA/Purdue University, 2001. p.317-320.

PROJETO PIRACENA. http://www.cena.usp.br/piracena/default.htm (07 Jun. 2000).

POIANI, K.A.; RICHTER, B.D.; ANDERSON, M.G.; RICHTER, H.E. Biodiversity conservation at multiple scales: functional sites, landscapes and networks. BioScience, v.50, n.2, p.133-146, 2000.

RAO, M.R.; COLE, R.D. Measuring crop yields in on-farm agroforestry studies.Agroforestry Systems . v.15, n.2/3, p.275-290. 1991

RAO, M.R.; NAIR, P.K.R.; ONG, C.K. Biophysical interactions in tropical agroforestry systems. Agroforestry Systems . v.38, n.1/3, p.3-50, 1997.

RIGHI, C. Interações ecofisológicas acima e abaixo do solo em um sistema agroflorestal de seringueira (Hevea brasiliensis) e feijoeiro (Phaseolus vulgaris). Piracicaba, 2000. 121p. Dissertação (Mestrado) Escola Superior de Agricultura “Luiz de Queiroz”, Universidade de São Paulo.

ROBERTSON, M.J.; WOOD, A.W.; MUCHOW, R.C. Growth of sugarcane under high input conditions in tropical Australia. I. Radiation use, biomass accumulation and partitioning. Field Crops Research. v.48, p.11-25, 1996.

RODRIGUEZ, L.C.E.; RODRIGUES. F.A. Plantações florestais: rentabilidade e visão de longo prazo. Preços Agrícolas, v.14, n.155, p.10-12, 1999.

ROLIM, J.C. Consorciação da cana-de-açúcar com plantas alimentares:fatores que influenciam sua adoção. Piracicaba, 1989. 179p. Dissertação (Mestrado) - Escola Superior de Agricultura “Luiz de Queiroz”, Universidade de São Paulo.

SANCHEZ, P.A. Science in agroforestry. Agroforestry Systems. v.30, p.5-55, 1995. 
SCHERR, S.J. On-farm research: the challenges of agroforestry. Agroforestry Systems. v.15, n.2/3, p.95-110. 1991.

SENTELHAS, P.C.; MARIN, F.R.; PEREIRA, A.R.; ANGELOCCI, L.R.; VILLANOVA, N.A. BARBIERI, V. Análise dos dados climáticos e do balanço hídrico climatológico de Piracicaba (1917-1997). Piracicaba: DFM/Esalq/USP. 1998. 81p.

SHARMA, R.K.; NEMA, G.K.; VERMA, H.D. Intercropping of different crops in autumn-planted sugarcane (Saccharum officinarum). Indian Journal Agronomy. v.42, n.3, p.422-424, 1997.

SHORROCKS, V.M.; TEMPLETON, J.K.; YIER, G.C. Mineral nutrition cycle of Hevea brasiliensis. III - The relationships between girth and shoot dry weight. Journal of Rubber Research Institute of Malaysia. v.19, n.2, p.85-92, 1965.

SINCLAIR, F.; LAWSON, G. Special issue on agroforestry modelling. Agroforestry Forum. v.8, n.2, p.55, 1997.

SOUZA, B.F. de; ANDRADE, M.J.B de. Bean production systems in intercropping with sugarcane. Pesquisa Agropecuária Brasileira. v.20, n.3, p.343-348, 1985.

SPAROVEK, G.; LEPSCH, I.F. Diagnóstico de uso e aptidão das terras agrícolas de Piracicaba. In: TAUK-TORNISIETO, S.M.; GOBBI, N.; FORESTI,C.; LIMA, S.T. (Ed.) Análise ambiental: estratégias e ações. São Paulo: Queiroz, 1995. p.273-279.

SPAROVEK, G.; PEREIRA, J.C.; ALLEONI, L.R.F.; ROSSETTO, R. Aptidão das terras de Piracicaba (SP) para o corte mecanizado de cana-de-açúcar. Stab, v.15, n.5, p.6-9, 1997.

SQUIRE, G.R. The physiology of tropical crop production. Wallingford, UK: CAB International. 1993. 236p.

STAPE, J.L. Utilização de delineamento sistemático tipo leque no estudo de espaçamentos florestais. Piracicaba, 1995. 86p. Dissertação (Mestrado) - Escola Superior de Agricultura “Luiz de Queiroz”, Universidade de São Paulo. 
STAPE, J.L.; ITRIA, W.H. Determinação do espaçamento do plantio de Eucalyptus spp na Ripasa para diferentes materiais genéticos e uso múltiplo de madeira., Araraquara: Ripasa, 1996. 80p.

STAPE, J.L. Production ecology of clonal Eucalyptus plantations in northeasthern Brazil. Fort Collins, 2002. 225 p. Thesis (Ph.D) - Colorado State University.

SZOTT, L.T.; FERNANDES, E.C.M.; SANCHEZ, P.A. Soil-plant interactions in agroforestry systems. Forest ecology and management. v.45, p.127-152, 1991.

TEMPLETON, J.K. Growth studies in Hevea brasiliensis. I. Growth analysis up to seven years after budgrafting. Journal of Rubber Research Institute of Malaysia. v.20, p.220-226, 1968.

VAN DEN BERG, M. Land use systems research on strongly weathered soils in sout and south-east Brazil.. Utrecht: The Royal Dutch Geographical Society, 2000. (Netherlands Geographical Studies, 271).

VAN NOORDWIJK, M.; LUSIANA, B. WaNuLCAS, a model of water, nutrient and light capture in agroforestry systems. Agroforestry systems. v.43, p.217-242, 1999.

VAN NOORDWIJK, M.; LUSIANA, B WaNuLCAS version 2.0: Backgrounds on a model of water, nutrient and light capture in agroforestry systems. Bogor: ICRAF. 2000. 186p.

VANDERMEER, J.; VAN NOORDWIJK, M; ANDERSON, J.; ONG, C.; PERFECTO, I. Global change and multi-species agroecosystems: Concepts and issues. Agriculture, Ecosystems and Environment, v.67, n.1-22, 1998.

WALLACE, J.S. The water balance of mixed tree-crop systems. In: ONG, C.K.; HUXLEY, P. (Ed.) Tree-crop interactions: a physiological approach. Wallingford: CAB \& ICRAF, 1996. cap.6, p.189-233.

WISCHMEIER, W.H.; SMITH, D.D. Predicting rainfall erosion losses - a guide to conservation planning.Washington, D.C.: USDA, 1978. 58p. (Agricultural Handbook, 537) 
WOSTEN, J.M.H.; FINKE, P.A.; JANSEN, M.J.W. Comparison of class and continuous pedotransfer functions to generate soil hydraulic characteristics. Geoderma. v.66, p.27-37, 1995.

YOUNG, A. Agroforestry in the control of soil erosion by water. Agroforestry Abstracts. v.1, n.2/3, p.39-48, 1988.

YOUNG, A. The effectiveness of contour hedgerows for soil and water conservation. Agroforestry Forum. v.8, n.4, p.2-4, 1997a.

YOUNG, A. Agroforestry for soil management. Wallingford: CAB-ICRAF. 2. ed. 1997b. 320p.

ZARIN, D.J.; DUCHESNE, A.L.; HIRAOKA, M. Shifting cultivation on the tidal floodplain of Amazonia: impacts on soil nutrients status. Agroforestry systems. v.41, n.3, p.307-311, 1998. 